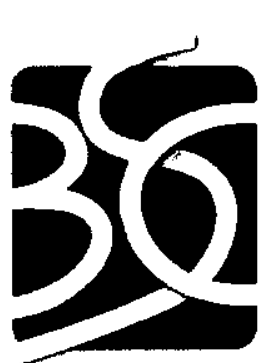

BECHTEL SAIC conparifue
QA: QA ANL-NBS-HS-000015 REV 02

August 2004

\title{
Development of Numerical Grids for UZ Flow and Transport Modeling
}

Prepared for:

U.S. Department of Energy

Office of Civilian Radioactive Waste Management

Office of Repository Development

1551 Hillshire Drive

Las Vegas, Nevada 89134-6321

Prepared by:

Bechtel SAIC Company, LLC

1180 Town Center Drive

Las Vegas, Nevada 89144

Under Contract Number

DE-AC28-01RW12101 


\section{DISCLAIMER}

This report was prepared as an account of work sponsored by an agency of the United States Government. Neither the United States Govermment nor any agency thereof, nor any of their employees, nor any of their contractors, subcontractors or their employees, makes any warranty, express or implied, or assumes any legal liability or responsibility for the accuracy, completeness, or any third party's use or the results of such use of any information, apparatus, product, or process disclosed, or represents that its use would not infringe privately owned rights. Reference herein to any specific commercial product, process, or service by trade name, trademark, manufacturer, or otherwise, does not necessarily constitute or imply its endorsement, recommendation, or favoring by the United States Government or any agency thereof or its contractors or subcontractors. The views and opinions of authors expressed herein do not necessarily state or reflect those of the United States Government or any agency thereof. 
Development of Numerical Grids for UZ Flow and Transport Modeling

ANL-NBS-HS-000015 REV 02

August 2004 


\begin{tabular}{|l|c|l|}
\hline \multirow{2}{*}{ OCRWM } & $\begin{array}{c}\text { Scientific Analysis Signature Page/ } \\
\text { Change History }\end{array}$ & Page iii \\
\cline { 2 - 3 } & & 1. Total Pages: 132 \\
\hline
\end{tabular}

\begin{tabular}{|c|c|c|c|}
\hline \multicolumn{4}{|c|}{$\begin{array}{l}\text { 2. Scientific Analyals Thlie } \\
\text { Development of Numerical Grids for UZ Flow and Transport Modeling }\end{array}$} \\
\hline \multicolumn{4}{|c|}{ 3. DI (Includlng Revision Number) } \\
\hline \multicolumn{4}{|c|}{ ANL-NBS-HS-000015 REV 02} \\
\hline \multirow{3}{*}{$\begin{array}{l}\text { 4. Total Appendicas } \\
\text { Three (3) }\end{array}$} & & \multirow{2}{*}{\multicolumn{2}{|c|}{$\begin{array}{l}\text { 5. Number of Pages in Each Appendix } \\
\text { Appendix A-4; B-12; C-16 }\end{array}$}} \\
\hline & & & \\
\hline & Printed Name & \begin{tabular}{|c|c|} 
Slgnature \\
\end{tabular} & Dato \\
\hline 6. Originator & P. Dobson & Patot Zotedel & $8 / 31 / 04$ \\
\hline 7. Checker & G. Lu & geopsida & $8 / 31 / 04$ \\
\hline 8. OER & K. McFall & OE Deshant & $8 / 3 1 \longdiv { 6 4 }$ \\
\hline $\begin{array}{l}\text { 8. Responsible } \\
\text { Managor/Loed }\end{array}$ & H.H. Liu/Y-S. Wu & 32 & $8 / 31 / 04$ \\
\hline 10. Responsible Manager & M. Zhu & 7 thanelum & 8131 tol \\
\hline \multicolumn{4}{|c|}{$\begin{array}{l}\text { 11. Remarks } \\
\text { Block 6: L. Pan, R. Hedegaard, and Y-S. Wu co-authored this report. Scientific contributions were made by J. } \\
\text { Hinds (author of ANL-NBS-HS-000015 REV0O ICNO1). }\end{array}$} \\
\hline \multicolumn{4}{|l|}{ Change History } \\
\hline 12. Revision No. & \multicolumn{3}{|c|}{ 13. Description of Change } \\
\hline REV 00 & \multicolumn{3}{|l|}{ Initial Issue } \\
\hline REV 00 ICN 01 & \multicolumn{3}{|c|}{$\begin{array}{l}\text { Deficiency Report LVMO-00-D-039, Inaccurate Documentation and Velidation of } \\
\text { Software Routine And/or Macros, identified software issues that are addressed in } \\
\text { MOL.200010816.0228 (Hinds 2001), additional software documentation. The } \\
\text { information in the record will be integrated into the AMR as } \\
\text { part of the next revision or ICN. }\end{array}$} \\
\hline REV 01 & \multicolumn{3}{|c|}{$\begin{array}{l}\text { Entire scientific analysis documentation was revised. Changes were too extensive to } \\
\text { use Step S.6e)1) per AP-SIn. } 9 \text { Q. }\end{array}$} \\
\hline REV 02 & \multicolumn{3}{|c|}{$\begin{array}{l}\text { Made changes to report in response to recommendations from Regulatory Integration } \\
\text { Team/ Natural Systems Team AP-SIII.9Q. Entire scientific analysis documentation } \\
\text { was revised. Changes were too extensive to use Step 5.6e)1) per AP-SIII.9Q. }\end{array}$} \\
\hline
\end{tabular}




\section{CONTENTS}

Page

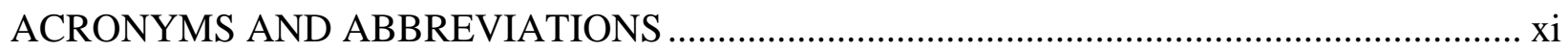

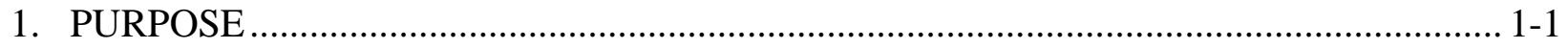

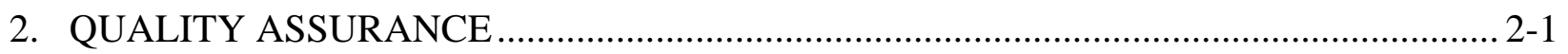

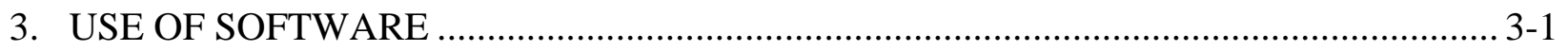

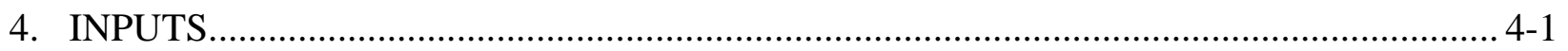

4.1 DIRECT INPUTS …………………………..................................................

4.1.1 Other Inputs ................................................................................ 4-5

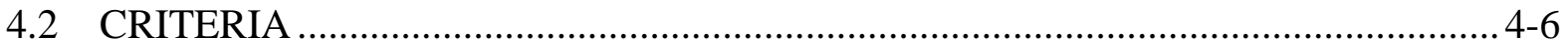

4.3 CODES, STANDARDS, AND REGULATIONS ................................................. 4-9

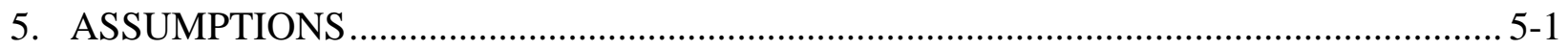

5.1 ASSUMPTIONS REGARDING PHYSICAL CONDITIONS EXTERIOR TO THE MODELING PROCESS ..................................................................................... 5-1

5.2 ASSUMPTIONS REGARDING NUMERICAL GRID CONSTRUCTION ................5-2

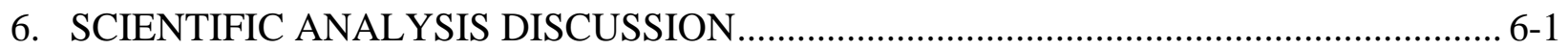

6.1 NUMERICAL GRID DEVELOPMENT-OVERVIEW AND APPROACH ............. 6-1

6.1.1 Summary of Changes to the UZ Model Grids ............................................... 6-4

6.2 BOUNDARIES AND CALIBRATION FEATURES............................................. 6-4

6.3 UZ MODEL LAYERS AND FAULT GEOMETRIES............................................... 6-9

6.4 EXTRACTION OF GFM2000 AND ISM3.1 DATA …........................................... 6-15

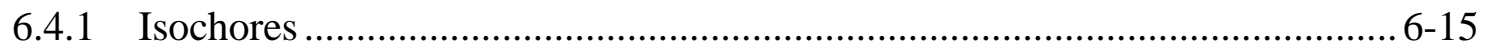

6.4.2 Reference Horizons, and Top and Bottom UZ Model Boundaries.................. 6-18

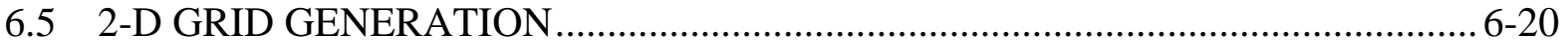

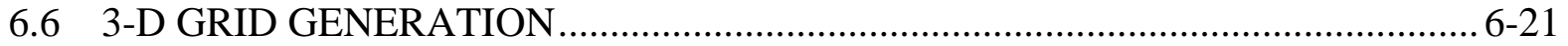

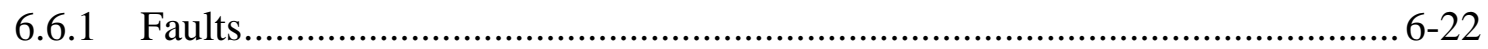

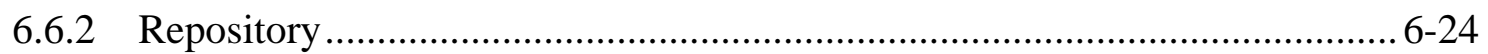

6.6.3 Vitric/Zeolitic Boundaries .................................................................. 6-25

6.7 DUAL-PERMEABILITY GRID GENERATION ……......................................... 6-35

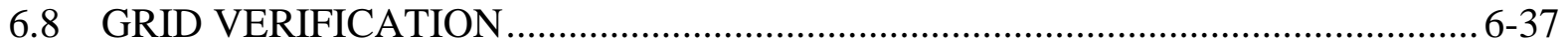

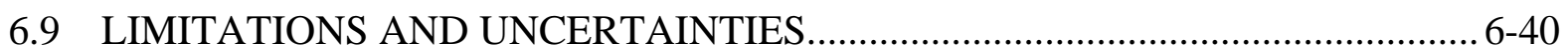

6.9.1 Water Table Uncertainty........................................................................... 6-42

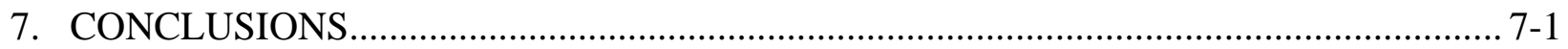

7.1 LIMITATIONS AND UNCERTAINTIES......................................................

7.2 SATISFACTION OF ACCEPTANCE CRITERIA ……………….........................

7.3 RESTRICTIONS FOR SUBSEQUENT USE ........................................................

7.4 TECHNICAL PRODUCT OUTPUT …………...................................................... 


\section{CONTENTS (Continued)}

Page

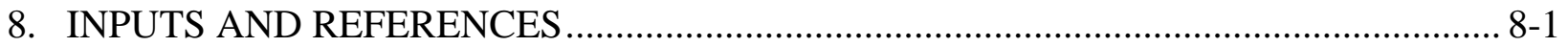

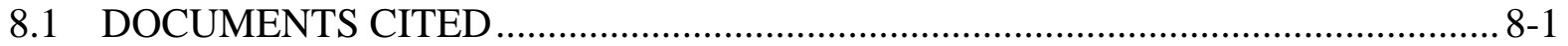

8.2 CODES, STANDARDS, REGULATIONS, AND PROCEDURES .......................... 8-5

8.3 SOURCE DATA, LISTED BY DATA TRACKING NUMBER .............................. 8-6

8.4 OUTPUT DATA, LISTED BY DATA TRACKING NUMBER ............................ 8-7

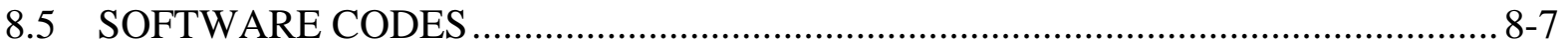

APPENDIX A - ELECTRONIC GFM2000, ISM3.1, RPM2000, AND ROCK- AND FRACTURE-PROPERTY DATA FILES USED TO DEVELOP UZ MODEL NUMERICAL GRIDS.............................................................. A-1

APPENDIX B - DEVELOPMENT OF NUMERICAL GRIDS FOR 1-D HYDROGEOLOGIC-PROPERTY-SET INVERSIONS .................................

APPENDIX C - GRID VERIFICATION …............................................................... 


\section{FIGURES}

Page

6-1. Plan-View Schematic Showing the UZ Model Boundary, the Repository Outline, Major Faults from GFM2000, the ESF, and the ECRB

6-2. Plan-View Schematic Showing Boreholes, the Contoured Water Table (Elevations in m), the UZ Model Boundary, the Repository Outline, the ESF, and the ECRB

6-3. Schematic Illustration of Fault-Related Gridblocks in Map View and in Cross Section

6-4. Distribution of $K_{s}$ from ISM3.1 Rock Properties Model, Upper 1/4 of Layer Tac (UZ Model Layer “ch2”)

6-5. Alteration Probability Contour (0.5) Plot from RPM2000, Upper 1/4 of Layer Tac (UZ Model Layer “ch2”)

6-6. Percent Zeolite Distribution from ISM3.1 Mineralogic Model, Upper 1/4 of Layer Tac (UZ Model Layer “ch2”) .............................................................................. 6-30

6-7. $\quad$ Extent of Vitric Region in Fiscal Year 2002 UZ Model Layers tsw39, ch1 and ch2 .... 6-31

6-8. $\quad$ Extent of Vitric Region in Fiscal Year 2002 UZ Model Layers ch3, ch4, ch5 and ch6......

6-9. Comparison of EARTHVISION V5.1 Gridded Potentiometric Surfaces 6-44

C2-1. Upper Contact Elevation Differences at Selected Borehole Locations (GFM2000 file contacts00el.dat Minus UZ Model Grid)

C2-2. Upper Contact Elevation Differences at All Borehole Locations (GFM2000 file contacts00el.dat Minus UZ Model Grid) ...............................................................

C3-1. 2-D (Plan-View) UZ Model Grid Design ...................................................................6

C3-2. Two-dimensional Cross Section from the UZ Model Grid ...........................................7

C3-3. Traverses 1-4 of 2-D Cross Section, Comparing Results of UZ Model and GFM2000 Grids

C3-4. Traverses 5-7 of 2-D Cross Section, Comparing Results of UZ Model and GFM2000 Grids

C3-5. Traverses 8-10 of 2-D Cross Section, Comparing Results of UZ Model and GFM2000 Grids

C4-1. Pressure-Evaluation Relations of 3-D Mesh (124,795 elements) after TOUGH2 Test Simulation. 


\section{INTENTIONALLY LEFT BLANK}




\section{TABLES}

Page

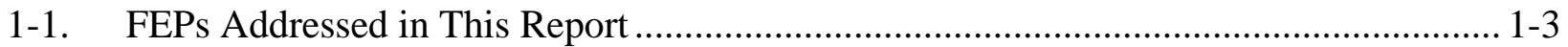

1-2. Reports Directly Linked to This Report..................................................................... 1-3

3-1. Qualified Software Used in Numerical Grid Development............................................. 3-1

4-1. Summary of Direct Input Data Used in Numerical Grid Development............................ 4-1

4-2. Fracture Hydrogeologic Properties ................................................................ 4-2

4-3. Summary of Other Inputs Used in Numerical Grid Development .................................. 4-5

4-4. Project Requirements and Acceptance Criteria Applicable to This Report..................... 4-6

6-1. Summary of Grids Developed for Fiscal Year 2002 UZ Modeling Activities ................. 6-1

6-2. Yucca Mountain Project Scientific Notebooks Used for Fiscal Year 2002

Numerical Grid Development and Grid Verification Analyses........................................ 6-2

6-3. UZ Model Areal Boundary Coordinates...................................................................... 6-5

6-4. Borehole Locations Used in the UZ Inversion and Calibration Models.......................... 6-8

6-5. Correlation of GFM2000 Lithostratigraphy, UZ Model Layers, and Hydrogeologic Units

6-6. Faults Within the UZ Model Domain ...................................................................... 6-13

6-7. Results of GFM2000 Fault-Slope Analysis ................................................................. 6-14

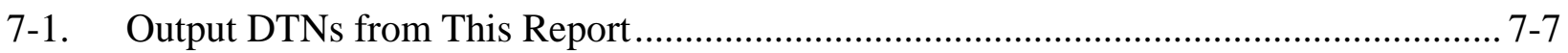

B-1. Comparison of Borehole Layer Contact Elevations from GFM2000 and UZ Model Grid ......................................................................................................

C3-1. UZ Model Layers and GFM2000 Surfaces.................................................................

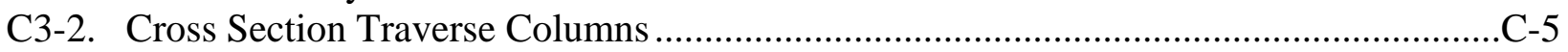




\section{INTENTIONALLY LEFT BLANK}




\section{ACRONYMS AND ABBREVIATIONS}

1-D one-dimensional

2-D two-dimensional

3-D three-dimensional

CHn Calico Hills nonwelded

DIRS document input reference system

DOE U.S. Department of Energy

DTN data tracking number

ECM effective-continuum model

ECRB enhanced characterization of repository block

ESF Exploratory Studies Facility

FEPs features, events, and processes

FY fiscal year

HGU hydrogeologic unit

IED information exchange drawings

IFD integral finite difference

$\mathrm{K}_{\mathrm{s}} \quad$ saturated hydraulic conductivity

LA license application

LBNL Lawrence Berkeley National Laboratory

masl meters above sea level

NRC Nuclear Regulatory Commission

NSP Nevada State Plane

PA performance assessment

PTn Paintbrush nonwelded

QARD Quality Assurance Requirements and Description

TSPA Total System Performance Assessment

TSw Topopah Spring welded

TWP technical work plan

USGS U.S. Geological Survey

UZ unsaturated zone 


\section{INTENTIONALLY LEFT BLANK}




\section{PURPOSE}

This report describes the methods used to develop numerical grids of the unsaturated hydrogeologic system beneath Yucca Mountain, Nevada. Numerical grid generation is an integral part of the development of the unsaturated zone (UZ) flow and transport model, a complex, three-dimensional (3-D) model of Yucca Mountain. This revision contains changes made to improve the clarity of the description of grid generation. The numerical grids, developed using current geologic, hydrogeologic, and mineralogic data, provide the necessary framework to: (1) develop calibrated hydrogeologic property sets and flow fields, (2) test conceptual hypotheses of flow and transport, and (3) predict flow and transport behavior under a variety of climatic and thermal-loading conditions. The technical scope, content, and management for the current revision of this report are described in the planning document Technical Work Plan for: Unsaturated Zone Flow Analysis and Model Report Integration (BSC 2004 [DIRS 169654], Section 2).

Grids generated and documented in this report supersede those documented in Revision 00 of this report, Development of Numerical Grids for UZ Flow and Transport Modeling (BSC 2001 [DIRS 159356]). The grids presented in this report are the same as those developed in Revision 01 (BSC 2003 [DIRS 160109]); however, the documentation of the development of the grids in Revision 02 has been updated to address technical inconsistencies and achieve greater transparency, readability, and traceability. The constraints, assumptions, and limitations associated with this report are discussed in the appropriate sections that follow. There were three deviations from the technical work plan (TWP) scope of work in this report. The software used in this report (see Table 3-1) differs from that listed in the TWP (BSC 2004 [DIRS 169654], Table 9-1), as ARCINFO was not used for Revision 02. Table 2.1.5-1 of the TWP (BSC 2004 [DIRS 169654]) lists two features, events, and processes (FEPs) (faults and stratigraphy) for U0000, but two additional FEPs are addressed in this report (see Table 1-1). Table 4-4 lists eight acceptance criteria for this report, seven more than were indicated in the TWP (BSC 2004 [DIRS 169654], Table 3-1).

The steps involved in numerical grid development include the following:

1. Defining the location of important calibration features

2. Determining model grid layers and fault geometry based on the geologic framework model (DTN: MO0012MWDGFM02.002 [DIRS 153777]), the integrated site model (MO9910MWDISMRP.002 [DIRS 145731]), and the definition of hydrogeologic units (HGUs) (Characterization of Hydrogeologic Units Using Matrix Properties, Yucca Mountain, Nevada [Flint 1998 (DIRS 100033)])

3. Analyzing and extracting geologic framework model and integrated site model data pertaining to layer contacts and property distributions

4. Discretizing and refining the two-dimensional (2-D), plan-view numerical grid 
5. Generating the 3-D grid, with finer resolution at the repository horizon and within the Paintbrush nonwelded (PTn) and uppermost Calico Hills Formation (ch1) (Table 6-5) HGUs

6. Formulating the dual-permeability mesh.

The products of grid development include a set of one-dimensional (1-D) vertical columns of gridblocks for hydrogeologic-property-set inversions, a 2-D UZ model vertical cross-sectional grid for fault hydrogeologic-property calibrations, and a 3-D UZ model grid for additional model calibrations and generating flow fields for the Total System Performance Assessment (TSPA).

Note that the repository layout utilized in constructing the numerical grids (Repository Design, Repository/PA IED [information exchange drawings] Subsurface Facilities Plan Sht.1 of 5, Sht. 2 of 5, Sht. 3 of 5, Sht. 4 of 5, and Sht. 5 of 5 [BSC 2002 (DIRS 159527)]) has been superseded by a revised repository design (D\&E/PA/C IED Subsurface Facilities [BSC 2004 (DIRS 164519)]) that does not include the lower block area. Because the repository layout used for grid construction includes all of the area covered by the most recent repository design, the use of the older repository design for grid construction will not impact license application (LA) model calculations that utilize these grids.

Numerical grid generation is an iterative process that must achieve a proper balance between desired numerical accuracy in terms of gridblock size and computational time controlled by the total number of gridblocks. Gridblock size should reflect the scale of the process to be modeled. For example, to capture flow and transport phenomena along individual waste emplacement drifts, gridblock thickness and width should not exceed the drift diameter or the drift spacing. For large models, such as the site-scale UZ model of Yucca Mountain, flow and transport phenomena occurring on scales of less than a few meters cannot be captured. Rather, the model is intended to provide an overview of key UZ characteristics and processes potentially affecting repository performance.

Grids must also be adapted to the particular needs of the processes to be modeled because sharp gradients may occur in different domains for different flow processes. At Yucca Mountain, the heterogeneous, variably fractured layers are better represented by a dual-continuum (matrix and fracture) model, rather than a single-continuum approach [Conceptual and Numerical Models for UZ Flow and Transport (CRWMS M\&O 2000 [DIRS 141187], Section 6.4)]. Once developed, the UZ model numerical grids are evaluated for appropriate resolution, representation of important features, and proper gridblock connections.

The following list of FEPs was taken from the LA FEP List (DTN: MO0407SEPFEPLA.000 [DIRS 170760]). The selected FEPs are those taken from the LA FEP List that are associated with the subject matter of this report. The results of this analysis are part of the basis for the treatment of FEPs. The cross-reference for each FEP to the relevant sections of this report is also given in Table 1-1. 
Table 1-1. FEPs Addressed in This Report

\begin{tabular}{|l|l|l|}
\hline \multicolumn{1}{|c|}{ FEP Number } & \multicolumn{1}{|c|}{ FEP Name } & Relevant Section of This Report \\
\hline $1.2 .02 .01 .0 \mathrm{~A}$ & Fractures & $4.1,6.7$ \\
\hline $1.2 .02 .02 .0 \mathrm{~A}$ & Faults & $5.2,6.2,6.3,6.6 .1$ \\
\hline $2.2 .03 .01 .0 \mathrm{~A}$ & Stratigraphy & $5.2,6.3,6.4,6.6 .3$ \\
\hline $2.3 .01 .00 .0 \mathrm{~A}$ & Topography and morphology & $6.2,6.9$ \\
\hline
\end{tabular}

Source: DTN: MO0407SEPFEPLA.000 [DIRS 170760].

This report is linked to several other reports through direct inputs. These documents are summarized in Table 1-2 below.

Table 1-2. Reports Directly Linked to This Report

\begin{tabular}{|c|c|}
\hline \multicolumn{2}{|l|}{ Reports providing direct inputs } \\
\hline Geologic Framework Model (GFM2000) & MDL-NBS-GS-000002 REV 02 [DIRS 170029] \\
\hline Analysis of Hydrologic Properties Data & ANL-NBS-HS-000042 REV 00 (DIRS 170038) \\
\hline Rock Properties Model & MDL-NBS-GS-000004 REV00 ICN03 (DIRS 159530) \\
\hline \multicolumn{2}{|l|}{ Reports receiving direct inputs } \\
\hline Calibrated Properties Model & MDL-NBS-HS-000003 REV 02 (DIRS 169857) \\
\hline UZ Flow Models and Submodels & MDL-NBS-HS-000006 REV 02 (DIRS 169861) \\
\hline $\begin{array}{l}\text { Features, Events, and Processes in UZ Flow and } \\
\text { Transport }\end{array}$ & ANL-NBS-MD-000001 REV 03 (DIRS 170012) \\
\hline Multiscale Thermohydrologic Model & ANL-EBS-MD-000049 REV 02 (DIRS 169565) \\
\hline
\end{tabular}




\section{INTENTIONALLY LEFT BLANK}




\section{QUALITY ASSURANCE}

Development of this report and the supporting analyses have been determined to be subject to the Yucca Mountain Project's quality assurance program as documented in Technical Work Plan for: Unsaturated Zone Flow Analysis and Model Report Integration (BSC 2004 [DIRS 169654], Section 8.1). Approved quality assurance procedures identified in the TWP (BSC 2004 [DIRS 169654], Section 4) have been used to conduct and document the activities described in this report. The TWP also identifies the methods used to control the electronic management of data (BSC 2004 [DIRS 169654], Section 8.4) during the analysis and documentation activities.

In Revision 01 of this report (BSC 2003 [DIRS 160109]), the procedure AP-SIII.2Q, Qualification of Unqualified Data and the Documentation of Rationale for Accepted Data, was utilized to qualify an input data file (DTN: MO0212GWLSSPAX.000 [DIRS 161271]) used to delineate the water table. This file was derived from the unqualified DTN: MO0110MWDGFM26.002 [DIRS 160565]. The derivative file was reviewed and qualified using the Data Qualification Plan found in the Technical Work Plan for: Performance Assessment Unsaturated Zone (BSC 2002 [DIRS 160819], Attachment III). The data reviews for DTN: MO0212GWLSSPAX.000 [DIRS 161271] are presented in Attachment IV in BSC 2003 [DIRS 160109].

This report includes HGUs that are identified as natural barriers that are classified in the Q-List (BSC 2004 [DIRS 168361]) as “Safety Category” because they are important to waste isolation, as defined in AP-2.22Q, Classification Analyses and Maintenance of the Q-List. This report contributes to the analysis and modeling data used to support performance assessment (PA). The conclusions of this report do not affect the repository design or engineered features important to safety as defined in AP-2.22Q. 


\section{INTENTIONALLY LEFT BLANK}




\section{USE OF SOFTWARE}

The software used in this study, listed in Table 3-1, was obtained from Software Configuration Management, was appropriate for the intended application, and was used only within the range of validation in accordance with applicable software procedures. There are no limitations on outputs due to the selected software. The qualification and baseline status of each of these codes is given in the Document Input Reference System (DIRS).

Table 3-1. Qualified Software Used in Numerical Grid Development

\begin{tabular}{|c|c|c|c|c|c|}
\hline Software Name & Version & $\begin{array}{c}\text { Software Tracking } \\
\text { Number }\end{array}$ & Platform & Operating System & $\begin{array}{c}\text { DIRS Reference } \\
\text { Number }\end{array}$ \\
\hline EARTHVISION & 5.1 & $10174-5.1-00$ & SGI & IRIX 6.2 & DIRS 171007 \\
\hline EARTHVISION & 5.1 & $10174-5.1-00$ & SGI & IRIX 6.5 & DIRS 167994 \\
\hline WINGRIDDER & 2.0 & $10024-2.0-00$ & PC & Windows NT 4.0 & DIRS 154785 \\
\hline 2kgrid8.for & 1.0 & $10503-1.0-00$ & PC & DOS V4.00.1111 & DIRS 154787 \\
\hline TOUGH2 & 1.4 & $10007-1.4-01$ & DEC ALPHA & OSF1V4.0 & DIRS 146496 \\
\hline
\end{tabular}

The use of the codes identified in Table 3-1 is documented in Section 6 and in the supporting scientific notebooks identified in Section 6. EARTHVISION V5.1 (Dynamic Graphics 2003 [DIRS 171007]) is used to evaluate and extract data from the geologic framework model (GFM2000) and integrated site model (ISM3.1) files listed in Appendix A, and to create grids utilizing the HGUs of Flint (1998 [DIRS 100033], pp. 21-32). EARTHVISION V 5.1 (Dynamic Graphics 2000 [DIRS 167994]) was used to convert data depicting the potentiometric surface from Universal Transverse Mercator coordinates to Nevada State Plane (NSP) coordinates. The WINGRIDDER V2.0 (LBNL 2002 [DIRS 154785]) software program is used to generate 1-, 2-, and 3-D gridblock element and connection information in a TOUGH2 format (the primary mesh is an "effective-continuum model," or ECM, mesh) (A General-Purpose Numerical Simulator for Multiphase Fluid and Heat Flow [Pruess 1991 (DIRS 100413)]). Data extracted from the HGU grids generated by EARTHVISION V5.1 are used as input to WINGRIDDER V2.0 to construct the TOUGH2 grid files. WINGRIDDER V2.0 contains new functionality that allows for creating a repository with multiple subregions. The software program 2kgrid8.for V1.0 (LBNL 2002 [DIRS 154787]) generates a dual-permeability mesh from a primary ECM mesh for modeling applications, using the TOUGH2 family of codes. TOUGH2 V1.4 (LBNL 2000 [DIRS 146496]) was used to perform a test simulation to check the 3-D grid, as described in Appendix C. EARTHVISION V5.1, WINGRIDDER V2.0 and 2kgrid8.for V1.0 were qualified under the software management procedures in effect at the time of qualification.

Microsoft Excel (97 SR-2) and Adobe Illustrator V8.0 were used to plot data and illustrate information generated in the gridding process. Several computations were performed using this commercial off-the-shelf software and are exempt from software qualifiation. All information needed to reproduce the work, including the input, computation, and output, is included in this report and the references specified. 
A fault slope analysis was conducted in Section 6.3. The Slope Grid Calculation utility in EARTHVISION V5.1 was used to determine the slope (rise/run) of each fault within the UZ: this input is listed in the second column of Table 6-7. Excel97 (SR-2) was used to make the following conversions: (1) arctangent of slope = fault dip in radians, and (2) radians to degrees. The output of these conversion calculations is given in columns 3-5 of Table 6-7. The specific details of these calculations can be found in Unsaturated Zone Modeling and Synthesis (Hinds and Dobson 2004 [DIRS 170886], pp. 73 to 74).

The relative proximity of all boreholes within the UZ model grid area was examined to determine whether or not neighboring boreholes should be grouped as composite locations. Boreholes that were closer than $80 \mathrm{~m}$ to another borehole were paired with the neighboring borehole, and an average borehole location was determined for use in grid construction. All borehole coordinates were converted from NSP feet to NSP meter coordinates for the use in the UZ model grid construction, as discussed in Section 6.2.

These unit conversion, borehole distance, and borehole averaging calculations are performed using Excel97 (SR-2) in the file borehole loc.xls (Output-DTN: LB0208HYDSTRAT.001). The input (NSP feet) coordinates for the boreholes are listed in columns A and B (with the coordinate values also transposed to rows 1 and 2) of the worksheet "All Boreholes" in the Excel file borehole loc.xls (Output-DTN: LB0208HYDSTRAT.001). For each borehole combination, where $\mathrm{x}_{1}, \mathrm{y}_{1}$ are the coordinates of borehole 1 , and $\mathrm{x}_{2}, \mathrm{y}_{2}$ are the coordinates of borehole 2 , the distance between the boreholes was calculated as the square root of the sum of the squares of the differences in $\mathrm{x}$ and $\mathrm{y}$ coordinates, given as the equation:

$$
\sqrt{\left(\mathrm{x}_{1}-\mathrm{x}_{2}\right)^{2}+\left(\mathrm{y}_{1}-\mathrm{y}_{2}\right)^{2}}
$$

This calculated distance was then converted from feet to meters using the conversion factor $1 \mathrm{ft}=0.3048 \mathrm{~m}$, and the output values are listed in the worksheet "All Boreholes" in the Excel file borehole loc.xls (Output-DTN: LB0208HYDSTRAT.001). Boreholes that are within $80 \mathrm{~m}$ of one another were then paired together in the worksheet "Selected Boreholes ( $\mathrm{ft}$ )" in the Excel file borehole loc.xls (Output-DTN: LB0208HYDSTRAT.001). Average x, y coordinates (NSP ft values from worksheet "All Boreholes" in the Excel file borehole loc.xls (Output-DTN: LB0208HYDSTRAT.001)) were calculated as $\left(\mathrm{x}_{1}+\mathrm{x}_{2}\right) / 2$ and $\left(\mathrm{y}_{1}+\mathrm{y}_{2}\right) / 2$. All of the borehole coordinates were then converted to meters using the conversion factor $1 \mathrm{ft}=0.3048 \mathrm{~m}$. The output for this calculation is in the worksheet "Selected Boreholes (m)" in the Excel file borehole loc.xls and the file boreholes_Rick_updated.hol (Output-DTN: LB0208HYDSTRAT.001), and is also given in Table 6-4 and Figure 6-2. The specific details of these calculations can be found in the Hinds and Dobson scientific notebook (2004 [DIRS 170886], p. 71).

Contact elevations from the input file contacts00el.dat (see GFM2000 files in Appendix A) were converted from feet to meters using the conversion factor $1 \mathrm{ft}=0.3048 \mathrm{~m}$, and the resulting values are listed in Table B-1. These calculations were performed using Excel97 (SR-2).

As discussed later in Section 6.4.1, some of the GFM2000 isochore files were combined or subdivided using the EARTHVISION V5.1 Formula Processor to generate the UZ model HGU isochores. For validation purposes (see Appendix B), the output UZ model HGU contact 
elevations for boreholes in the file Boreholes.mck from Output-DTN: LB02081DKMGRID.001 were compared to layer contact elevations in the file contacts00el.dat from DTN: MO0012MWDGFM02.002 [DIRS 153777]. The GFM2000 borehole elevations from contacts00el.dat were first converted to feet to meters using the conversion factor of $1 \mathrm{ft}=0.3048 \mathrm{~m}$. The unit contact elevations were then adjusted in the same manner as described in Section 6.4.1 to make the GFM2000 stratigraphic units correspond to the UZ model HGUs. These calculations were performed using Excel97 (SR-2). The output data for these calculations are recorded in Table B-1 under the columns labeled GFM2000.

There are actually two different "foot" units. One of these, the U.S. Survey foot, used for geodetic survey coordinates, is defined as $1,200 \mathrm{~m}=3,937 \mathrm{ft}$, while the standard foot is equal to $0.3048 \mathrm{~m}$ [Standard for Use of the International System of Units (SI): The Modern Metric System (IEEE/ASTM SI 10-1997 [DIRS 151762], pp. 18, 25)]. By using the standard foot-to-meter conversion factor (instead of the more appropriate U.S. Survey foot conversion), a small error is introduced into the model. For example, the NSP coordinates for the borehole G-1 (given as 561,000 E, 770,502 N in NSP ft in contacts00el.dat) convert to 170,993.1 E, $234,849.0 \mathrm{~N}$ in NSP $\mathrm{m}$ using the conversion factor of $0.3048 \mathrm{~m} / \mathrm{ft}$, and to $170,993.4 \mathrm{E}, 234,849.5$ $\mathrm{N}$ using the more appropriate U.S. Survey feet conversion factor. The model grid is not sensitive to the magnitude of the maximum difference $(0.5 \mathrm{~m})$ resulting from the use of the $0.3048 \mathrm{~m} / \mathrm{ft}$ conversion factor. 


\section{INTENTIONALLY LEFT BLANK}




\section{INPUTS}

The initial stage of grid development begins with the definition of lateral domain and repository boundaries, along with the location of important calibration features (e.g., boreholes). In order to generate a 3-D grid, WINGRIDDER V2.0 (LBNL 2002 [DIRS 154785]) requires specification of three reference horizons: an upper and lower model boundary (usually the bedrock surface and water table, respectively) and a structural reference horizon that defines layer displacement along fault traces and sets the elevation of the remaining layer interfaces. These reference horizon files consist of regularly spaced $\mathrm{x}, \mathrm{y}$, and elevation data. Isochore (borehole layer thickness) maps, consisting of regularly spaced $\mathrm{x}, \mathrm{y}$, and thickness data for each model layer, are then stacked above or below the structural reference horizon to build the vertical component of the UZ model.

\subsection{DIRECT INPUTS}

The input data used directly in numerical grid development are summarized in Table 4-1. The Q-status of each of these data tracking numbers (DTNs) can be determined by referring to the DIRS. Uncertainty in the input data and parameters is discussed in Sections. 6.9, 6.9.1, and 7.1.

Table 4-1. Summary of Direct Input Data Used in Numerical Grid Development

\begin{tabular}{|l|l|l|}
\hline \multicolumn{1}{|c|}{ Description } & \multicolumn{1}{|c|}{ DTN } & \multicolumn{1}{c|}{ Data Use $^{a^{\prime}}$} \\
\hline $\begin{array}{l}\text { Geologic Framework Model } \\
\text { (GFM2000) }\end{array}$ & MO0012MWDGFM02.002 (DIRS 153777) & $\begin{array}{l}\text { Sections 6.1, 6.2, 6.3, 6.4, } \\
\text { Appendices A, B, C }\end{array}$ \\
\hline Water Table Elevations & $\begin{array}{l}\text { MO0212GWLSSPAX.000 } \\
\text { (DIRS 161271) }\end{array}$ & Sections 6.2, 6.4.2 \\
\hline Fracture Data for HGUs & $\begin{array}{l}\text { LB0205REVUZPRP.001 (DIRS 159525) } \\
\text { LB0207REVUZPRP.001 (DIRS 159526) }\end{array}$ & Section 6.7 \\
\hline $\begin{array}{l}\text { Rock Property Data for Delineating } \\
\text { Vitric and Zeolitic Units }\end{array}$ & $\begin{array}{l}\text { MO9910MWDISMRP.002 (DIRS 145731) } \\
\text { LB0207REVUZPRP.002 (DIRS 159672) } \\
\text { MO0109HYMXPROP.001 (DIRS 155989) }\end{array}$ & Sections 5.2, 6.6.3 \\
\hline $\begin{array}{l}\text { GS980808312242.014 (DIRS 106748) } \\
\text { GS980908312242.038 (DIRS 107154) } \\
\text { GS951108312231.009 (DIRS 108984) } \\
\text { GS960808312231.004 (DIRS 108985) }\end{array}$ & \\
\hline Repository Layout Configuration & BSC 2002 (DIRS 159527) & Section 6.6.2 \\
\hline
\end{tabular}

a Sections and appendices where the use of data is described in detail.

b See Attachment IV of Development of Numerical Grids for UZ Flow and Transport Modeling (BSC 2003 [DIRS 160109]) for details regarding qualification of DTN MO0212GWLSSPAX.000 [DIRS 161271].

c The latest version of the repository layout (BSC 2004 [DIRS 164519]) does not include the lower block area.

The primary data feed for UZ model grids is the geologic framework model (GFM2000) (DTN: MO0012MWDGFM02.002 [DIRS 153777]). The GFM2000 is a representation of lithostratigraphic layering and major fault geometry in the Yucca Mountain area that was created using geologic mapping and borehole data as primary input data [Geologic Framework Model (GFM2000) (BSC 2004 [DIRS 170029], Section 4.1)]. The model contains information about layer thickness and layer contact elevation, and defines major fault orientation and displacement. 
The data for each layer and each fault within GFM2000 are available on a regular horizontal grid spacing of $61 \times 61 \mathrm{~m}$ over the model's domain (methodology described in Geologic Framework Model (GFM2000) (BSC 2004 [DIRS 170029]), Section 6.4; data files in DTN: MO0012MWDGFM02.002 [DIRS 153777]). A total of 50 geologic units and 44 faults are represented in GFM2000. As listed in Appendix A, 42 of these units and 19 faults (those that lie within the UZ model domain) are incorporated into the 3-D UZ model grids. Alternate geologic models are not available for use in the UZ model, nor were they developed in the geologic framework model report (BSC 2004 [DIRS 170029], Section 6.4.1). However, alternative conceptual geologic models would result in only minor changes to unit elevations and thicknesses in the vicinity of the Exploratory Studies Facility (ESF) (BSC 2004 [DIRS 170029], Section 6.4.1). Therefore, no impact of alternative interpretations is anticipated on the geologic framework model or subsequent model users in the vicinity of the ESF (BSC 2004 [DIRS 170029], Section 6.6.5), where the UZ model area is located. The conceptual model used in the development of GFM2000 is founded on the observation that Yucca Mountain is composed of volcanic rocks originating from several calderas or vent sources (BSC 2004 [DIRS 170029], Section 6.4.1). The resulting geologic interpretation it represents is the Office of Repository Development's geologic model to be used in site-scale process models. GFM2000 files used in UZ model grid development are listed in Appendix A.

As discussed in Sections 6.2 and 6.4.2, the lower UZ model boundary is based on the contoured potentiometric surface (DTN: MO0212GWLSSPAX.000 [DIRS 161271]). The review and qualification process for this DTN is presented in Attachment IV in Development of Numerical Grids for UZ Flow and Transport Modeling (BSC 2003 [DIRS 160109]).

Fracture hydrogeologic properties (DTNs: LB0205REVUZPRP.001 [DIRS 159525] and LB0207REVUZPRP.001 [DIRS 159526]) describing UZ model layers are used to formulate the dual-permeability (dual-k) meshes for 1-D hydrogeologic-property-set inversions, for 2-D fault property calibration, and for 3-D UZ model calibration and flow fields for PA. Fracture hydrogeologic properties used for dual-k grid generation are listed in Table 4-2.

Table 4-2. Fracture Hydrogeologic Properties

\begin{tabular}{|c|c|c|c|c|}
\hline Model Layer & $\begin{array}{c}\text { Fracture Porosity } \\
\left(\mathbf{m}^{3} / \mathbf{m}^{3}\right)\end{array}$ & $\begin{array}{c}\text { Fracture Aperture } \\
(\mathbf{m})\end{array}$ & $\begin{array}{c}\text { Fracture Frequency } \\
\left(\mathbf{m}^{-1}\right)\end{array}$ & $\begin{array}{c}\text { Fracture Interface } \\
\text { Area } \\
\left(\mathbf{m}^{2} / \mathbf{m}^{3}\right)\end{array}$ \\
\hline$t c w 11$ & $2.4 \mathrm{E}-02$ & $7.3 \mathrm{E}-04$ & $9.2 \mathrm{E}-01$ & $1.6 \mathrm{E}+00$ \\
\hline$t c w 12$ & $1.7 \mathrm{E}-02$ & $3.2 \mathrm{E}-04$ & $1.9 \mathrm{E}+00$ & $1.3 \mathrm{E}+01$ \\
\hline$t c w 13$ & $1.3 \mathrm{E}-02$ & $2.7 \mathrm{E}-04$ & $2.8 \mathrm{E}+00$ & $3.8 \mathrm{E}+00$ \\
\hline$p t n 21$ & $9.2 \mathrm{E}-03$ & $3.9 \mathrm{E}-04$ & $6.7 \mathrm{E}-01$ & $1.0 \mathrm{E}+00$ \\
\hline$p t n 22$ & $1.0 \mathrm{E}-02$ & $2.0 \mathrm{E}-04$ & $4.6 \mathrm{E}-01$ & $1.4 \mathrm{E}+00$ \\
\hline$p t n 23$ & $2.1 \mathrm{E}-03$ & $1.8 \mathrm{E}-04$ & $5.7 \mathrm{E}-01$ & $1.8 \mathrm{E}+00$ \\
\hline$p t n 24$ & $1.0 \mathrm{E}-02$ & $4.3 \mathrm{E}-04$ & $4.6 \mathrm{E}-01$ & $3.4 \mathrm{E}-01$ \\
\hline$p t n 25$ & $5.5 \mathrm{E}-03$ & $1.6 \mathrm{E}-04$ & $5.2 \mathrm{E}-01$ & $1.1 \mathrm{E}+00$ \\
\hline$p t n 26$ & $3.1 \mathrm{E}-03$ & $1.4 \mathrm{E}-04$ & $9.7 \mathrm{E}-01$ & $3.6 \mathrm{E}+00$ \\
\hline$t s w 31$ & $5.0 \mathrm{E}-03$ & $1.6 \mathrm{E}-04$ & $2.2 \mathrm{E}+00$ & $3.9 \mathrm{E}+00$ \\
\hline$t s w 32$ & $8.3 \mathrm{E}-03$ & $2.0 \mathrm{E}-04$ & $1.1 \mathrm{E}+00$ & $3.2 \mathrm{E}+00$ \\
\hline$t s w 33$ & $5.8 \mathrm{E}-03$ & $2.3 \mathrm{E}-04$ & $8.1 \mathrm{E}-01$ & $4.4 \mathrm{E}+00$ \\
\hline
\end{tabular}


Table 4-2. Fracture Hydrogeologic Properties (Continued)

\begin{tabular}{|c|c|c|c|c|}
\hline Model Layer & $\begin{array}{l}\text { Fracture Porosity } \\
\left(\mathrm{m}^{3} / \mathrm{m}^{3}\right)\end{array}$ & $\begin{array}{l}\text { Fracture Aperture } \\
(\mathrm{m})\end{array}$ & $\begin{array}{l}\text { Fracture Frequency } \\
\qquad\left(\mathrm{m}^{-1}\right)\end{array}$ & $\begin{array}{c}\text { Fracture Interface } \\
\text { Area } \\
\left(\mathrm{m}^{2} / \mathrm{m}^{3}\right)\end{array}$ \\
\hline tsw34 & 8.5E-03 & 9.7E-05 & $4.3 E+00$ & $1.4 \mathrm{E}+01$ \\
\hline tsw35 & 9.6E-03 & $1.5 \mathrm{E}-04$ & $3.2 \mathrm{E}+00$ & $9.7 E+00$ \\
\hline tsw36 & 1.3E-02 & 1.6E-04 & $4.0 \mathrm{E}+00$ & $1.2 \mathrm{E}+01$ \\
\hline tsw37 & 1.3E-02 & 1.6E-04 & $4.0 \mathrm{E}+00$ & $1.2 \mathrm{E}+01$ \\
\hline tsw38 & 1.1E-02 & 1.3E-04 & $4.4 \mathrm{E}+00$ & $1.3 \mathrm{E}+01$ \\
\hline tsw39 & 4.3E-03 & $2.2 \mathrm{E}-04$ & 9.6E-01 & $3.0 \mathrm{E}+00$ \\
\hline $\operatorname{ch} 1 \mathrm{VI}$ & 6.1E-04 & 3.0E-04 & 1.0E-01 & 3.0E-01 \\
\hline ch2VI & 7.7E-04 & 2.7E-04 & $1.4 \mathrm{E}-01$ & 4.3E-01 \\
\hline ch3VI & 7.7E-04 & 2.7E-04 & 1.4E-01 & 4.3E-01 \\
\hline ch4VI & 7.7E-04 & 2.7E-04 & 1.4E-01 & 4.3E-01 \\
\hline ch5VI & 7.7E-04 & 2.7E-04 & $1.4 \mathrm{E}-01$ & 4.3E-01 \\
\hline ch6VI & 7.7E-04 & 2.7E-04 & $1.4 \mathrm{E}-01$ & 4.3E-01 \\
\hline $\operatorname{ch} 1 Z e$ & 1.6E-04 & 2.0E-04 & 4.0E-02 & 1.1E-01 \\
\hline ch2Ze & 3.7E-04 & 1.3E-04 & 1.4E-01 & 4.3E-01 \\
\hline ch3Ze & 3.7E-04 & 1.3E-04 & 1.4E-01 & 4.3E-01 \\
\hline ch4Ze & 3.7E-04 & 1.3E-04 & 1.4E-01 & 4.3E-01 \\
\hline ch5Ze & 3.7E-04 & 1.3E-04 & 1.4E-01 & 4.3E-01 \\
\hline ch6Ze & $1.6 \mathrm{E}-04$ & 2.0E-04 & 4.0E-02 & 1.1E-01 \\
\hline pp4 & 3.7E-04 & 1.3E-04 & 1.4E-01 & 4.3E-01 \\
\hline pp3 & 9.7E-04 & $2.4 \mathrm{E}-04$ & 2.0E-01 & $6.1 \mathrm{E}-01$ \\
\hline pp2 & 9.7E-04 & $2.4 \mathrm{E}-04$ & 2.0E-01 & 6.1E-01 \\
\hline pp1 & 3.7E-04 & 1.3E-04 & 1.4E-01 & 4.3E-01 \\
\hline bf3 & 9.7E-04 & $2.4 \mathrm{E}-04$ & 2.0E-01 & $6.1 E-01$ \\
\hline bf2 & 3.7E-04 & 1.3E-04 & 1.4E-01 & 4.3E-01 \\
\hline tr3 & 9.7E-04 & $2.4 \mathrm{E}-04$ & 2.0E-01 & $6.1 \mathrm{E}-01$ \\
\hline tr2 & 3.7E-04 & 1.3E-04 & $1.4 \mathrm{E}-01$ & 4.3E-01 \\
\hline tcwf $^{\mathrm{a}}$ & $2.9 \mathrm{E}-02$ & 5.5E-04 & $1.9 \mathrm{E}+00$ & $1.3 \mathrm{E}+01$ \\
\hline $\operatorname{ptnf}^{a}$ & 1.1E-02 & 4.1E-04 & 5.4E-01 & $1.3 \mathrm{E}+00$ \\
\hline tswf $^{\mathrm{a}}$ & $2.5 \mathrm{E}-02$ & 4.6E-04 & $1.7 \mathrm{E}+00$ & 8.7E+00 \\
\hline $\operatorname{chnf}^{\mathrm{a}}$ & 1.0E-03 & 3.3E-04 & 1.3E-01 & $4.6 \mathrm{E}-01$ \\
\hline
\end{tabular}

Source: DTN: LB0205REVUZPRP.001 [DIRS 159525] and LB0207REVUZPRP.001 [DIRS 159526].

${ }^{a}$ Values for fault fracture properties within the Tiva Canyon welded (tcwf), Paintbrush nonwelded (ptnf), Topopah Spring welded (tswf), and Calico Hills nonwelded (chnf) units.

VI=Vitric Subunit, Ze=Zeolitic Subunit

Because of the importance of mineral (especially zeolitic) alteration for flow and transport calculations, boundaries between vitric and zeolitic areas are defined within certain UZ model grid layers (tsw39, ch1, ch2, ch3, ch4, ch5, and ch6) below the repository horizon (Section 6.6.3). Alteration to zeolites has been shown to greatly reduce permeability ([Flint 1998 (DIRS 100033), p. 32] and A Summary and Discussion of Hydrologic Data from the Calico Hills Nonwelded Hydrogeologic Unit at Yucca Mountain, Nevada [Loeven 1993 (DIRS 101258), pp. 18 to 19 and p. 22]) and may increase the rock's ability to adsorb some radionuclides. As discussed in Section 5.2 (Assumptions 2 and 3), the data considered as direct input to identifying 
the location of low-permeability, zeolitic volumes of rock within the numerical grids are obtained from the rock properties model of the integrated site model, Version 3.1 (RPM3.1) (DTN: MO9910MWDISMRP.002 [DIRS 145731]), along with saturation, porosity, and hydraulic conductivity data obtained from a variety of boreholes within the UZ model domain (LB0207REVUZPRP.002 [DIRS 159672]; MO0109HYMXPROP.001 [DIRS 155989]; GS980808312242.014 [DIRS 106748]; GS980908312242.038 [DIRS 107154]; GS951108312231.009 [DIRS 108984]; GS960808312231.004 [DIRS 108985]). The specific integrated site model (ISM3.1) files used in UZ model grid development are listed in Appendix A.

DTN MO9910MWDISMRP.002 [DIRS 145731] is a technical product output of the Rock Properties Model Analysis Model Report (BSC 2002 [DIRS 159530]), a controlled document, and thus this qualified DTN is appropriate for use as a direct input. The RPM3.1 hydraulic conductivity data were previously used in delineating vitric and zeolitic regions in Revision 01 of this report (BSC 2003 [DIRS 160109], Section 6.6.3). The correlation of low hydraulic conductivity values with zeolitic alteration in the Calico Hills tuff unit was noted in the Rock Properties Model Analysis Model Report (BSC 2002 [DIRS 159530], Section 6.5.3). The suitability of the RPM3.1 hydraulic conductivity data for differentiating between vitric and zeolitic tuffs is further supported by qualified borehole saturation, porosity, and hydraulic conductivity data from the DTNs listed above, which were also used in the delineation of the vitric-zeolitic boundaries. These factors provide sufficient justification to consider DTN: MO9910MWDISMRP.002 [DIRS 145731] to be qualified for the intended use within this report, as per AP-SIII.9Q, Scientific Analyses, Section 5.2.1. Detailed discussion of how the boundaries between the vitric and zeolitic subunits are defined on a unit-by-unit basis is presented in Section 6.6.3.

As discussed in Section 6.6.2, an assumed repository layout configuration, based on Data Sheets 2 and 3 from Repository Design, Repository/PA IED Subsurface Facilities Plan Sht. 1 of 5, Sht. 2 of 5, Sht. 3 of 5, Sht. 4 of 5, and Sht. 5 of 5 (BSC 2002 [DIRS 159527]), is used during numerical grid generation to delineate areas for finer spatial resolution. The repository layout used in the formulation of the numerical grids consists of an extended upper repository area (consisting of two parts) that covers much of the footprint of the previous repository as presented in Development of Numerical Grids for UZ Flow and Transport Modeling, Revision 00, Interim Change Notice 01 (BSC 2001 [DIRS 159356], Figure 1), and an additional lower repository area that is situated just east of the upper repository area. The areal boundary coordinates for, and elevations of, the repository (in meters above sea level, [masl]) are listed in Data Sheets 2 and 3 from Repository Design, Repository/PA IED Subsurface Facilities Plan Sht. 1 of 5, Sht. 2 of 5, Sht. 3 of 5, Sht. 4 of 5, and Sht. 5 of 5 (BSC 2002 [DIRS 159527]) and the repository outline is shown in Figures 6-1 and 6-2 (Section 6.2). As noted in Section 6.6.2, the repository layout may be subject to future design modifications. The most recent version of the repository layout (BSC 2004 [DIRS 164519]), created after the formulation of the numerical grids described in this report, does not include the lower block area designated in Figures 6-1 and 6-2.

The direct data inputs utilized in this report are appropriate for this study because they represent the key elements (geologic framework, hydrologic properties, UZ boundary, and repository layout) required for numerical grids used for UZ modeling at Yucca Mountain. Each of these data sets consist of data qualified in accordance to the requirements of the U.S. Department of 
Energy (DOE) Office of Civilian Radioactive Waste Management Quality Assurance Requirements and Description (QARD), DOE/RW-0333P, or as in the case of the repository layout, are design drawings prepared in accordance with governing procedures. The appropriateness of the data is also discussed throughout Section 6, where they are used in the construction of the numerical grids. Limitations and uncertainties associated with these grids are presented in Sections 6.9, 6.9.1, and 7.1.

\subsubsection{Other Inputs}

The inputs in Table 4-3 are corroborative data associated with scientific analyses and the formulation of the numerical grids. The first row of inputs is used to assign hydrogeologic nomenclature to layers in the numerical grids. The middle two rows of inputs are used to corroborate definition of vitric and zeolitic subunits in the units tsw39, ch1, ch2, ch3, ch4, ch5, and ch6. The last row of inputs in Table 4-3 is used to to interpret hydrologic features away from the repository area.

Table 4-3. Summary of Other Inputs Used in Numerical Grid Development

\begin{tabular}{|l|l|l|}
\hline \multicolumn{1}{|c|}{ Description } & \multicolumn{1}{c|}{ Reference } & \multicolumn{1}{c|}{ Data Use } \\
\hline HGU Definitions & Flint 1998 (DIRS 100033) $)^{\text {a }}$ & Sections 6.3, 6.4.1 \\
\hline $\begin{array}{l}\text { Mineralogic Model (MM3.1) of Integrated } \\
\text { Site Model (ISM3.1) }\end{array}$ & $\begin{array}{l}\text { MO9910MWDISMMM.003 } \\
\text { (DIRS 119199) }\end{array}$ & Section 6.6.3 \\
\hline Rock Properties Model (RPM2000) & $\begin{array}{l}\text { SN0112T0501399.004 } \\
\text { (DIRS 159524) }\end{array}$ & Section 6.6.3 \\
\hline Perched-Water Elevations & $\begin{array}{l}\text { GS010608312332.001 } \\
\text { (DIRS 155307) } \\
\text { MO0106RIB00038.001 } \\
\text { (DIRS 155631) }\end{array}$ & Sections 5.1, 6.2, 6.4.2 \\
\hline
\end{tabular}

${ }^{a}$ HGU unit definitions (Flint 1998 [DIRS 100033]) used qualitatively; individual sample data not used.

Geologic data alone cannot adequately capture all important features that affect flow and transport in the UZ at Yucca Mountain. Hydrogeologic rock-property data have also been considered in the development of the numerical grids, as discussed in Section 6.3. Based on analyses of several thousand rock samples performed by the U.S. Geological Survey (USGS), 30 HGUs have been identified, based on "limited ranges where a discrete volume of rock contains similar hydrogeologic properties” (Flint 1998 [DIRS 100033], p. 1, Table 1). The layering within the UZ model numerical grid was chosen to correspond as closely as possible to the Flint (1998 [DIRS 100033]) HGUs because the hydrogeologic property sets that are calculated with the UZ model grid use, to a large extent, the matrix-property data collected and analyzed by Flint (1998 [DIRS 100033]). The boundaries of HGUs are not defined by regularly spaced data, but are more qualitative in nature. The qualitative descriptions (but not any sample or other data) given by Flint (1998 [DIRS 100033], pp. 21-32), when correlated with GFM2000 data (DTN: MO0012MWDGFM02.002 [DIRS 153777]), are used to develop a set of hydrogeologic layers whose thickness and elevation are described by regularly spaced data for the UZ model. The correlation between the GFM2000 lithostratigraphy (BSC 2004 [DIRS 170029], Table 6-2), the Flint (1998 [DIRS 100033], Table 1) HGUs, and the HGUs utilized in this report is presented in Sections 6.3 and 6.4 and summarized in Table 6-5. 
As mentioned in Sections 4.1, 5.2, and 6.6.3, vitric and zeolitic zones within the UZ model layers tsw39, ch1, ch2, ch3, ch4, ch5, and ch6 were defined using data obtained from rock properties model 3.1 (DTN: MO9910MWDISMRP.002 [DIRS 145731]), along with rock property data listed in Table 4-1 from a variety of boreholes. Information from the rock properties model (RPM2000) (DTN: SN0112T0501399.004 [DIRS 159524]) and the mineralogic model of the integrated site model, Version 3.1 (MM3.1) (DTN: MO9910MWDISMMM.003 [DIRS 119199]) was used to corroborate the selection of the vitric/zeolitic boundaries for the units in question.

\subsection{CRITERIA}

The general requirements to be satisfied by TSPA are stated in 10 CFR 63.114 [DIRS 156605] (Requirements for Performance Assessment). Technical requirements to be satisfied by TSPA are identified in the Project Requirements Document (Canori and Leitner 2003 [DIRS 166275]). The acceptance criteria that will be used by the U.S. Nuclear Regulatory Commission to determine whether the technical requirements have been met are identified in the Yucca Mountain Review Plan, Final Report (NRC 2003 [DIRS 163274]).

Table 4-4. Project Requirements and Acceptance Criteria Applicable to This Report

\begin{tabular}{|c|c|c|c|}
\hline $\begin{array}{c}\text { Requirement } \\
\text { Number }^{\mathbf{a}}\end{array}$ & \multicolumn{1}{|c|}{ Requirement Title $^{\mathbf{a}}$} & \multicolumn{1}{c|}{ 10 CFR 63 Link } & \multicolumn{1}{c|}{$\begin{array}{c}\text { YMP Acceptance } \\
\text { Criteria }^{\mathbf{b}}\end{array}$} \\
\hline PRD -002/T-015 & Requirements for Performance Assessment & $\begin{array}{l}\text { 10 CFR 63.114 } \\
\text { (a)-(c) and (e)-(g) }\end{array}$ & $\begin{array}{c}\text { 2.2.1.3.6.3, criteria 1 to 4 } \\
\text { 2.2.1.3.7.3, criteria 1 to 4 }\end{array}$ \\
\hline
\end{tabular}

a from Canori and Leitner (2003 [DIRS 166275])

b from NRC (2003 [DIRS 163274])

YMRP=Yucca Mountain Review Plan

The acceptance criteria identified in Sections 2.2.1.3.6.3 and 2.2.1.3.7.3 of the Yucca Mountain Review Plan (NRC 2003 [DIRS 163274] are included below. In cases where subsidiary criteria are listed in the Yucca Mountain Review Plan for a given criterion, only the subsidiary criteria addressed by this report are listed below. How this report satisfies these criteria is presented in Section 7.2.

Acceptance Criteria from Section 2.2.1.3.6.3, Flow Paths in the Unsaturated Zone

Acceptance Criterion 1: System Description and Model Integration Are Adequate.

(1) Total system performance assessment adequately incorporates, or bounds, important design features, physical phenomena, and couplings, and uses consistent and appropriate assumptions throughout the flow paths in the unsaturated zone abstraction process. Couplings include thermal-hydrologic-mechanical-chemical effects as appropriate;

(2) The aspects of geology, hydrology, geochemistry, physical phenomena, and couplings that may affect flow paths in the unsaturated zone are adequately considered. Conditions and assumptions in the abstraction of flow paths in the unsaturated zone are readily identified and consistent with the body of data presented in the description; 
(3) The abstraction of flow paths in the unsaturated zone uses assumptions, technical bases, data, and models that are appropriate and consistent with other related U.S. Department of Energy abstractions. For example, the assumptions used for flow paths in the unsaturated zone are consistent with the abstractions of quality and chemistry of water contacting waste packages and waste forms, climate and infiltration, and flow paths in the saturated zone (Sections 2.2.1.3.3, 2.2.1.3.5 and 2.2.1.3.8 of the Yucca Mountain Review Plan, respectively). The descriptions and technical bases are transparent and traceable to site and design data.

(9) Guidance in NUREG-1297 and NUREG-1298 (Altman et al., 1988 [DIRS 103597 and DIRS 103750]), or other acceptable approaches for peer review and data qualification is followed.

Acceptance Criterion 2: Data Are Sufficient for Model Justification.

(1) Hydrological and thermal-hydrological-mechanical-chemical values used in the license application are adequately justified. Adequate descriptions of how the data were used, interpreted, and appropriately synthesized into the parameters are provided;

(2) The data on the geology, hydrology, and geochemistry of the unsaturated zone, are collected using acceptable techniques;

(6) Accepted and well-documented procedures are used to construct and calibrate numerical models;

(7) Reasonably complete process-level conceptual and mathematical models are used in the analyses. In particular: (i) mathematical models are provided that are consistent with conceptual models and site characteristics; and (ii) the robustness of results from different mathematical models is compared.

Acceptance Criterion 3: Data Uncertainty is Characterized and Propagated Through the Model Abstraction.

(1) Models use parameter values, assumed ranges, probability distributions, and bounding assumptions that are technically defensible, reasonably account for uncertainties and variabilities, and do not result in an under-representation of the risk estimate;

(4) The initial conditions, boundary conditions, and computational domain used in sensitivity analyses and/or similar analyses are consistent with available data. Parameter values are consistent with the initial and boundary conditions and the assumptions of the conceptual models for the Yucca Mountain site.

Acceptance Criterion 4: Model Uncertainty is Characterized and Propagated Through the Model Abstraction.

(1) Alternative modeling approaches of features, events, and processes, consistent with available data and current scientific understanding, are investigated. The results and limitations are appropriately considered in the abstraction; 
(3) Consideration of conceptual model uncertainty is consistent with available site characterization data, laboratory experiments, field measurements, natural analog information and process-level modeling studies; and the treatment of conceptual model uncertainty does not result in an under-representation of the risk estimate.

Acceptance Criteria from Section 2.2.1.3.7.3, Radionuclide Transport in the Unsaturated Zone

Acceptance Criterion 1: System Description and Model Integration Are Adequate.

(1) Total system performance assessment adequately incorporates important design features, physical phenomena, and couplings, and uses consistent and appropriate assumptions throughout the radionuclide transport in the unsaturated zone abstraction process;

(2) The description of the aspects of hydrology, geology, geochemistry, design features, physical phenomena, and couplings, that may affect radionuclide transport in the unsaturated zone, is adequate. For example, the description includes changes in transport properties in the unsaturated zone, from water-rock interaction. Conditions and assumptions in the total system performance assessment abstraction of radionuclide transport in the unsaturated zone are readily identified, and consistent with the body of data presented in the description;

(3) The abstraction of radionuclide transport in the unsaturated zone uses assumptions, technical bases, data, and models that are appropriate and consistent with other related U.S. Department of Energy abstractions. For example, the assumptions used for radionuclide transport in the unsaturated zone are consistent with the abstractions of radionuclide release rates and solubility limits and flow paths in the unsaturated zone (Sections 2.2.1.3.4 and 2.2.1.3.6 of the Yucca Mountain Review Plan). The descriptions and technical bases provide transparent and traceable support for the abstraction of radionuclide transport in the unsaturated zone.

(4) Boundary and initial conditions used in the abstraction of radionuclide transport in the unsaturated zone are propagated throughout its abstraction approaches. For example, the conditions and assumptions used to generate transport parameter values are consistent with other geological, hydrological, and geochemical conditions in the total system performance assessment abstraction of the unsaturated zone;

(5) Sufficient data and technical bases for the inclusion of features, events, and processes, related to radionuclide transport in the unsaturated zone in the total system performance assessment abstraction, are provided; and

(6) Guidance in NUREG-1297 and NUREG-1298 (Altman et al., 1988 [DIRS 103597 and DIRS 103750]), or other acceptable approaches, is followed for peer review and data qualification. 
Acceptance Criterion 2: Data Are Sufficient for Model Justification.

(1) Geological, hydrological, and geochemical values, used in the license application, are adequately justified (e.g., flow-path length, sorption coefficients, retardation factors, colloid concentrations, etc.). Adequate descriptions of how the data were used, interpreted, and appropriately synthesized into the parameters are provided;

(3) Data on the geology, hydrology, and geochemistry of the unsaturated zone, including the influence of structural features, fracture distributions, fracture properties, and stratigraphy, used in the total system performance assessment abstraction are based on appropriate techniques. These techniques may include laboratory experiments, site-specific field measurements, natural analog research, and process-level modeling studies. As appropriate, sensitivity or uncertainty analyses, used to support the U.S. Department of Energy total system performance assessment abstraction, are adequate to determine the possible need for additional data.

Acceptance Criterion 3: Data Uncertainty Is Characterized and Propagated Through the Model Abstraction.

(1) Models use parameter values, assumed ranges, probability distributions, and bounding assumptions that are technically defensible, reasonably account for uncertainties and variabilities, and do not result in an under-representation of the risk estimate;

(4) Uncertainty is adequately represented in parameter development for conceptual models, process-level models, and alternative conceptual models, considered in developing the abstraction of radionuclide transport in the unsaturated zone. This may be done either through sensitivity analyses or use of conservative limits.

Acceptance Criterion 4: Model Uncertainty Is Characterized and Propagated Through the Model Abstraction.

(1) Alternative modeling approaches of features, events, and processes are considered and are consistent with available data and current scientific understanding, and the results and limitations are appropriately considered in the abstraction;

(2) Conceptual model uncertainties are adequately defined and documented, and effects on conclusions regarding performance are properly assessed;

(3) Consideration of conceptual model uncertainty is consistent with available site characterization data, laboratory experiments, field measurements, natural analog information and process-level modeling studies; and the treatment of conceptual model uncertainty does not result in an under-representation of the risk estimate.

\subsection{CODES, STANDARDS, AND REGULATIONS}

No specific formally established codes, standards, or regulations have been identified as applying to this scientific analysis activity. 


\section{INTENTIONALLY LEFT BLANK}




\section{ASSUMPTIONS}

The assumptions presented below are those used, in the absence of direct confirming data or evidence, that are necessary to develop the UZ model numerical grids, in compliance with AP-SIII.9Q. This section presents the rationale and supporting data for these assumptions, and references the sections of this report in which each assumption is used. The assumptions presented in this section are based on interpretation and synthesis of a variety of geologic and hydrologic inputs. Other assumptions associated with the conceptual model and numerical grid development are presented in Section 6.

Assumptions used in developing the numerical grids are of two kinds: assumptions made about the physical world, and assumptions made about the effects of certain features of the grid upon the results of model calculations. None of the assumptions listed below requires confirmation. No hydrologic and rock property values are assigned, justified, or qualified for gridblocks in this report.

Certain features of the grid are simplifications known to be different from the physical prototype. These simplifications are necessary for calculations to be done with existing computers and qualified software. Assumptions about the effects of such simplifications upon the results of calculations can be verified through sensitivity analyses; that is, by running simulations with the assumptions as stated and with alternative assumptions. The effects of numerical grid resolution on flow and transport model simulation results are discussed in Section 6.8 through the utilization of previous studies.

\subsection{ASSUMPTIONS REGARDING PHYSICAL CONDITIONS EXTERIOR TO THE MODELING PROCESS}

The following assumption pertains to the elevation of the water table, which defines the lower UZ model boundary.

Assumption 1. The observed water levels in boreholes WT\#6 and G-2 (at 1,034 and 1,020 masl, respectively) are assumed to be perched water (Section 6.2).

Observed water levels in these two boreholes from northern Yucca Mountain (located east of the Solitario Canyon fault) are much higher than 840 masl, the elevation of the water level encountered in the nearby USW WT-24 borehole, which is interpreted to represent the regional water table. In boreholes WT\#6 and USW G-2, water levels measure about 1,034 masl and 1,020 masl, respectively (MO0106RIB00038.001 [DIRS 155631]). The UZ model simulates and calibrates to perched-water data under selected portions of northern Yucca Mountain. This assumption is supported by a variety of studies on the water table at Yucca Mountain (e.g., FY 01 Supplemental Science and Performance Analyses, Volume I: Scientific Bases and Analyses [BSC 2001 (DIRS 155950, Figure 12.3.1.2-2)]; Revised Potentiometric-Surface Map, Yucca Mountain and Vicinity, Nevada [Ervin et al. 1994 (DIRS 100633, p. 15)]; "Is There Perched Water Under Yucca Mountain in Borehole USW G-2?” [Czarnecki et al. 1994 (DIRS 142594)]; and "Testing in Borehole USW G-2 at Yucca Mountain: The Saga Continues” [Czarnecki et al. 1995 (DIRS 103371)]), as discussed in more detail in Section 6.2. 


\subsection{ASSUMPTIONS REGARDING NUMERICAL GRID CONSTRUCTION}

The distribution of low-permeability zeolites within the Topopah Spring welded (TSw, specifically, tsw39) and Calico Hills nonwelded (CHn) HGUs impacts flowpaths and groundwater travel times from the repository horizon to the water table and is, therefore, an important feature to capture in the UZ model grids. The data considered in numerical grid development for defining low-permeability, zeolitic volumes of rock come from the rock properties model of the integrated site model, Version 3.1 (RPM3.1) (DTN: MO9910MWDISMRP.002 [DIRS 145731]) and from measurements of borehole rock matrix hydrologic properties (DTNs: LB0207REVUZPRP.002 [DIRS 159672], MO0109HYMXPROP.001 [DIRS 155989], GS980808312242.014 [DIRS 106748], GS980908312242.038 [DIRS 107154], GS951108312231.009 [DIRS 108984], GS960808312231.004 [DIRS 108985]). The locations of the boundaries between vitric and zeolitic zones were corroborated using data from the rock properties model (RPM2000) (DTN: SN0112T0501399.004 [DIRS 159524]) and the mineralogic model of the integrated site model, Version 3.1 (MM3.1) (DTN: MO9910MWDISMMM.003 [DIRS 119199]); see Assumptions 2 and 3 below.

The following three assumptions pertain to the definition of low-permeability, zeolitic regions within UZ model layers corresponding to portions of the TSw and CHn. Within UZ model layers tsw39, ch1, ch2, ch3, ch4, ch5, and ch6, the tuff has been altered from vitric to zeolitic in some areas and remains unaltered in other areas. For the purposes of flow and transport modeling, the principal differences between these two types of tuff are the adsorptive properties and the saturated hydraulic conductivity. Each gridblock within these UZ model layers is assigned to either the vitric or zeolitic material. A combination of geologic data is used to define vitric-zeolitic boundaries, including saturated hydraulic conductivity values, matrix saturation measurements, the difference between oven-dried and relative-humidity porosities, and the relative structural position of these layers within the UZ model area. The assumptions associated with these data are described below.

Assumption 2. Saturated hydraulic conductivity (Ks) data from the RPM3.1 (DTN: MO9910MWDISMRP.002 [DIRS 145731]) are assumed to be an appropriate surrogate for assigning gridblocks either vitric or zeolitic material names (and thus, separate hydrogeologic properties) within certain layers of the Topopah Spring welded (TSw) and CHn HGUs. Vitric rock properties are assigned for areas within UZ model layers tsw39, ch1, ch2, ch3, ch4, ch5, and ch6 where $\mathrm{Ks}$ is greater than $10-10 \mathrm{~m} / \mathrm{s}$, whereas zeolitic properties are used where Ks is less than $10-10 \mathrm{~m} / \mathrm{s}$ (Section 6.6.3).

There are two main reasons why $\mathrm{K}_{\mathrm{s}}$ data are used as a surrogate to assign gridblocks either vitric or zeolitic material names. First, existing data show that the $\mathrm{K}_{\mathrm{s}}$ of vitric tuff is orders of magnitude greater than that of zeolitic tuff (Flint 1998 [DIRS 100033], Table 7). In addition, many more data are available on saturated hydraulic conductivity than on mineralogic alteration (e.g., percentage of zeolite). Results from analyses by Flint (1998 [DIRS 100033], Table 7) indicate that vitric $K_{s}$ values are on the order of $10^{-7} \mathrm{~m} / \mathrm{s}$, while zeolitic $K_{s}$ values are on the order of $10^{-10}$ to $10^{-11} \mathrm{~m} / \mathrm{s}$. No definitive $\mathrm{K}_{\mathrm{s}}$ cutoff value exists by which to distinguish vitric from zeolitic material, because this transition occurs over about three orders of magnitude. The 
$\mathrm{K}_{\mathrm{s}}$-value cutoff of $10^{-10} \mathrm{~m} / \mathrm{s}$ is arbitrarily chosen; however, the sensitivity of the $10^{-10} \mathrm{~m} / \mathrm{s}$ cutoff is not expected to be significant compared to using a $10^{-9} \mathrm{~m} / \mathrm{s}$ or $10^{-8} \mathrm{~m} / \mathrm{s}$ cutoff, since these contours are closely spaced in the repository footprint within the RPM3.1 (DTN MO9910MWDISMRP.002 [DIRS 145731]) (see Figure 6-4). Based on these observations, no additional confirmation of this assumption is required.

Assumption 3. In UZ model layers tsw39, ch1, ch2, ch3, ch4, ch5, and ch6, tuff is assumed to be vitric where matrix saturations are relatively low (less than approximately 90 percent) and the difference between oven-dried $\left(105^{\circ} \mathrm{C}\right)$ and relative-humidity porosities are less than 5 percent (Section 6.6.3).

Results from analyses by Flint (1998 [DIRS 100033], p. 29) indicate that altered (i.e., zeolitic) nonwelded tuffs have oven-dried porosities that are typically more than 5 percent higher than relative-humidity porosities. The loss of water from hydrous secondary minerals (such as zeolites and clays) from oven-dried altered tuffs results in higher estimates of the matrix porosity (relative to those obtained using the relative-humidity method) for these samples. Boreholes where oven-dried porosities exceed relative-humidity porosities by more than 5 percent for each of the UZ model layers in question (tsw39, ch1-ch6) generally coincide with zeolite-rich zones, as predicted by MM3.1 (DTN: MO9910MWDISMMM.003 [DIRS 119199]). Based on these observations, no additional confirmation of this assumption is required.

Assumption 4. Major faults with significant vertical displacement may be assumed to serve as lateral boundaries for vitric (unaltered) areas within UZ model layers tsw39, ch1, ch2, ch3, ch4, ch5, and ch6 (Section 6.6.3).

Vitric portions of the CHn and TSw may be laterally continuous within fault blocks that have a higher structural position above the water table compared to correlative layers within adjacent structural blocks. For example, the Solitario Canyon fault offsets the $\mathrm{CHn}$ by more than $300 \mathrm{~m}$ in the southern part of the UZ model domain. CHn layers west of the Solitario Canyon fault lie near or below the water table in this area, and thus these tuffs likely have abundant zeolitic alteration. The correlative CHn layers on the east side of the fault may be over $300 \mathrm{~m}$ above the water table and are much less likely to have undergone zeolitization, owing to limited water-rock interaction. Because major faults (i.e., Solitario Canyon and Dune Wash faults) determine the proximity of the CHn layers to the water table, they are used as boundaries between vitric and zeolitic areas, where appropriate. The observed structural offsets provide sufficient justification for this assumption. 


\section{INTENTIONALLY LEFT BLANK}




\section{SCIENTIFIC ANALYSIS DISCUSSION}

\subsection{NUMERICAL GRID DEVELOPMENT-OVERVIEW AND APPROACH}

Numerical grids of the UZ beneath Yucca Mountain are used to develop calibrated hydrogeologic property sets and flow fields, to test conceptual hypotheses of flow and transport, and to predict flow and transport behavior under a variety of climatic and thermal-loading conditions. This report describes the development of three different sets of grids. The purpose and general characteristics of each grid set are summarized in Table 6-1. A description of the steps involved in the generation of these grids is provided in Section 6 and in scientific notebooks. Key scientific notebooks used for numerical grid generation activities described in this report, along with relevant page numbers and accession numbers, are listed in Table 6-2.

Table 6-1. Summary of Grids Developed for Fiscal Year 2002 UZ Modeling Activities

\begin{tabular}{|c|c|c|}
\hline Output DTN (Filename) & Purpose & Grid Description \\
\hline 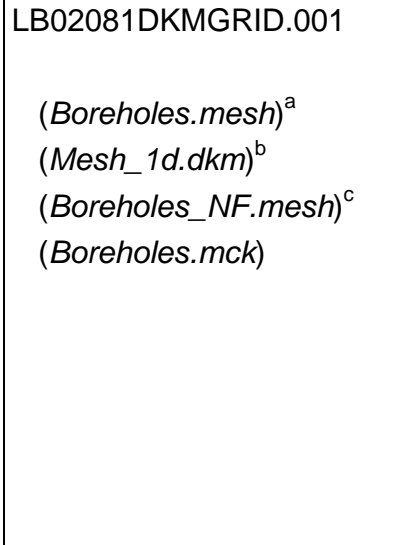 & $\begin{array}{l}\text { 1-D } \\
\text { hydrogeologic } \\
\text { property set } \\
\text { inversions and } \\
\text { calibrations }\end{array}$ & 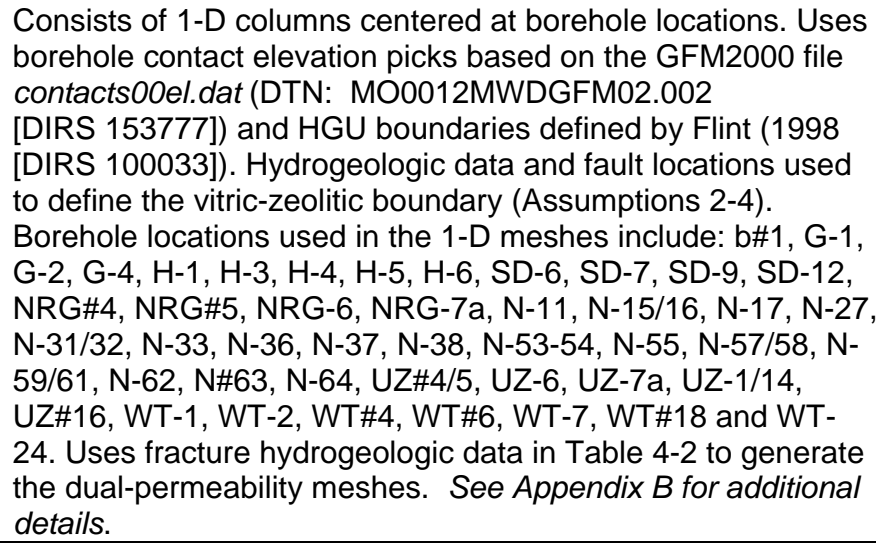 \\
\hline $\begin{array}{l}(E W U Z 7 a . m e s h)^{\mathrm{a}} \\
(\text { Mesh_2d.dkm })^{\mathrm{b}} \\
\left(E W U Z 7 a \_N F . m e s h\right)^{\mathrm{c}} \\
(E W U Z 7 a . m c k)\end{array}$ & $\begin{array}{l}\text { 2-D fault } \\
\text { hydrogeologic } \\
\text { property } \\
\text { calibration }\end{array}$ & $\begin{array}{l}\text { East-west, cross-sectional grid through borehole UZ-7a. Grid } \\
\text { columns are generated using GFM2000 isochore and } \\
\text { elevation data provided on a regular grid spacing of } 61 \times 61 \mathrm{~m} \\
\text { (DTN: MO0012MWDGFM02.002 [DIRS 153777]). Uses } \\
\text { fracture hydrogeologic data in Table } 4-2 \text { to generate the dual- } \\
\text { permeability meshes. See Section } 6.5 \text { and Appendix C for } \\
\text { additional details. }\end{array}$ \\
\hline 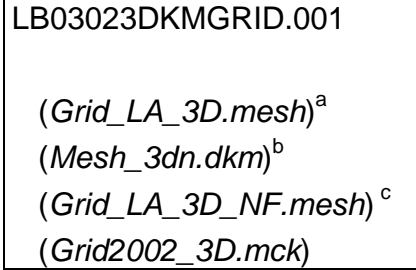 & $\begin{array}{l}\text { 3-D UZ Site } \\
\text { Scale Modeling }\end{array}$ & $\begin{array}{l}\text { Three-dimensional site-scale model with enhanced } \\
\text { discretization along major faults and repository drifts. The 3-D } \\
\text { grids are generated using GFM2000 isochore and elevation } \\
\text { data provided on a regular grid spacing of } 61 \times 61 \mathrm{~m} \text {. Uses } \\
\text { fracture hydrogeologic data in Table } 4-2 \text { to generate the dual- } \\
\text { permeability meshes. See Sections } 6.6,6.7 \text {, and Appendix C } \\
\text { for additional details. }\end{array}$ \\
\hline
\end{tabular}

a The primary mesh represents matrix blocks only; also referred to as an ECM grid.

${ }^{b}$ Dual-permeability model mesh generated with fracture properties from Table 4-2 and a 1-D fracture continuum (Type \#1 fractures: See Section 6.7 for details).

c The "*_NF.mesh" files were used to generate the dual-permeability model mesh files, and are not considered output files 
Table 6-2. Yucca Mountain Project Scientific Notebooks Used for Fiscal Year 2002 Numerical Grid Development and Grid Verification Analyses

\begin{tabular}{|l|l|l|l|}
\hline \multicolumn{1}{c|}{$\begin{array}{c}\text { LBNL Scientific } \\
\text { Notebook ID }\end{array}$} & \multicolumn{1}{c|}{$\begin{array}{c}\text { M\&O Scientific } \\
\text { Notebook ID }\end{array}$} & \multicolumn{1}{c|}{ Relevant Pages } & \multicolumn{1}{c|}{ Citation } \\
\hline YMP-LBNL-YSW-JH-2 & SN-LBNL-SCI-143-V1 & $137-140$ & Hinds 2001 (DIRS 155955) \\
\hline YMP-LBNL-YSW-WZ-1 & SN-LBNL-SCI-115-V1 & $52-56,66-72$ & Zhang 2000 (DIRS 159531) \\
\hline YMP-LBNL-YSW-JH-3 & SN-LBNL-SCI-213-V1 & $7-34,63-134$ & $\begin{array}{l}\text { Hinds and Dobson 2004 } \\
\text { (DIRS 170886) }\end{array}$ \\
\hline YMP-LBNL-GSB-LP-2 & SN-LBNL-SCI-103-V1 & $\begin{array}{l}111-115,122,134-141, \\
145-151\end{array}$ & Pan 2003 (DIRS 170887) \\
\hline YMP-LBNL-YSW-3 & SN-LBNL-SCl-199-V1 & $82-92,237-238$ & Wu 2004 (DIRS 170888) \\
\hline YMP-LBNL-GSB-LP-2.1 & SN-LBNL-SCI-103-V2 & $17-28$ & Wang 2003 (DIRS 162380) \\
\hline
\end{tabular}

$\mathrm{LBNL}=$ Lawrence Berkeley National Laboratory, $\mathrm{M} \& \mathrm{O}=$ management and operating contractor; $\mathrm{YMP}=\mathrm{Yucca}$ Mountain Project

Data extracted from the geologic framework model (GFM2000) (DTN: MO0012MWDGFM02.002 [DIRS 153777]) and rock properties model of the integrated site model, Version 3.1 (RPM3.1) (DTN: MO9910MWDISMRP.002 [DIRS 145731]) form the basis for numerical grid development. In addition to the direct data inputs used to create the numerical grids (Table 4-1), several corroborative data sets (Table 4-3) are utilized to help define the HGUs and delineate vitric and zeolitic subunits. With these data, an initial 2-D (plan-view) grid is developed (see Section 6.5) that defines borehole, fault, and repository column locations, where appropriate. Using the 2-D grid as the basis for column locations, a 3-D effective-continuum model (ECM) grid is constructed (see Section 6.6) using layer reference and bounding horizons, along with thickness data from GFM2000 (DTN: MO0012MWDGFM02.002 [DIRS 153777]). Initial grid generation is followed by an iterative process of grid evaluation and modification to achieve appropriate spatial resolution and representation of important features, such as the repository, faults, and calibration boreholes, and to ensure proper connections between the various elements of the grid (for details, see User's Manual (UM) for WinGridder V2.0 [LBNL 2002 (DIRS 170551)]). Revisions are made accordingly until these criteria are met. Next, the 3-D ECM grid is modified to allow for modeling dual-continuum processes (matrix and fracture flow) using a dual-permeability (dual-k) mesh maker, 2kgrid8.for V1.0 (LBNL 2002 [DIRS 154787]). The 2kgrid8.for V1.0 software program incorporates information (i.e., fracture porosity, spacing, aperture, and fracture-matrix interaction area) from fracture data analyses (see Table 4-2) into the grids.

The computer code WINGRIDDER V2.0 (LBNL 2002 [DIRS 154785]) is used to generate 1-, 2-and 3-D integral finite difference (IFD) grids for the UZ model domain. The type of grid generated by WINGRIDDER V2.0 is consistent with the computational requirements for V1.4 and later versions of the TOUGH2 numerical code simulator (Pruess 1991 [DIRS 100413], pp. 27 to 30 and 41 to 42). TOUGH2 and the inverse modeling code ITOUGH2 [ITOUGH2 User's Guide (Finsterle 1999 [DIRS 104367])] use cells, or gridblocks, and connections between those gridblocks to represent the flow system without requiring a global coordinate for each gridblock or connection. This approach provides great flexibility in describing complex flow geometry and relationships between individual objects within the system. 
Unlike other gridding software, WINGRIDDER V2.0 has the capability of designing complex, irregular grids with large numbers of cells and connections, and it can incorporate nonvertical faults and other embedded refinements, such as waste emplacement drifts within the repository area at Yucca Mountain. WINGRIDDER V2.0 can generate a grid that includes a repository with multiple subregions and drifts. A bilinear interpolation between points of known elevation of a regular grid is used in WINGRIDDER V2.0 to determine the thickness or elevation at intermediate points, thus helping to conserve layer discontinuity resulting from faulting.

The grids produced by this work are IFD grids. This is one of several technically appropriate gridding methods. Alternative gridding methods include finite difference and finite element methods, but IFD was chosen for compatibility with the TOUGH2 family of codes employed by downstream users. The use of IFD grids to support subsequent TOUGH2 flow and transport simulations is in accordance with the scientific approach prescribed in Table 2.1.2-1 of the TWP (BSC 2004 [DIRS 169654]).

Described in this report are the methods used to develop numerical grids for hydrogeologic-property-set inversions, for model calibration, and for calculation of 3-D UZ flow fields for PA. The steps of grid development include the following:

1. Establish domain boundaries and location of important calibration features such as boreholes (Section 6.2).

2. Determine UZ model layers and fault geometries based on GFM2000

(DTN: MO0012MWDGFM02.002 [DIRS 153777]), RPM3.1

(DTN: MO9910MWDISMRP.002 [DIRS 145731]), and correlation with Flint's HGUs (1998 [DIRS 100033], Section 6.3).

3. Extract and format GFM2000 (DTN: MO0012MWDGFM02.002 [DIRS 153777]) and RPM3.1 (DTN: MO9910MWDISMRP.002 [DIRS 145731]) data for incorporation into 3-D grids (Section 6.4).

4. Generate a 2-D grid, incorporating information from Steps 1 and 2, and refine as needed to capture spatial variability and important features such as faults and the repository (Section 6.5).

5. Generate a 3-D ECM grid, based on the column locations established in the 2-D grid and data from Step 3 (Section 6.6).

6. Combine the results of fracture analyses with the ECM grid from Step 5 to generate a dual-permeability mesh (Section 6.7).

The process of verifying that appropriate gridblock material names, gridblock volumes and locations, connection lengths and directions, and interface areas between gridblocks are used in the UZ model numerical grids is documented in Section 6.8 and in Appendices B and C. Section 6.8 also summarizes results from corroborative studies that support the use of fairly coarse numerical grids to model flow and transport processes. 


\subsubsection{Summary of Changes to the UZ Model Grids}

There have been a number of changes made to the report in accordance with Technical Work Plan for: Unsaturated Zone Flow Analysis and Model Report Integration (BSC 2004 [DIRS 169654], Section 1.2.1) to address technical inconsistencies and achieve greater transparency, readability, and traceability. These changes include the following items:

- Change of classification of rock property data used to delineate vitric and zeolitic units to direct input

- Change of classification of repository layout data to direct input

- Clarification of direct input for water table elevations

- Addition of justification for data used in the report

- Addition of new tables listing FEPs and summarizing reports that are linked by direct data inputs or outputs to this report

- Removal of tables listing water levels in selected boreholes and repository boundary coordinates

- Relocation of the discussion of some assumptions from Section 5 to Section 6

- Shift in the location of the Limitations and Uncertainties presentation from Section 7.1 to Section 6.9

- Update of the use of applicable codes, standards, regulations, and procedures

- Addition of new section on satisfaction of acceptance criteria (Section 7.2)

- Resolution of Condition Reports associated with the previous version of this report

- Editorial and DIRS changes

Note that these changes are made to enhance the transparency and traceability of this report and do not result in any change in numerical grids from those reported in Revision 01 (BSC 2003 [DIRS 160109]).

\subsection{BOUNDARIES AND CALIBRATION FEATURES}

The areal domain of the UZ model encompasses approximately $40 \mathrm{~km}^{2}$ of the Yucca Mountain area. Yucca Wash lies near the northern model boundary, while the approximate latitude of borehole G-3 defines the southern boundary. The eastern model boundary lies just to the east of the Bow Ridge fault, and the western boundary lies approximately $1 \mathrm{~km}$ west of the Solitario Canyon fault. These boundaries encompass many of the existing hydrology wells for which extensive moisture saturation and water potential data are used as calibration points for determining layer properties. One important objective of selecting these boundaries was to minimize potential boundary effects on numerical simulation results within the repository footprint. Figures 6-1 and 6-2 show map views of the model domain, including the repository 
boundary, the paths of the ESF and the enhanced characterization of repository block (ECRB) cross drift, major faults defined in GFM2000 (DTN: MO0012MWDGFM02.002 [DIRS 153777]), calibration boreholes, and the contoured regional water table. Table 6-3 lists the NSP coordinates for the domain boundary. The lateral boundary conditions for the numerical grids are imposed by the downstream user. For example, a description of lateral boundary conditions used for UZ Flow Model simulations can be found in UZ Flow Models and Submodels (BSC 2004 [DIRS 169861], Section 6.1.3).

Table 6-3. UZ Model Areal Boundary Coordinates

\begin{tabular}{|c|c|}
\hline $\begin{array}{c}\text { NSP Easting } \\
(\mathbf{m})\end{array}$ & $\begin{array}{c}\text { NSP Northing } \\
(\mathbf{m})\end{array}$ \\
\hline 168100 & 229500 \\
\hline 169600 & 238900 \\
\hline 171400 & 238550 \\
\hline 173910 & 236320 \\
\hline 172820 & 229500 \\
\hline
\end{tabular}

Output-DTN: LB0208HYDSTRAT.001.

The upper boundary of the UZ model is the bedrock surface (topography minus alluvium), which is defined by the GFM2000 file s00bedrockRWC.2grd (see Appendix A, GFM2000 files). The lower boundary is the water table, or potentiometric surface, derived from water-level-elevation data and represented by the potentiometric surface presented in DTN: MO0212GWLSSPAX.000 [DIRS 161271]. This surface is consistent with borehole water level measurements (DTNs: MO0106RIB0038.001 [DIRS 155631] and GS010608312332.001 [DIRS 155307]), but does not represent a unique interpretation of the data [see Sections 6.4.2 and 6.9.1 of this report and Attachment IV of Development of Numerical Grids for UZ Flow and Transport Modeling (BSC 2003 [DIRS 160109]) for discussion]. Borehole water-level elevations beneath northern Yucca Mountain suggest a large hydraulic gradient, as seen in the contoured potentiometric surface (BSC 2001 [DIRS 155950], Figure 12.3.1.2-2) and the water-level data contained in DTN: MO0106RIB00038.001 [DIRS 155631], with water levels increasing northward from about 730 masl at the south end of the repository area to $840 \mathrm{~m}$ (USW WT-24; see DTN: GS010608312332.001 [DIRS 155307]) less than a kilometer north of the repository area. Two boreholes north of WT-24, G-2 and WT\#6, have significantly higher water levels (greater than 1,000 masl). One explanation for the fairly abrupt water-level difference between WT-24 and the G-2 and WT\#6 boreholes is the occurrence of perched or semi-perched water under portions of northern Yucca Mountain (Water-Level Data Analysis for the Saturated Zone Site-Scale Flow and Transport Model [USGS 2004 (DIRS 168473)]; Ervin et al. 1994 [DIRS 100633], p. 15; Czarnecki et al. 1994 [DIRS 142594]; Czarnecki et al. 1995 [DIRS 103371]). For the purpose of developing UZ model grids, water table elevations beneath portions of northern Yucca Mountain are assumed to represent perched water, as stated in Section 5.1, Assumption 1. The contoured regional water table elevations (Figure 6-2) are represented by the surface defined in the file gwl_sspac_60.96.2grd (see Appendix C, Table C-1). Details on how this surface was generated are presented in Section 6.4.2 of this report and Attachment IV of Development of Numerical Grids for UZ Flow and Transport Modeling (BSC 2003 [DIRS 160109]). 


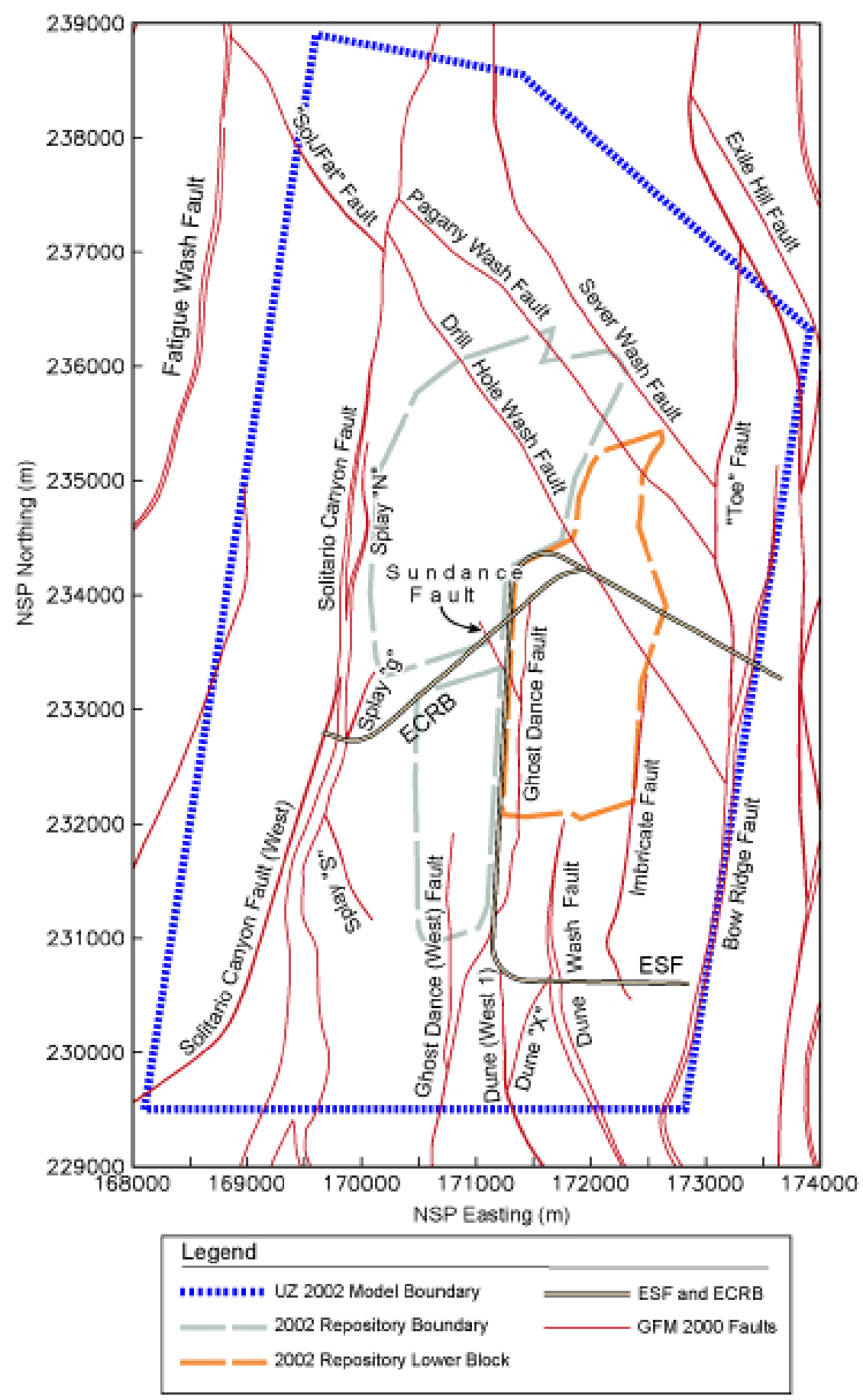

Source: (Repository Design) BSC 2002 (DIRS 159527); (GFM2000 Faults)

DTN: MO0012MWDGFM02.002 (DIRS 153777).

NOTE: 2002 Repository Lower Block will not be used in any LA calculations.

Figure 6-1. Plan-View Schematic Showing the UZ Model Boundary, the Repository Outline, Major Faults from GFM2000, the ESF, and the ECRB. 


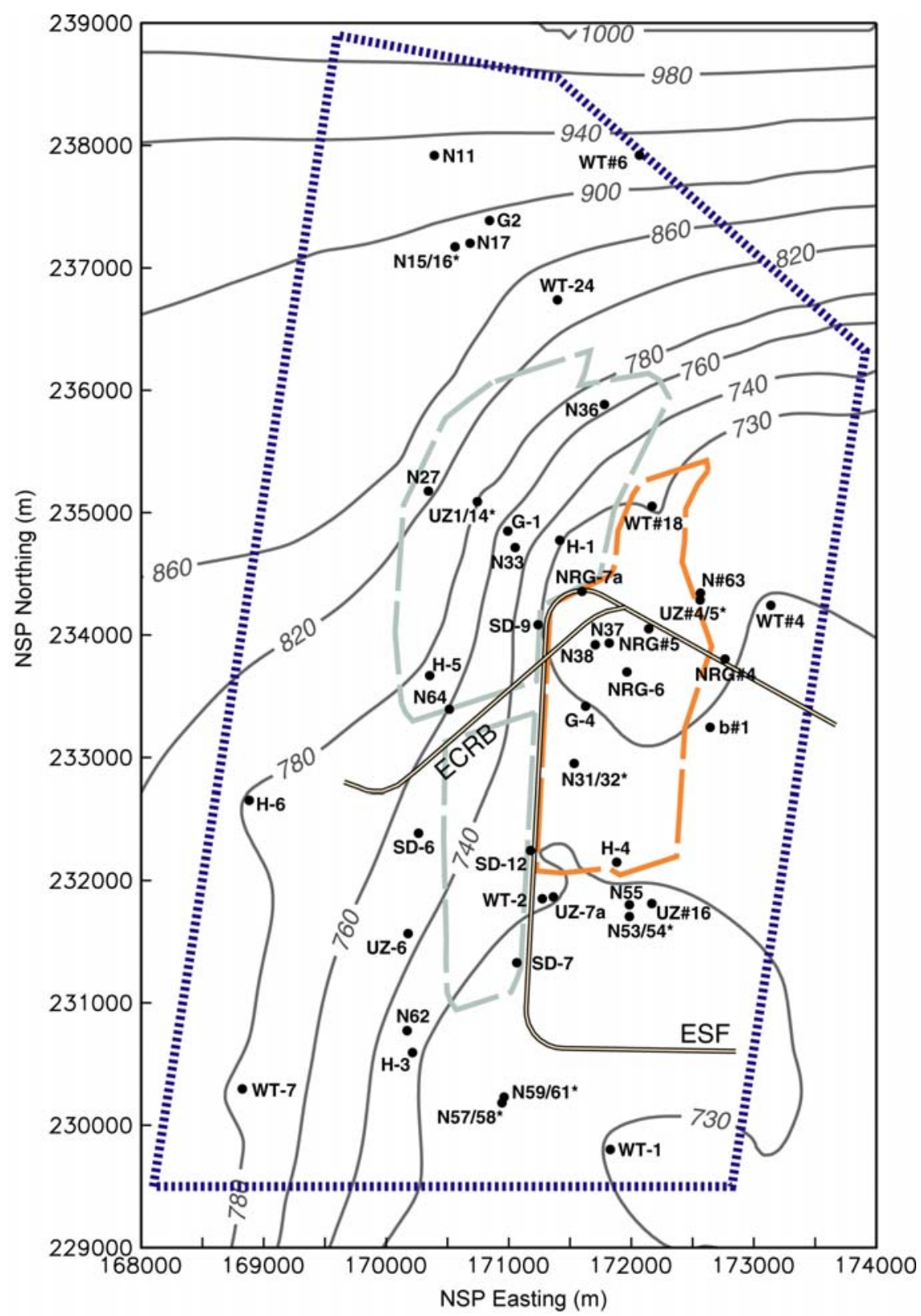

\begin{tabular}{|c|c|}
\hline \multicolumn{2}{|l|}{ LEGEND } \\
\hline 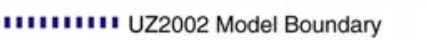 & - 900 - Water Table Elevation Contours \\
\hline - 2002 Repository Boundary & - UZ\#16 Boreholes \\
\hline $\begin{array}{l}\text { - } 2002 \text { Repository Lower Block } \\
=\mathrm{ESF} \text { and ECRB }\end{array}$ & $\begin{array}{l}\text { Note: * Denotes single location used for } \\
\text { adjacent boreholes. }\end{array}$ \\
\hline
\end{tabular}

Source: (Repository Design) BSC 2002 (DIRS 159527); Output-DTNs: LB0208HYDSTRAT.001 (UZ2002 Model Boundary, Modified Borehole Locations); LB02092DGRDVER.001 (Water Table).

NOTE: 2002 Repository Lower Block will not be used in any LA calculations.

Figure 6-2. Plan-View Schematic Showing Boreholes, the Contoured Water Table (Elevations in $\mathrm{m}$ ), the UZ Model Boundary, the Repository Outline, the ESF, and the ECRB 
UZ model borehole calibration features, represented as column centers in the 1-D inversion and 3-D calibration grids, are listed in Table 6-4. For simplicity, the borehole names used throughout the remainder of this document drop the USW and UE-25 prefixes. Where boreholes are closer than $80 \mathrm{~m}$ to one another, the boreholes (as indicated on Table 6-4 by a superscripted "a”) are jointly represented by an intermediate location calculated by averaging the coordinates of the two boreholes (Section 3). Because borehole UZ-7a is located adjacent to a fault, the fault column also represents the borehole.

Table 6-4. Borehole Locations Used in the UZ Inversion and Calibration Models

\begin{tabular}{|c|c|c|}
\hline NSP Easting (m) & NSP Northing (m) & Borehole Name \\
\hline 170993 & 234849 & G-1 \\
\hline 170842 & 237386 & G-2 \\
\hline 171627 & 233418 & G-4 \\
\hline 171416 & 234774 & $\mathrm{H}-1$ \\
\hline 170216 & 230594 & $\mathrm{H}-3$ \\
\hline 171880 & 232149 & $\mathrm{H}-4$ \\
\hline 170355 & 233670 & $\mathrm{H}-5$ \\
\hline 168882 & 232654 & $\mathrm{H}-6$ \\
\hline 172767 & 233806 & NRG\#4 \\
\hline 172142 & 234053 & NRG\#5 \\
\hline 171964 & 233698 & NRG-6 \\
\hline 171598 & 234355 & NRG-7a \\
\hline 171178 & 232245 & SD-12 \\
\hline 171066 & 231328 & SD-7 \\
\hline 170264 & 232386 & SD-6 \\
\hline 171242 & 234086 & SD-9 \\
\hline 170744 & 235090 & UZ-1/14 ${ }^{\mathrm{a}}$ \\
\hline 172168 & 231811 & UZ\#16 \\
\hline 172559 & 234286 & $U Z \# 4 / 5^{a}$ \\
\hline 170178 & 231566 & UZ-6 \\
\hline 171363 & 231866 & $U Z-7 a^{b}$ \\
\hline 171398 & 236739 & WT-24 \\
\hline 171828 & 229802 & WT-1 \\
\hline 171274 & 231850 & WT-2 \\
\hline 173138 & 234243 & WT\#4 \\
\hline 172067 & 237920 & WT\#6 \\
\hline 168826 & 230298 & WT-7 \\
\hline 172168 & 235052 & WT\#18 \\
\hline 172644 & 233246 & $\mathrm{b \# 1}$ \\
\hline 170390 & 237919 & N11 \\
\hline 170563 & 237171 & $\mathrm{~N} 15 / 16^{\mathrm{a}}$ \\
\hline 170687 & 237203 & N17 \\
\hline 170344 & 235175 & N27 \\
\hline 171534 & 232951 & $\mathrm{~N} 31 / 32^{\mathrm{a}}$ \\
\hline 171051 & 234717 & N33 \\
\hline 171780 & 235885 & N36 \\
\hline 171820 & 233934 & N37 \\
\hline 171707 & 233924 & N38 \\
\hline 171983 & 231704 & $\mathrm{~N} 53 / 54^{\mathrm{a}}$ \\
\hline
\end{tabular}


Table 6-4. Borehole Locations Used in the UZ Inversion and Calibration Models (Continued)

\begin{tabular}{|c|c|c|}
\hline NSP Easting (m) & NSP Northing (m) & Borehole Name \\
\hline 171983 & 231801 & N55 \\
\hline 170946 & 230186 & $\mathrm{~N} 57 / 58^{\mathrm{a}}$ \\
\hline 170960 & 230230 & $N 59 / 61^{a}$ \\
\hline 170171 & 230772 & N62 \\
\hline 172568 & 234342 & $\mathrm{~N} \# 63$ \\
\hline 170516 & 233394 & N64 \\
\hline
\end{tabular}

Source: Output-DTN: LB0208HYDSTRAT.001 (file boreholes_Rick_updated.hol).

NOTES: Borehole locations were used for 1-D column construction; see file Boreholes.mck in Output-DTN: LB02081DKMGRID.001.

A subset of the listed boreholes was used for property inversion and calibration.

a Single location used for boreholes in close proximity to one another, as explained in Sections 3 and 6.2. Original northing and easting values (in feet) were converted to meters by multiplying by 0.3048 . See discussion of metric conversion in Section 3.

${ }^{b}$ Location of UZ-7a shifted to accommodate fault grid geometry.

For the earlier versions of this report, many fewer boreholes were used for the calibration, but these were supplemented by the ESF, ECRB, and associated alcoves and niches. Because more boreholes were used for the UZ 2002 grid model calibration, the ESF and ECRB features were not needed for the present model calibrations, and thus these features were not discretized in the UZ 2002 Model grids. The GFM2000 file contacts00el.dat (see Appendix A, GFM2000 files) is used to define the location of most of the boreholes that serve as column centers within the various UZ model grids. Since the coordinates contained within this file are listed in feet, rather than meters (which is the desired unit of measure in the UZ model), a simple unit conversion was performed ( $1 \mathrm{ft}=0.3048 \mathrm{~m}$; see metric conversion discussion in Section 3 ). The locations of the N-series boreholes not listed in this file (N15/16, N17, N27, N36, N57/58, N59/61, N\#63, and N64) that were used for model calibration were obtained from the Yucca Mountain Site Characterization Project Site Atlas 1995 (DOE 1995 [DIRS 102884], vol. 1, p. 9.14). Where boreholes were located within $80 \mathrm{~m}$ of one another, the boreholes were listed as a pair, and the average location of the two boreholes was used for property calibration.

The spatial relationship between boreholes and faults (determination of fault locations in the 2-D grid is described in Sections 6.3, and 6.5, and 6.6.1) is such that these features may intersect or lie within $30 \mathrm{~m}$ of each other (which is typically less than the desired lateral resolution of the grid). As a result, the selection of the location of column centers during the construction of the numerical grid is prioritized based upon the relative importance of the different features. In general, the location of column centers (grid nodes) at calibration boreholes was given highest priority in constructing the grid geometry, followed by the repository layout, followed by faults.

\subsection{UZ MODEL LAYERS AND FAULT GEOMETRIES}

The geologic data provided in the geologic framework model (GFM2000) (DTN: MO0012MWDGFM02.002 [DIRS 153777]) cannot, by themselves, adequately capture all important features that affect flow and transport in the UZ at Yucca Mountain. Hydrogeologic rock-property data must also be considered. The 30 HGUs identified by the USGS (Flint 1998 [DIRS 100033], p. 1, Table 1) based on similarities in rock hydrogeologic 
properties are assumed to be adequate to define the layering scheme used for the UZ model grids.

Because the hydrogeologic property sets to be utilized in UZ flow and transport modeling use, to a large extent, the matrix properties data collected and analyzed by Flint (1998 [DIRS 100033]), layering within the numerical grid was chosen to correspond as closely as possible to HGUs to facilitate data usage. The qualitative descriptions given by Flint (1998 [DIRS 100033], pp. 21-32), when correlated with GFM2000 data (DTN: MO0012MWDGFM02.002 [DIRS 153777]), are used to develop a set of hydrogeologic layers (whose thickness and elevation are described by regularly spaced data) for the UZ model grids. The detailed analysis of hydrogeologic properties and definition of HGUs by Flint (1998 [DIRS 100033]) provides justification for the use of these units in development of the UZ model grids.

As discussed previously in Section 4, layering within the UZ model grid is chosen to correspond as closely as possible to HGUs, to facilitate usage of rock-property data. Table 6-5 provides a correlation between major HGUs, GFM2000 lithostratigraphic units (BSC 2004 [DIRS 170029], Table 6-2), UZ model layers, and Flint's HGUs (1998 [DIRS 100033]). In many cases, HGUs correlate 1-to-1 with, or are simple combinations of, GFM2000 layers. In a few instances, multiple HGUs can be present within one GFM2000 layer, such as within the Yucca Mountain Tuff (Tpy), the lower nonlithophysal zone of the Topopah Spring Tuff (Tptpln), or the Calico Hills Formation (Tac). Using Table 6-5 as a basis for UZ model layering, GFM2000 layer-thickness (isochore) grid files (DTN: MO0012MWDGFM02.002 [DIRS 153777]) are combined or subdivided, as appropriate (see Section 6.4.1), to correspond to Flint's HGUs (1998 [DIRS 100033]).

Faults are important features to include in the UZ model grids, because they may provide fast pathways for flow or serve as barriers to flow. A fault can be a surface with arbitrary shape in the 3-D UZ model domain and is represented as a surface (defined by a set of $\mathrm{x}, \mathrm{y}, \mathrm{z}$ data on a regular grid spacing) in GFM2000 (BSC 2004 [DIRS 170029], Sections 6.4.2 and 6.4.4). In UZ model grids, fault surfaces are represented by a series of connected columns of gridblocks (Section 6.6.1). Faults can be represented in the grid as either vertical or nonvertical features. Many of the faults at Yucca Mountain are steeply dipping, particularly within the UZ. For UZ flow and transport modeling studies of Yucca Mountain, it is believed that flow through faults is much more sensitive to the rock properties assigned to fault zones than to slight variations in fault dip. The simplification of (a) representing steeply dipping faults as vertical in the UZ model grids and (b) representing related, near-parallel faults as a single feature that incorporates the cumulative offset (e.g., the Solitario Canyon and Solitario Canyon (west) faults) are assumed to not significantly affect model calculations. 
Table 6-5. Correlation of GFM2000 Lithostratigraphy, UZ Model Layers, and Hydrogeologic Units

\begin{tabular}{|c|c|c|c|}
\hline $\begin{array}{l}\text { Major Unit } \\
\text { (Modified from Montazer } \\
\text { and Wilson 1984 } \\
\text { [DIRS 100161]) }\end{array}$ & $\begin{array}{c}\text { GFM2000 Lithostratigraphic } \\
\text { Nomenclature }^{\mathrm{a}}\end{array}$ & $\begin{array}{c}\text { FY } 02 \text { UZ Model } \\
\text { Layer }\end{array}$ & $\begin{array}{c}\text { HGU (Flint } 1998 \\
\text { [DIRS 100033], } \\
\text { Table 1) } \\
\end{array}$ \\
\hline \multirow{5}{*}{$\begin{array}{l}\text { Tiva Canyon welded } \\
\text { (TCw) }\end{array}$} & Tpcr & tcw11 & CCR, CUC \\
\hline & Трср & \multirow[t]{2}{*}{ tcw12 } & \multirow[t]{2}{*}{ CUL, CW } \\
\hline & TpcLD & & \\
\hline & Tpcpv3 & \multirow[t]{2}{*}{ tcw13 } & \multirow[t]{2}{*}{ CMW } \\
\hline & Tpcpv2 & & \\
\hline \multirow{10}{*}{$\begin{array}{l}\text { Paintbrush nonwelded } \\
\text { (PTn) }\end{array}$} & Tpcpv1 & ptn21 & CNW \\
\hline & Tpbt4 & \multirow[t]{2}{*}{ ptn22 } & \multirow[t]{2}{*}{ BT4 } \\
\hline & \multirow[t]{3}{*}{ Tpy (Yucca) } & & \\
\hline & & ptn23 & TPY \\
\hline & & \multirow[t]{2}{*}{ ptn24 } & \multirow[t]{2}{*}{ BT3 } \\
\hline & Tpbt3 & & \\
\hline & Tpp (Pah) & ptn25 & TPP \\
\hline & Tpbt2 & \multirow[t]{3}{*}{ ptn26 } & \multirow[t]{3}{*}{ BT2 } \\
\hline & Tptrv3 & & \\
\hline & Tptrv2 & & \\
\hline \multirow{11}{*}{$\begin{array}{l}\text { Topopah Spring welded } \\
\text { (TSw) }\end{array}$} & Tptrv1 & \multirow[t]{2}{*}{ tsw31 } & \multirow[t]{2}{*}{ TC } \\
\hline & \multirow[t]{2}{*}{ Tptrn } & & \\
\hline & & tsw32 & TR \\
\hline & Tptrl, Tptf & \multirow[t]{2}{*}{ tsw33 } & \multirow[t]{2}{*}{ TUL } \\
\hline & Tptpul, RHHtop & & \\
\hline & Tptpmn & tsw34 & TMN \\
\hline & Tptpll & tsw35 & TLL \\
\hline & \multirow[t]{2}{*}{ Tptpln } & tsw36 & $\begin{array}{l}\text { TM2 (upper } 2 / 3 \text { of } \\
\text { Tptpln) }\end{array}$ \\
\hline & & tsw37 & $\begin{array}{l}\text { TM1 (lower } 1 / 3 \text { of } \\
\text { Tptpln) }\end{array}$ \\
\hline & Tptpv3 & tsw38 & PV3 \\
\hline & Tptpv2 & tsw39 (vit, zeo) & PV2 \\
\hline
\end{tabular}


Table 6-5. Correlation of GFM2000 Lithostratigraphy, UZ Model Layers, and Hydrogeologic Units (Continued)

\begin{tabular}{|c|c|c|c|}
\hline $\begin{array}{c}\text { Major Unit } \\
\text { (Modified from Montazer } \\
\text { and Wilson 1984 } \\
\text { [DIRS 100161]) }\end{array}$ & $\begin{array}{c}\text { GFM2000 Lithostratigraphic } \\
\text { Nomenclature }^{\mathrm{a}}\end{array}$ & $\begin{array}{c}\text { FY } 02 \text { UZ Model } \\
\text { Layer }\end{array}$ & $\begin{array}{c}\text { HGU (Flint } 1998 \\
\text { [DIRS 100033], } \\
\text { Table 1) }\end{array}$ \\
\hline \multirow{14}{*}{$\begin{array}{l}\text { Calico Hills nonwelded } \\
(\mathrm{CHn})\end{array}$} & Tptpv1 & \multirow[t]{2}{*}{ ch1 (vit, zeo) } & \multirow{2}{*}{$\begin{array}{l}\text { BT1 or } \\
\text { BT1a (altered) }\end{array}$} \\
\hline & Tpbt1 & & \\
\hline & \multirow[t]{4}{*}{ Tac (Calico) } & ch2 (vit, zeo) & \multirow{4}{*}{$\begin{array}{l}\mathrm{CHV} \text { (vitric) } \\
\text { or } \\
\mathrm{CHZ} \text { (zeolitic) }\end{array}$} \\
\hline & & ch3 (vit, zeo) & \\
\hline & & ch4 (vit, zeo) & \\
\hline & & ch5 (vit, zeo) & \\
\hline & Tacbt (Calicobt) & ch6 (vit, zeo) & BT \\
\hline & Tcpuv (Prowuv) & pp4 & PP4 (zeolitic) \\
\hline & Tcpuc (Prowuc) & pp3 & PP3 (devitrified) \\
\hline & Tcpmd (Prowmd) & \multirow[t]{2}{*}{ pp2 } & \multirow[t]{2}{*}{ PP2 (devitrified) } \\
\hline & Tcplc (Prowlc) & & \\
\hline & Tcplv (Prowlv) & \multirow[t]{3}{*}{ pp1 } & \multirow[t]{3}{*}{ PP1 (zeolitic) } \\
\hline & Tcpbt (Prowbt) & & \\
\hline & Tcbuv (Bullfroguv) & & \\
\hline \multirow{11}{*}{$\begin{array}{l}\text { Crater Flat undifferentiated } \\
(\mathrm{CFu})\end{array}$} & Tcbuc (Bullfroguc) & \multirow[t]{3}{*}{ bf3 } & \multirow[t]{3}{*}{ BF3 (welded) } \\
\hline & Tcbmd (Bullfrogmd) & & \\
\hline & Tcblc (Bullfroglc) & & \\
\hline & Tcblv (Bullfroglv) & \multirow[t]{3}{*}{ bf2 } & \multirow[t]{3}{*}{ BF2 (nonwelded) } \\
\hline & Tcbbt (Bullfrogbt) & & \\
\hline & Tctuv (Tramuv) & & \\
\hline & Tctuc (Tramuc) & \multirow[t]{3}{*}{$\operatorname{tr} 3$} & \multirow[t]{3}{*}{ Not Available } \\
\hline & Tctmd (Trammd) & & \\
\hline & Tctlc (Tramlc) & & \\
\hline & Tctlv (Tramlv) & \multirow[t]{2}{*}{ tr2 } & \multirow[t]{2}{*}{ Not Available } \\
\hline & Tctbt (Trambt) and below & & \\
\hline
\end{tabular}

${ }^{a}$ Buesch et al. (1996 [DIRS 100106]) define the units in the Paintbrush Group (layers beginning with "Tp"). Moyer et al. (1995 [DIRS 103777]) describe the Tac and Tacbt. Buesch and Spengler (1999 [DIRS 107905]) describe the symbols for the Crater Flat Tuffs. GFM2000 nomenclature (BSC 2004 [DIRS 170029], Table 6-2) uses the symbols that are included parenthetically below layer Tpbt1. Additional details on how the GFM2000 units were combined or subdivided to obtain the UZ model units are found in the scientific notebook by Hinds and Dobson (2004 [DIRS 170886], pp. 11 to 15).

The use of a single fault to represent the offset observed for the Solitario Canyon and the Solitario Canyon (west) faults is in part required by the use of wide vertical columns to model dipping faults (see Section 6.6.1 for discussion). If the projection of near-parallel dipping faults overlap over the depth interval of the UZ model, then separate faults are difficult to portray in the UZ model grids without the use of very fine gridding. By accomodating the cumulative offset along a single structural feature, the overall structural and stratigraphic integrity of the UZ geology (as represented by GFM2000 in DTN: MO0012MWDGFM02.002 [DIRS 153777]) is preserved, albeit in a simplified manner. The representation of structural offset by the UZ model 
grids is evaluated in Appendix $\mathrm{C}$, and the results of the grid verification studies indicate that this assumption is justified.

Because large numbers of gridblocks are needed to discretize nonvertical fault zones (which adds significantly to the computational time of model calibration and forward simulations), certain criteria have been developed to reduce the total number of gridblocks along faults in order to simplify the UZ model grids. Faults are modeled as vertical if they meet any of the following criteria: (1) their average dip exceeds $85^{\circ}$, (2) their average dip exceeds $80^{\circ}$ and they lie sufficiently far (greater than $1 \mathrm{~km}$ ) from the repository layout area so as not to significantly affect flow and transport calculations, (3) they lie west of the Solitario Canyon fault, (4) they are adjacent to UZ model boundaries, or (5) they pass through or abut the repository (see Figure 6-1). Fine-resolution gridding of the repository is deemed to be more important than incorporating dipping faults, which require larger gridblocks (see Section 6.6.1 and Figure 6-3). Table 6-6 lists the GFM2000 faults that lie within or along UZ model boundaries.

Table 6-6. Faults Within the UZ Model Domain

\begin{tabular}{|c|c|}
\hline Fault Name & GFM2000 File Name \\
\hline Solitario Canyon & f00sol.2grd \\
\hline Solitario Canyon (west) & f00solwest.2grd \\
\hline "SolJFat" a & f00soljfat.2grd \\
\hline Splay "G" & f00splayg.2grd \\
\hline Splay "N" (north) & f00splayn.2grd \\
\hline Splay "S" (south) & f00splays.2grd \\
\hline Sundance & f00sundance.2grd \\
\hline "Toe" & f00toe.2grd \\
\hline Sever Wash & f00sever.2grd \\
\hline Pagany Wash & foopagany.2grd \\
\hline Drill Hole Wash & f00drill.2grd \\
\hline Ghost Dance & fooghost.2grd \\
\hline Ghost Dance (west) & f00ghostw.2grd \\
\hline Dune Wash & foodune.2grd \\
\hline Dune Wash "X" & foodunex.2grd \\
\hline Dune Wash (west 1) & foodunew1.2grd \\
\hline "Imbricate" & f00imb.2grd \\
\hline Bow Ridge & fOObow.2grd \\
\hline Exile Hill (or Bow Ridge east) & fooexile.2grd \\
\hline
\end{tabular}

Source: DTN: MO0012MWDGFM02.002 [DIRS 153777].

a The "SolJFat" fault corresponds to an unnamed fault joining the Solitario Canyon and Fatigue Wash faults.

The average slope of each fault was evaluated to determine which faults can be reasonably approximated by vertical columns of gridblocks in UZ model grids. This task involves the calculation of slope (defined as the tangent of the dip angle) along each fault (as it transects the UZ) using the Slope Grid Calculation utility in EARTHVISION V5.1 (Dynamic Graphics 2003 [DIRS 171007]). Refer to the scientific notebook by Hinds and Dobson (2004 [DIRS 170886], pp. 73 to 74) for details regarding this calculation. The results are summarized in Table 6-7. 
Table 6-7. Results of GFM2000 Fault-Slope Analysis

\begin{tabular}{|l|c|c|c|c|}
\hline \multicolumn{1}{|c|}{ Fault Name } & $\begin{array}{c}\text { Slope Range } \\
\text { (average) }\end{array}$ & $\begin{array}{c}\text { Minimum Dip } \\
\text { (degrees) }\end{array}$ & $\begin{array}{c}\text { Maximum Dip } \\
\text { (degrees) }\end{array}$ & $\begin{array}{c}\text { Average Dip } \\
\text { (degrees) }\end{array}$ \\
\hline Solitario Canyon & $1.0-6.8(2.4)$ & 44.7 & 81.7 & 67.5 \\
\hline Solitario Canyon (west) & $5.3-10.5(6.4)$ & 79.3 & 84.6 & 81.1 \\
\hline "SolJFat" " & $3.2-4.5(3.8)$ & 72.9 & 77.4 & 75.1 \\
\hline Splay "G" & $1.6-2.9(2.2)$ & 58.7 & 70.8 & 65.4 \\
\hline Splay "N" & $1.3-4.1(2.0)$ & 53.0 & 76.4 & 63.2 \\
\hline Splay "S" & $1.3-2.7(2.0)$ & 52.1 & 69.7 & 63.8 \\
\hline Sundance & $7.1-12.3(11.9)$ & 82.0 & 85.4 & 85.2 \\
\hline "Toe" & $3.6-5.2(4.2)$ & 74.3 & 79.1 & 76.6 \\
\hline Sever Wash & $5.6-8.4(7.0)$ & 79.9 & 83.2 & 81.8 \\
\hline Pagany Wash & $8.8-13.8(11.5)$ & 83.5 & 85.8 & 85.1 \\
\hline Drill Hole Wash & $10.7-14.0(11.9)$ & 84.7 & 85.9 & 85.2 \\
\hline Ghost Dance & $8.4-14.5(11.6)$ & 83.2 & 86.1 & 85.1 \\
\hline Ghost Dance (west) & $10.0-13.4(11.7)$ & 84.3 & 85.7 & 85.1 \\
\hline Dune Wash & $1.4-3.0(1.9)$ & 55.0 & 71.3 & 62.5 \\
\hline Dune Wash "X" & $3.7-5.0(4.5)$ & 75.0 & 78.6 & 77.5 \\
\hline Dune Wash (west1) & $3.1-4.4(3.7)$ & 72.2 & 77.1 & 74.7 \\
\hline "Imbricate" & $9.2-15.8(12.2)$ & 83.8 & 86.4 & 85.3 \\
\hline Bow Ridge & $0.4-36.9(3.8)$ & 23.4 & 88.4 & 75.1 \\
\hline Exile Hill & $0.02-6.5(4.7)$ & 1.0 & 81.3 & 78.0 \\
\hline
\end{tabular}

Output-DTN: LB0208HYDSTRAT.001.

a The "SolJFat" fault corresponds to an unnamed fault joining the Solitario Canyon and Fatigue Wash faults

In accordance with the assumption described above, the following faults are represented by vertical columns of gridblocks (i.e., are assumed to be vertical) in the UZ model grids: "SolJFat," Sundance, “Toe," Sever Wash, Pagany Wash, Drill Hole Wash, Ghost Dance, Ghost Dance (west), and "Imbricate” faults. The "Toe” and Bow Ridge faults are represented by a single structural feature, which, due to its proximity to the eastern boundary of the UZ model area, is considered as a vertical fault. The remaining faults (Solitario Canyon, Dune Wash, Dune Wash "X," and Dune Wash [west1]) are represented by nonvertical columns of gridblocks in the 3-D grids.

The relatively coarse gridding used in the southwest portion of the UZ model area (resulting from its location away from the repository area) precludes the individual portrayal of closely spaced west-dipping normal faults. The splay faults "N", "S", and "G" lie close to the Solitario Canyon fault and intersect it at a relatively shallow depth. This presents complications when generating the 3-D grids because of the preferred numerical grid resolution and fault representation method (described in Section 6.6.1). Thus, these three splay faults are considered part of the Solitario Canyon fault zone and are not explicitly defined. However, after grid generation, fault properties can be assigned to the gridblocks closest to the location of these faults, as needed. As mentioned above, the Solitario Canyon (west) fault was not depicted as a distinct feature in the UZ model grids. However, the cumulative vertical offset observed in the GFM2000 (DTN: MO0012MWDGFM02.002 [DIRS 153777]) for the Solitario Canyon and 
Solitario Canyon (west) faults is captured by the single nonvertical fault (Solitario Canyon) and the adjacent columns used in the UZ model grids, thus preserving the general stratigraphic and structural relations of GFM2000.

Preparation of GFM2000 fault data (DTN: MO0012MWDGFM02.002 [DIRS 153777]) for incorporation into UZ model grids first involves a simple unit conversion from feet to meters. The spatial position of the faults is then determined by intersecting each fault surface (*.2grd, listed in Table 6-6) with one or more horizontal planes, producing data files describing fault-trace locations at prescribed elevations. Faults represented as vertical features in the UZ grids use fault-trace information at an arbitrary elevation of 1,100 masl. This elevation was chosen because it is just above the repository and near the middle of the UZ. During grid generation, vertical columns of gridblocks are assigned along each fault trace.

Faults represented as nonvertical features (i.e., by nonvertical columns of gridblocks) use fault-trace information at three elevations (one near the land surface, one near the water table, and one located approximately midway between the other two) to capture variations in dip. The UZ model gridding process interpolates the location of each nonvertical fault using data points at the three prescribed elevations. With this approach, the dip of a fault within a given fault column is uniform in the upper interval between the highest and middle elevations, and is again uniform in the lower interval between the middle and lowest elevations. This allows the dip in the upper interval to be different from the dip in the lower interval (which may occur if the fault surface is curved, rather than planar). Furthermore, dip angles within the same vertical interval can be different in different columns (i.e., laterally along a fault). Thus, even a fault with variable dip along its trace can be represented with this method. In some cases, the upper and lower portions of dipping faults have been adjusted to a vertical orientation to ensure appropriate grid resolution and comply with the requirement that gridblock columns adjacent to fault columns be at least as wide as the fault columns (see Dune Wash fault in Figure C3-2). For specific details regarding manipulation of fault data, refer to the scientific notebooks by Hinds and Dobson (2004 [DIRS 170886], p. 19) and Hinds (Unsaturated Zone Modeling \& Synthesis [2001 (DIRS 155955), pp. 137 to 140]).

\subsection{EXTRACTION OF GFM2000 AND ISM3.1 DATA}

\subsubsection{Isochores}

Geologic layers are correlated with Flint's HGUs (1998 [DIRS 100033]) in Table 6-5, and UZ model layers are determined based on this correlation (Section 6.3). Because of its large thickness beneath northern Yucca Mountain, layer Tac is vertically subdivided equally into four layers throughout the UZ model domain. Based on the relations provided in Table 6-5, certain GFM2000 (DTN: MO0012MWDGFM02.002 [DIRS 153777]) layers (represented by isochore grids) are combined, while others were subdivided, to create hydrogeologic model layers for the UZ grids.

GFM2000 isochore grids (DTN: MO0012MWDGFM02.002 [DIRS 153777]) used in fiscal year (FY) 2002 UZ grid development include those lying between the upper Tpcpv3 contact and the lower Trambt contact. Layers are combined if (1) they have similar hydraulic properties based on analyses by Flint (1998 [DIRS 100033]), (2) they are very thin across Yucca Mountain, or 
(3) property data are very limited for the rock units. GFM2000 isochores (DTN: MO0012MWDGFM02.002 [DIRS 153777]) are subdivided if rock-property data exist that suggest two or more distinct hydrogeologic layers within a geologic unit.

For specific details describing the manipulation and formatting of GFM2000 isochore files (DTN: MO0012MWDGFM02.002 [DIRS 153777]), refer to the scientific notebook by Hinds and Dobson (2004 [DIRS 170886], pp. 11 to 15). Below is a brief summary of the steps taken.

GFM2000 isochore files (DTN: MO0012MWDGFM02.002 [DIRS 153777]) that are not combined or subdivided include:

- ia00cpv1RWC.2grd

- ia00tppRWC.2grd

- ia00tpmnRWC.2grd

- ia00tpllRWC.2grd

- ia00tpv3RWC.2grd

- ia00tpv2RWC.2grd

- ia00tacbtRWC.2grd

- ia00prowuvRWC.2grd

- ia00prowucRWC.2grd

These grids, which contain regularly spaced $(61 \times 61 \mathrm{~m})$ data, require no manipulation other than simple formatting for incorporation into the UZ grids. EARTHVISION V5.1 (Dynamic Graphics 2003 [DIRS 171007]) is used to export the regularly spaced data and to convert the units (x, y, and thickness) from feet to meters. Because GFM2000 data coverage (BSC 2004 [DIRS 170029], Figure 1-1) extends well beyond the UZ model boundaries, each data file is reduced to the approximate UZ model domain, using the EARTHVISION V5.1 Graphic Editor to remove data points lying south of $\mathrm{N} 228,820 \mathrm{~m}$ and east of $\mathrm{E} 174,860 \mathrm{~m}$.

GFM2000 isochore files (DTN: MO0012MWDGFM02.002 [DIRS 153777]) that are combined include:

- ia00cpv3RWC.2grd + ia00cpv2RWC.2grd

- ia00bt4RWC.2grd + part of ia00tpyRWC.2grd (see discussion of Tpy below)

- ia00bt3RWC.2grd + part of ia00tpyRWC.2grd (see discussion of Tpy below)

- ia00bt2RWC.2grd + ia00trv3RWC.2grd + ia00trv2RWC.2grd

- ia00trv1RWC.2grd + part of ia00trnRWC.2grd (see discussion of Tptrv1 and Tptrn below)

- ia00trltfRWC.2grd + ia00tpulRWC.2grd

- ia00tpv1RWC.2grd + ia00bt1RWC.2grd

- ia00prowmdRWC.2grd + ia00prowlcRWC.2grd

- ia00prowlvRWC.2grd + ia00prowbtRWC.2grd + ia00bulluvRWC.2grd

- ia00bullucRWC.2grd + ia00bullmdRWC.2grd + ia00bulllcRWC.2grd

- ia00bulllvRWC.2grd + ia00bullbtRWC.2grd + ia00tramuvRWC.2grd

- ia00tramucRWC.2grd + ia00trammdRWC.2grd + ia00tramlcRWC.2grd 
The EARTHVISION V5.1 (Dynamic Graphics 2003 [DIRS 171007]) Formula Processor is used to add the *.2grd files as shown above. The resulting files are then formatted as previously described for uncombined isochores.

Subdivided GFM2000 isochore files (DTN: MO0012MWDGFM02.002 [DIRS 153777]) are described below and include:

- ia00tpyRWC.2grd

- ia00trv1RWC.2grd + ia00trnRWC.2grd

- ia00tplnRWC.2grd

- ia00tacRWC.2grd

GFM2000 layer Tpy (Yucca Mountain Tuff)—Based on the HGUs defined by Flint (1998 [DIRS 100033]), GFM2000 layer Tpy is subdivided vertically into three layers (see Table 6-5). The upper portion is typically nonwelded and has properties similar to Tpbt4 (BT4); therefore, it is combined with layer Tpbt4 (GFM2000 isochore file ia00bt4RWC.2grd (see Appendix A, GFM2000 files)) to make UZ02 Model layer “ptn22.” The middle portion can become moderately welded to the north (porosity less than 30 percent), where layer Tpy is generally thicker. This middle portion corresponds to HGU "TPY" and is designated "ptn23" in the UZ02 grid. The lower portion is typically nonwelded and has properties similar to Tpbt4 and Tpbt3, and is therefore combined with layer Tpbt3 (GFM2000 isochore file ia00bt3RWC.2grd (see Appendix A, GFM2000 files)) to make UZ02 Model layer "ptn24." Because the presence of the hydrologically distinct middle portion of layer Tpy depends on the overall thickness of the unit, the isochore for layer Tpy is subdivided as follows:

- Where Tpy is less than $6 \mathrm{~m}$ thick, the total Tpy thickness is combined with layer Tpbt4 to create UZ02 Model layer “ptn22” (corresponding to HGU “BT4”).

- Where Tpy thickness is between 6 and $9 \mathrm{~m}$, the thickness is split in half: the upper half is combined with Tpbt4 to make UZ model layer "ptn22," while the lower half is combined with Tpbt3 to make UZ02 Model layer "ptn24” (corresponding to HGU “BT3”).

- Where Tpy thickness is between 9 and $12 \mathrm{~m}, 2 \mathrm{~m}$ is assigned to UZ02 Model layer "ptn23" (corresponding to HGU "TPY"); the remainder is split in half, and these equal portions are combined with Tpbt4 to make UZ02 layer "ptn22" and TPbt3 to make layer "ptn24."

- Where Tpy thickness is between 12 and $15 \mathrm{~m}, 3 \mathrm{~m}$ is assigned to UZ02 Model layer "ptn23" (corresponding to HGU “TPY”); the remainder is split in half, and these equal portions are combined with Tpbt4 to make UZ02 layer "ptn22” and TPbt3 to make layer "ptn24."

- Where Tpy thickness is greater than $15 \mathrm{~m}$, the unit is divided in thirds, with one third assigned (in combination with Tpbt4) to "ptn22," one third to "ptn23," and the remaining third is combined with Tpbt3 to make "ptn24." 
GFM2000 layers Tptrv1 and Tptrn (upper Topopah Spring Tuff)—The densely welded Tptrv1 is relatively thin (0-2 m thick, typically less than $0.5 \mathrm{~m}$ ) across Yucca Mountain (Flint 1998 [DIRS 100033], p. 27). Given a minimum vertical resolution of $1.0 \mathrm{~m}$ for the UZ model grids (Section 6.6), this layer would be missing from UZ simulations across most of Yucca Mountain. To capture this potentially important flow unit at the PTn/TSw interface (see Table 6-5), GFM2000 isochores (DTN: MO0012MWDGFM02.002 [DIRS 153777]) for Tptrv1 and Tptrn were combined, and then the upper $2 \mathrm{~m}$ of this combined unit were assigned a distinct model layer name corresponding to Flint's "TC" HGU. The remaining thickness of the combined unit (Tptrv1 + Tptrn - 2 m) corresponds to Flint's “TR” HGU. Where the combined thickness of Tptrv1 and Tptrn is less than $0.5 \mathrm{~m}$, the isochore for the "TC" HGU is assigned zero thickness.

GFM2000 layer Tptpln (Topopah Spring, lower nonlithophysal) - Tptpln is characterized by HGUs, “TM2" and "TM1" (see Table 6-5). According to the proportions given by Flint (1998 [DIRS 100033], p. 3), GFM2000 layer Tptpln is vertically subdivided into an upper portion (with 2/3 the total thickness of Tptpln) and a lower portion (with 1/3 the total thickness of Tptpln) for incorporation into the UZ model.

GFM2000 layer Tac (Calico Hills Formation) - The Tac is subdivided vertically into four equal layers because of its large thickness beneath northern Yucca Mountain (see Table 6-5). After the isochores have been subdivided according to the specified criteria/proportions, they are formatted using the same steps that were used to format the uncombined isochores. A further division of these layers into vitric and zeolitic subunits is presented in Section 6.6.3.

\subsubsection{Reference Horizons, and Top and Bottom UZ Model Boundaries}

WINGRIDDER V2.0 (LBNL 2002 [DIRS 154785]) generates a numerical grid based on the elevations of three major horizons: (1) a top boundary (e.g., the topographic or bedrock surface), (2) a structural reference horizon, which identifies faults and their associated offsets, and (3) a bottom boundary (i.e., the water table). The reference horizon is a surface from which elevations of all hydrogeologic-unit interfaces are calculated by stacking layer thicknesses above or below it, based on their stratigraphic position. All offsets resulting from faulting are described by the reference horizon data. Any portions of HGUs lying above the top boundary or below the bottom boundary after stacking are removed (clipped).

GFM2000 horizons used (see Appendix A, GFM2000 files):

- s00bedrockRWC.2grd (bedrock/present-day erosional surface; UZ model top boundary)

- s00TpcpEXuncut.2grd (top of Tpcp; surface used in the absence of Tpcp isochore)

- s00Tptpv3EXuncut.2grd (top of Tptpv3; primary structural reference horizon for UZ grids).

The top of layer Tpcp (the contact between the crystal-rich and crystal-poor tuffs of the Tiva Canyon, defined as a surface in GFM2000) (DTN: MO0012MWDGFM02.002 [DIRS 153777]) is used to separate UZ model layers, "tcw11" and "tcw12" (see Table 6-5), since no GFM2000 isochore grids (DTN: MO0012MWDGFM02.002 [DIRS 153777]) exist for these layers. 
As with the isochore grids, the horizon grids, which also contain regularly spaced $(61 \times 61 \mathrm{~m})$ data, require no manipulation other than simple formatting for incorporation into the UZ model. EARTHVISION V5.1 (Dynamic Graphics 2003 [DIRS 171007]) is used to export the regularly spaced data and to convert the units (x,y, and elevation) from feet to meters. The complete details for formatting these GFM2000 horizon grids (DTN: MO0012MWDGFM02.002 [DIRS 153777]) are documented in the scientific notebook by Hinds and Dobson (2004 [DIRS 170886], pp. 20 to 22).

The lower boundary of the UZ model (the water table) was discussed previously in Section 6.2. The input data set ( $\left.g w l \_s s p a c 2 . a s c\right)$ used to define the water table at the base of the UZ was obtained from DTN: MO0212GWLSSPAX.000) [DIRS 161271]. These input data consist of borehole water-level elevations (consistent with qualified data in DTNs: MO0106RIB00038.001 [DIRS 155631] and GS010608312332.001 [DIRS 155307]) along with interpreted potentiometric surface contour lines. This surface was constructed under the assumption that the water levels in G-2 and WT-6 represent perched water, and the level in WT-24 represents the regional groundwater surface (USGS 2004 [DIRS 168473]; also see Assumption 1 in Section 5.1). The data were derived from the Vulcan GFM2000 layer "GWL_SSPAC" (DTN: MO0110MWDGFM26.002 [DIRS 160565]). The review and qualification process for this data set is documented in Attachment IV of Development of Numerical Grids for UZ Flow and Transport Modeling (BSC 2003 [DIRS 160109]). The file containing the water table data was then edited to make it compatible with EARTHVISION V5.1.

The resulting data were gridded using the 2-D minimum tension gridding function in EARTHVISION V5.1 to produce a surface defined by a regularly spaced (182.88 by $182.88 \mathrm{~m}$ ) data set. The data defining this surface were then exported using the 2-D and 3-D grid export function in EARTHVISION V5.1, and subsequently regridded using the 2-D minimum tension gridding function to produce a surface defined by a regularly spaced (60.96 by $60.96 \mathrm{~m}$ ) data set (gwl_sspac_60.96.2grd in output-DTN LB02092DGRDVER.001). The 2-D and 3-D grid export function was then utilized again to produce a file with the 60.96 by $60.96 \mathrm{~m}$ regularly spaced data set required as input for grid generation using WINGRIDDER V2.0. The file was edited to ensure that a minimum elevation of $730 \mathrm{~m}$ was used, thus revising lower elevations that resulted from the minimum tension gridding process (Hinds and Dobson 2004 [DIRS 170886], p. 117). This file was then edited (by cropping the data, removing xy coordinates, and modifying the header) to create a reference horizon file (REF_wt_sspac.dat in output DTN: LB0208HYDSTRAT.001) suitable as input for WINGRIDDER V2.0. The details of these steps can be found in the scientific notebook by Hinds and Dobson (2004 [DIRS 170886], pp. 21 to 22).

The gridding procedure used to define the water table in EARTHVISION V5.1 was conducted using a two-step process (irregularly spaced data to a coarsely spaced grid, followed by a finely spaced grid) to avoid generating large deviations from the contoured potentiometric surface as represented by the contours from DTN: MO0212GWLSSPAX.000 [DIRS 161271]. However, this gridding process, which is required to produce the data input needed for numerical grid generation using WINGRIDDER V2.0, does result in small deviations in the water table relative to the surface initially defined by DTN: MO0110MWDGFM26.002 [DIRS 160565]. The deviations in water table elevation are typically less than $5 \mathrm{~m}$ in the area of the repository footprint. Further minor modification to this surface occurs when the reference horizon file 
REF_wt_sspac.dat (Output-DTN: LB0208HYDSTRAT.001) is used to constrain the lower bounds for each column of the numerical grids produced by WINGRIDDER V2.0. However, there are larger (up to $60 \mathrm{~m}$ ) observed discrepancies in the original (USGS 2004 [DIRS 168473], Figure 6-1) and output (Figure 6-2) water table elevations that may result from errors associated with contour digitization prior to generation of the Vulcan water table representation [See Attachment IV of Development of Numerical Grids for UZ Flow and Transport Modeling (BSC 2003 [DIRS 160109])]. Further discussion of the uncertainties associated with the definition of the water table is presented in Section 6.9.1 of this report and Attachment IV of Development of Numerical Grids for UZ Flow and Transport Modeling (BSC 2003 [DIRS 160109]).

\subsection{2-D GRID GENERATION}

Used by WINGRIDDER V2.0 (LBNL 2002 [DIRS 154785]) to organize grid information, the 2-D (map-view) grid (Figure C3-1) defines the structure of columns and segments that provide the basis for projecting the 3-D grid. Each column is represented by a node in map-view indicating the column's position in the $x-y$ plane. Additionally, the shape of each column is a polygon in the $x-y$ plane whose boundaries consist of segments defined prior to 3-D grid generation.

Grid development begins with the assignment of nodes in map view for each object (e.g., domain nodes, fault nodes, repository nodes) with specified orientation and density; details relating to the gridding of rock layers, faults, and the repository can be found in Sections 6.6, 6.6.1, and 6.6.2, respectively. Based on the location of these nodes, a primary 2-D grid is generated using Voronoi tessellation techniques [e.g., "Voronoi Diagrams-A Survey of a Fundamental Geometric Data Structure" (Aurenhammer 1991 [DIRS 160333])] embedded in the WINGRIDDER V2.0 numerical code. The 2-D grid is then improved systematically and interactively by deleting physically incorrect or unnecessary connections. A few iterations of these steps, including adding, moving, and deleting certain nodes, are necessary to create a final 2-D grid, or column scheme, that serves as the basis for generating the vertical (3-D) component of the grid. Detailed instructions for grid construction can be found in the WinGridder V2.0 users manual (LBNL 2002 [DIRS 170551]).

Two-dimensional grid generation for the UZ model incorporates the location of domain and repository boundaries, borehole locations, and map-view traces of major faults. As mentioned in Section 6.3, the fault trace information taken from an elevation of 1,100 masl from GFM2000 (DTN: MO0012MWDGFM02.002 [DIRS 153777]) was used to define the map-view traces for the 2-D grid. Various subsets of these features are included in the different UZ model grids, depending on their intended use. For example, the columns that contain the boreholes are used for the 1-D hydrogeologic-property-set inversions.

Another issue considered in 2-D grid generation is spatial resolution. Grid resolution (node spacing) is a compromise between computational efficiency and a need to capture spatial variability in rock properties and boundary conditions (such as infiltration rate). As discussed in Section 6.6, additional grid resolution was added to the PTn units and the repository, two features that previous Yucca Mountain flow model studies identified as needing enhanced numerical resolution to capture the effects of spatial variability on flow (BSC 2001 
[DIRS 155950], Section 3.3.4.8.1). The 3-D grid captures the needed spatial variability in the infiltration rate at the bedrock surface for calibration purposes, while containing sufficient numerical resolution within the repository boundary, the area most important to PA studies.

\subsection{3-D GRID GENERATION}

UZ model grid nodes are assigned in plan view within the 2-D grid and polygons are generated representing the lateral extent of each grid column. Then, model layer contact elevations are determined for each vertical column within the UZ model grid, using a bilinear interpolation method to determine values between the regularly spaced (61 x $61 \mathrm{~m}$ ) nodes of the GFM2000 grid (DTN: MO0012MWDGFM02.002 [DIRS 153777]). The estimated maximum error in layer contact elevations at UZ model column centers associated with this interpolation method is about $5 \mathrm{~m}$, except in areas affected by faulting (see Appendices B and C for grid verification), assuming that the hydrogeologic layers dip $10^{\circ}$. Dips are generally less than $10^{\circ}$ (BSC 2004 [DIRS 170029], Section 6.4), and thus a value of $10^{\circ}$ was used to calculate the maximum error value. This amount of potential error is considered insignificant to grid development and subsequent site-scale UZ model simulation activities because lateral column dimensions almost always exceed $61 \times 61 \mathrm{~m}$ (except along faults), thus encompassing the nearest GFM2000 data point.

The 3-D grid describes the location, rock material name, and connection information for each 3-D gridblock in the UZ model domain. All 3-D gridblocks are generated column by column with WINGRIDDER V2.0 (LBNL 2002 [DIRS 154785]), based on the 2-D (plan-view) grid design, to ensure that each vertical connection occurs between adjacent gridblocks and that each gridblock has at least one vertical connection. Lateral connections are then generated segment by segment within a model layer, with each segment joining two neighboring columns. This ensures that only gridblocks in two adjacent columns have lateral connections and that no connections between two adjacent columns are missing.

For a given column, 3-D gridblocks are built for each HGU, first above the Tptpv3 structural reference surface until reaching the bedrock surface, and then below this reference surface down to the water table. The interfaces of the generated gridblocks are located exactly at the interfaces of the corresponding hydrogeologic layers. Vertical connections within the column are generated after each gridblock is built. A dummy gridblock is added to the top and bottom of each column to enable assignment of model boundary conditions.

When building lateral connections, each pair of two adjacent columns are searched top-to-bottom. If gridblocks in the adjacent columns belong to the same layer, a lateral connection is built for them. The lateral interface area is determined by the length of the shared side multiplied by the height of the shorter of the two gridblocks that are connected. If the layer is missing in one of the two neighboring columns (resulting from a layer pinching out), the gridblock representing the last occurrence of the pinch-out layer is laterally connected to the adjacent gridblock, now occupied by the next hydrogeologic layer. The height of that interface at the pinch-out margin is reduced to $0.10 \mathrm{~m}$ (10 percent of the minimum gridblock height). This value was chosen assuming that the pinch-out layers are not just layer discontinuities, and that permeable connections are preserved. If one of the two adjacent columns is a fault, the lateral connections are built based on elevations only. 
The maximum thickness of any cell within the UZ grids is $20 \mathrm{~m}$ (Unsaturated Zone Modeling \& Synthesis [Pan 2003 (DIRS 170887), pp. 135 to 136]). If the thickness of a model layer within a column exceeds $20 \mathrm{~m}$, the layer is subdivided equally into two layers. Minimum vertical grid resolution is $1.0 \mathrm{~m}$; thus, if the thickness of a hydrogeologic layer is less than $1.0 \mathrm{~m}$ within a column, the layer is considered absent, and no gridblock is generated for the layer at this location. To conserve the total thickness of the UZ, layer thicknesses below this cutoff are added to the overlying layer if they lie above the structural reference horizon (i.e., top of Tptpv3), or are added to the underlying layer if they lie below the reference horizon. Still, this may lead to a significant discontinuity if many thin, adjacent layers exist. Within UZ model boundaries, however, no more than two adjacent hydrogeologic layers, each with a thickness less than $1.0 \mathrm{~m}$, occur in any vertical column, except for a few locations near the land surface where erosion has removed most of the crystal-poor Tiva Canyon Tuff (Трср), and the underlying Tpcpv units (model layers tcw13 and ptn21) are also less than $1.0 \mathrm{~m}$ thick. In this rare case, the small layer thicknesses are added to the underlying layer, ptn22.

Further vertical grid resolution is added within the PTn units ptn22, ptn24, ptn25, and ptn26, as well as the unit ch1 and the repository horizon, where a maximum cell thickness of $5 \mathrm{~m}$ is used (Pan 2003 [DIRS 170887], pp. 135 to 136). Sensitivity studies examining the effects of grid refinement on flow and transport models indicate that a vertically refined grid is needed to capture lateral flow caused by capillary barriers formed by the layers ptn21 and ptn23 [(BSC 2001 [DIRS 155950], Sections 3.3.3.4.2 and 3.3.4.8.1); "Modeling Capillary Barriers in Unsaturated Fractured Rock” (Wu et al. 2002 [DIRS 161058], pp. 7 to 8, p. 11, and Fig. 7)], and thus enhanced grid refinement (maximum cell thickness of $2 \mathrm{~m}$ ) was assigned to ptn21 and ptn23. Having detailed grid resolution within the repository (Section 6.6.2) allows flow models to better capture spatial variability (BSC 2001 [DIRS 155950], Section 3.3.4.8.1). The repository itself is represented by five grid layers, each $5 \mathrm{~m}$ thick.

Material properties are assigned to gridblocks depending on the hydrogeologic layer to which the gridblock corresponds. For layers with multiple properties, such as the vitric and zeolitic zones within the lowermost Topopah Spring and the Calico Hills units, polygons defining the areal extent of these zones are created (see Section 6.6.3). Assignment of material properties (i.e., vitric or zeolitic) to model gridblocks is then confined to the appropriate polygon.

\subsubsection{Faults}

Although faults may occur as displacement surfaces only or as deformation zones of variable width, each fault within the current UZ model domain is represented by columns of gridblocks having an arbitrary width of $30 \mathrm{~m}$. Nevertheless, adjustments can be made within a grid to assign appropriate rock properties to each fault zone to handle various fault configurations. Conceptually, there are three important features of a fault that are conserved in the numerical grid. First, a fault is a separator that causes discontinuity of geological layers and may serve as a structural barrier to lateral flow. Second, a fault zone is continuous and may serve as a fast path for vertical flow depending on its hydraulic properties. Third, a fault may or may not be vertical, and its angle of inclination may vary spatially. To implement these features in the UZ grids, three parallel rows of fault-related columns are built for each fault. Each section of a fault in map view consists of three connected columns, with the fault column located in the middle 
(Figure 6-3). Each fault column is connected to two side columns and two neighboring fault columns only. Columns on opposite sides of a fault are always separated by a fault column.
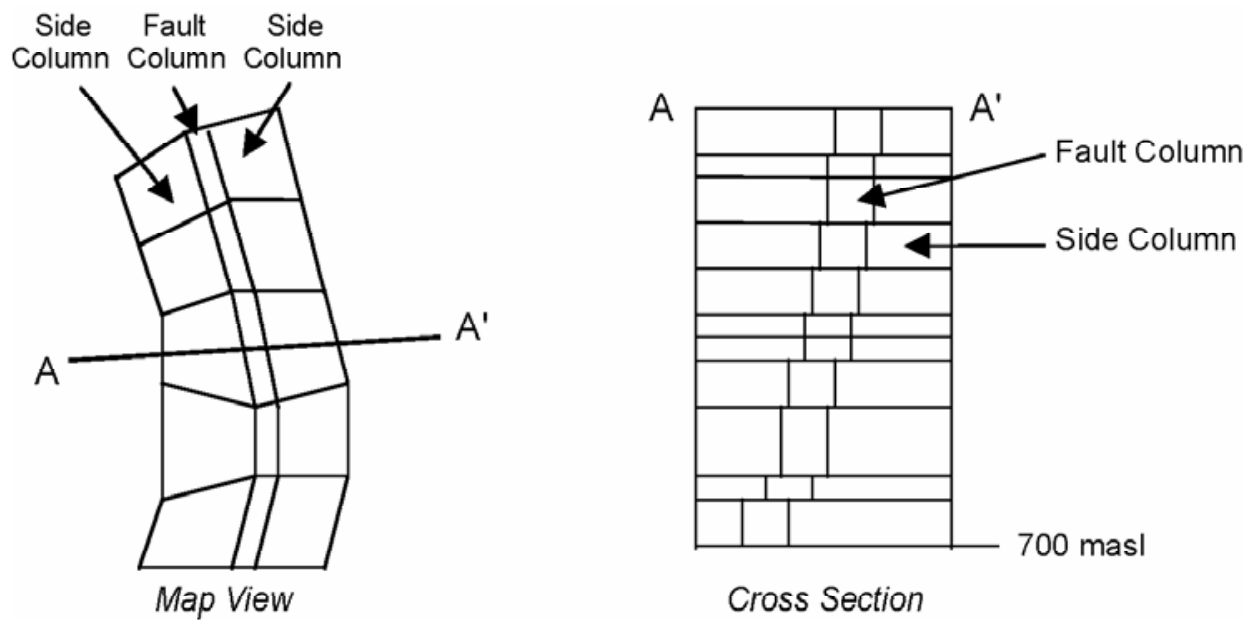

Figure 6-3. Schematic Illustration of Fault-Related Gridblocks in Map View and in Cross Section

The three fault-related columns (the fault column and its two side columns) are processed together to generate 3-D gridblocks representing the fault and layer offset. From the bedrock surface to the water table, the $\mathrm{x}$, $\mathrm{y}$ location of fault gridblocks may shift according to the elevation and dip of the fault. Similarly, the volumes and the center (nodal point) location of the corresponding side cells are adjusted accordingly. As a result, the inclination of the fault is described by a series of connected gridblocks whose $\mathrm{x}$, $\mathrm{y}$ locations vary with elevation. The fault-related gridblocks are connected vertically, if they belong to the same column, regardless of the fault angle. Columns of side cells are connected in a similar fashion regardless of the horizontal shifting of position and change in volume. To look at it from another perspective, each set of three fault-related columns (i.e., the fault column plus its two side columns) can be viewed collectively as one vertical column that is subdivided into three nonvertical columns to capture the angle of inclination along a fault. One limitation of this method is that intersecting faults cannot be represented.

This method of representing the three-dimensionality of faults requires that all fault gridblocks have the same elevation and thickness as the laterally adjacent gridblock to facilitate vertical displacement of geologic layers. Because Yucca Mountain is comprised of hydrogeologic layers with variable thickness, simply reassigning material properties from one row of gridblocks to another to establish offset along faults is insufficient for representing the true layer configurations. This approach would remove certain layers from columns adjacent to fault columns and often misrepresents layer thicknesses. To avoid such error, additional vertical resolution is added to fault-related gridblocks based on the elevation of hydrogeologic layer contacts encountered on both sides of the fault. Therefore, vertical grid discretization in each set of three fault-related columns is identical, and all contacts between HGUs in each of the side columns are represented by layer interfaces between the fault-column gridblocks. The layer and rock properties of fault gridblocks are then assigned according to the stratigraphy of the fault column. 
The assignment of lateral connections that involve fault-related gridblocks is different from the way lateral connections are assigned to normal (non-fault-related) gridblocks. Fault-related lateral connections are of two types, fault-fault gridblock connections and fault-side cell connections. In these two cases, lateral connections occur between gridblocks that share the same interface. The interface area is precisely determined by the contact area between the two gridblocks.

As mentioned in Section 6.3, some simplification of the GFM2000 faults was made in creating the UZ model grids, including the representation of the Solitario Canyon and Solitario Canyon (west) faults as a single fault. During the evaluation of the 3-D grid described in Appendix C, it was discovered that some matrix columns adjacent to fault columns exhibited fault-related stratigraphic offset with their neighboring columns. To ensure proper flow behavior in the grid, the columns with observed offsets were classified as "faults" while building the 3-D grid so that lateral connections between gridblocks in these columns and those in the adjacent columns were made with the closest lateral neighbor, and not with the same stratigraphic interval (UZ model layer). A total of 18 columns, all adjacent to faults, were treated in this manner (see Appendix C for details).

\subsubsection{Repository}

The repository layout configuration presented on Data Sheets 2 of 5 and 3 of 5 from Repository Design, Repository/PA IED Subsurface Facilities Plan Sht. 1 of 5, Sht. 2 of 5, Sht. 3 of 5, Sht. 4 of 5, and Sht. 5 of 5 (BSC 2002 [DIRS 159527]) was used to define those areas within the numerical grid that require enhanced numerical resolution.

The repository design used was the most recent representation of the repository layout at the time the numerical grids presented in this document were generated and was the best source for this information. This design consists of an upper (primary) block located west and north of the ESF, and a lower elevation region located east of the primary repository block and areally overlapping part of the ESF. It is recognized that the repository design may undergo change, and that the appropriateness of the grid should be evaluated against the final design configuration. As noted in Section 4.1, a revised version of the repository layout was created after the formulation of the numerical grids described in this report (BSC 2004 [DIRS 164519]). The new layout does not include the lower block area delineated in Figures 6-1 and 6-2. As discussed in Section 3.3.4.8.1 of FY 01 Supplemental Science and Performance Analyses, Volume 1: Scientific Bases and Analyses (BSC 2001 [DIRS 155950]), the use of more refined gridding in the area of the repository layout (see Section 6.6.2, Figures C-3 and C-4) provides needed resolution for flow models.

For numerical gridding purposes, the repository is defined as a 3-D object that is subdivided into a regular mesh of gridblocks. The repository design used in the constuction of the numerical grids (BSC 2002 [DIRS 159527]) calls for two sets of waste emplacement drifts to be constructed, with the primary repository area located west and/or north of the ESF Main Drift, and the lower elevation block located east of the primary block. Note that the lower elevation block has been removed from the most recent revision of the repository layout (BSC 2004 [DIRS 164519]). All repository columns are aligned along the direction of the emplacement drifts, as currently designed, and each column of gridblocks (except those corresponding to 
borehole locations) has four sides to facilitate the representation of a drift with a series of connected 3-D gridblocks.

Local refinement is added vertically at the repository horizon in the UZ model grids for PA. For each repository column, a repository thickness of $25 \mathrm{~m}$ is assigned at the appropriate elevation. This thickness is then divided vertically into five layers, each $5 \mathrm{~m}$ thick. For the interfaces between repository gridblocks, lateral connections are established if two adjacent gridblocks belong to the same layer within the five-layer grid structure of the repository horizon. For interfaces between a repository gridblock and a nonrepository gridblock, the connection is built based on their hydrogeologic-layer similarity. The assignment of rock properties to repository gridblocks is determined by the elevation of the gridblock and the corresponding hydrogeologic layer present at that elevation.

\subsubsection{Vitric/Zeolitic Boundaries}

The ISM3.1 rock properties model (Section 5.2, Assumptions 2 and 3) is used together with measured rock-property measurements from boreholes and corroborative data from the RPM2000 and mineralogic model 3.1 (MM3.1) to add resolution to UZ model grids within the lowermost Topopah Spring tuffs (TSw) and CHn. Of great importance to UZ flow and transport modeling is the distribution of low-permeability zeolites, because of their potential to significantly alter flowpaths and travel times and to retard radionuclides migrating from the repository horizon to the water table.

At high matrix saturations, groundwater flow within the TSw and $\mathrm{CHn}$ should be diverted around zeolitic volumes of rock and preferentially flow through the less-altered, higher-permeability vitric matrix. Consequently, only a low percentage of the total percolation flux is expected to travel through significantly zeolitized tuffs. This suggests that sorption within the slightly altered (mostly vitric) tuffs is of far greater importance. As such, high- and low-permeability regions are defined within certain UZ model layers corresponding to the tuffs of the lowermost TSw and upper CHn (above lithostratigraphic unit Tcpuv).

Lateral boundaries between high- and low-permeability tuffs within the lowermost TSw and upper $\mathrm{CHn}$ were determined using results from the geostatistical RPM3.1 (DTN: MO9910MWDISMRP.002 [DIRS 145731]) and rock-property data from selected boreholes. The location of these boundaries was corroborated using information found in RPM2000 (DTN: SN0112T0501399.004 [DIRS 159524]) and MM3.1 (DTN: MO9910MWDISMMM.003 [DIRS 119199]). The details and results of this exercise and a comparison between RPM3.1, RPM2000, and MM3.1 are provided below. The net result is the subdivision of the lithostratigraphic unit Tac (see Table 6-5) vertically into four grid layers (ch2, ch3, ch4, ch5), and laterally into vitric and zeolitic regions for which separate hydrogeologic and sorptive properties are assigned. The UZ model layers tsw39 (corresponding to the Tptpv2), ch1 (corresponding to the combined lithostratigraphic units Tptpv1 and Tpbt1), and ch6 (corresponding to the Tacbt) are also laterally subdivided into vitric and zeolitic regions. Note that the horizontal and vertical resolution of the UZ model grids is too coarse to capture meter-scale heterogeneity within the CHn. Small-scale heterogeneity is, however, observed within the CHn and may have an impact on flow and transport calculations. 
Direct input data from the rock properties model 3.1 (DTN: MO9910MWDISMRP.002 [DIRS 145731]) and corroborative data from the rock properties model 2000 (DTN: SN0112T0501399.004 [DIRS 159524]) and the mineralogic model 3.1 (DTN: MO9910MWDISMMM.003 [DIRS 119199]) are analyzed in EARTHVISION V5.1 (Dynamic Graphics 2003 [DIRS 171007]) by generating map-view figures of interpreted saturated hydraulic conductivity $\left(\mathrm{K}_{\mathrm{s}}\right)$ data (from RPM3.1), a contoured region with less than 0.5 probability of hydrous-phase alteration (from RPM2000), and percent-zeolite distribution (from MM3.1). Results from the RPM3.1 (DTN: MO9910MWDISMRP.002 [DIRS 145731]) were used as the primary means to define vitric and zeolitic boundaries. Because RPM3.1 (DTN: MO9910MWDISMRP.002 [DIRS 145731]) does not include more recent rock-property data from SD-6, saturation, porosity, and hydraulic conductivity data from this borehole (DTNs: GS980908312242.038 [DIRS 107154] and GS980808312242.014 [DIRS 106748]) are used to modify zeolitic and vitric boundaries where appropriate. Additional rock-property data from SD-7 (DTN: GS951108312231.009 [DIRS 108984]), SD-12 (DTN: GS960808312231.004 [DIRS 108985]), and a variety of other boreholes (DTNs: LB0207REVUZPRP.002 [DIRS 159672] and MO0109HYMXPROP.001 [DIRS 155989]) were also evaluated. In general, vitric material is characterized by relatively low saturation (less than approximately 90 percent), relatively high $\mathrm{K}_{\mathrm{s}}$ (greater than approximately $10^{-10} \mathrm{~m} / \mathrm{s}$ ), and oven-dried porosity that is less than 5 percent higher than relative-humidity porosity. Because the MM3.1 (DTN: MO9910MWDISMMM.003 [DIRS 119199]) is based on limited data and the RPM2000 (DTN: SN0112T0501399.004 [DIRS 159524]) data are not qualified, these DTNs are used only as corroborative evidence for the presence of vitric and zeolitic tuffs.

Rock-property data from boreholes SD-6, SD-7, SD-9, SD-12, UZ-14, UZ-16, NRG-7a, and WT-24 (DTN: LB0207REVUZPRP.002 [DIRS 159672]) are the primary input used to define the vitric and zeolitic regions for layer tsw39. Additional rock property data from a variety of boreholes are selectively used to refine the location of the vitric-zeolitic boundary in other layers. Detailed descriptions of how the layers tsw39, ch1, ch2, ch3, ch4, ch5, and ch6 are delineated is presented later in this section.

Major faults are assumed to represent appropriate lateral boundaries for unaltered areas (Section 5.2, Assumption 4). Vitric portions of the CHn may reasonably be assumed to be laterally continuous within fault blocks that have a higher structural position above the water table compared to adjacent downthrown structural blocks. For example, the Solitario Canyon fault system offsets the CHn by more than $300 \mathrm{~m}$ in the southern part of the UZ model domain. $\mathrm{CHn}$ layers west of the Solitario Canyon fault lie near or below the water table in this area; consequently they are most likely altered to zeolites. In contrast, CHn layers east of the Solitario Canyon fault may be up to $300 \mathrm{~m}$ above the water table and are less likely to have undergone alteration because of limited rock/water interaction. The vertical offset along the Dune Wash fault suggests that this is another possible boundary for vitric and zeolitic subunits within the $\mathrm{CHn}$. As a result, major faults are considered as potential boundaries between vitric and zeolitic areas when interpreting data from RPM3.1 (DTN: MO9910MWDISMRP.002 [DIRS 145731]) and corroborative evidence from RPM2000 (DTN: SN0112T0501399.004 [DIRS 159524]) and MM3.1 (DTN: MO9910MWDISMMM.003 [DIRS 119199]).

RPM3.1 uses porosity (data that are relatively abundant at Yucca Mountain) as a surrogate to predict $\mathrm{K}_{\mathrm{s}}$ values. The limitations of this correlation are discussed by Rautman and McKenna in 
Three-Dimensional Hydrological and Thermal Property Models of Yucca Mountain, Nevada (1997 [DIRS 100643], pp. 13 to 14). In the RPM3.1 (DTN: MO9910MWDISMRP.002 [DIRS 145731]), the CHn consists of the volume of rock lying between the upper Tptpv1 contact and the lower Tacbt contact (in other words, geologic layers Tptpv1, Tpbt1, Tac, and Tacbt, shown in Table 6-5, equivalent to the UZ model HGUs ch1-ch6). $\mathrm{K}_{\mathrm{s}}$ distributions within the RPM3.1 CHn unit (represented by 24 grid layers in the rock properties model) are plotted in EARTHVISION V5.1 by contouring (2-D minimum tension gridding) the regularly spaced $(200 \times 200 \mathrm{~m}) \mathrm{K}_{\mathrm{s}}$ data for each of the 24 rock-property grid layers. The 24 rock-property grid layers are not stratabound; rather, they are equally thick at any given $\mathrm{x}, \mathrm{y}$ coordinate. An equivalent GFM2000 isochore file was created by combining the thicknesses of the layers mentioned above. Using the midpoint surface positions for each of the UZ model layers, $\mathrm{K}_{\mathrm{s}}$ isosurfaces were then back-interpolated from the RPM3.1 file ChnZksStrat.3grd (see Appendix A, ISM3.1 files). The plots show $K_{\mathrm{s}}$ data that range from approximately $10^{-5}$ to $10^{-12} \mathrm{~m} / \mathrm{s}$; note that $K_{s}$ values greater than $10^{-10} \mathrm{~m} / \mathrm{s}$ are assumed to represent vitric tuffs (Section 5.2, Assumption 2). Figure 6-4 shows an example of one of these $K_{\mathrm{s}}$ plots for the upper Tac (UZ model layer ch2) lithostratigraphic unit. Details explaining the extraction of relevant ISM3.1 rock-property data used to define vitric boundaries within UZ model grid layers are documented in the scientific notebook by Hinds and Dobson (2004 [DIRS 170886], p. 24).

A similar approach was used to evaluate vitric and altered tuffs using data from RPM2000 (DTN: SN0112T0501399.004 [DIRS 159524]). This version of the rock properties model contains data from boreholes not included in RPM3.1 (DTN: MO9910MWDISMRP.002 [DIRS 145731]), but is not qualified, and thus can be used only for corroborative purposes. The RPM2000 file CHn_hmap_etype.out (see Appendix A, RPM2000 files) is an "E-type" model of hydrous-phase mineral alteration in the form of a probability distribution, with values close to 1 indicating a strong probability of mineral alteration to phases such as zeolites and clays. For more discussion on E-type models, see Rock Properties Model Analysis Model Report (BSC 2002 [DIRS 159530], Sections 6.1 and 6.4.8.3). Using the mid-point elevation of UZ model layers ch1, ch2, ch3, ch4, ch5, and ch6, faces files were created for each unit, where the 0.5 probability contour is interpreted to represent the vitric-zeolitic boundary, and where altered (zeolitic) tuffs lie on the greater than 0.5 probability side of the contour line. Figure 6-5 shows an example of one of these alteration-probability contour plots for the upper Tac (UZ model layer ch2) lithostratigraphic unit. Details explaining the extraction of RPM2000 rock-property data used to define vitric boundaries within UZ model grid layers are documented in the scientific notebook by Hinds and Dobson (2004 [DIRS 170886], pp. 24 to 25).

Percent-zeolite plots were also made from MM3.1 data (DTN: MO9910MWDISMMM.003 [DIRS 119199]) in EARTHVISION V5.1 by contouring (2-D minimum tension gridding) the regularly spaced $(61 \times 61 \mathrm{~m})$ percent-zeolite data for the CHn contained in the ISM3.1 file mineralsM.pdat (see Appendix A, ISM3.1 files). The plots essentially represent the exact results of the mineralogic model. The plots show a general trend of increased zeolitic alteration to the north and east across the model area. Figure 6-6 is an example of one of these plots for the upper one-fourth of the Tac lithostratigraphic unit. This representation of zeolite distribution is not appropriate for use in defining vitric-zeolitic boundaries in the numerical grids discussed in this report. This is because of the paucity of mineralogic sample data and the interpolation technique used in the development of the mineralogic model. However, these data can be used for corroborative purposes. 
The interpreted extent of the vitric-zeolitic boundaries from the above analysis are shown in Figures 6-7 and 6-8. These boundaries are used in WINGRIDDER V2.0 (LBNL 2002 [DIRS 154785]) to assign material names to gridblocks (i.e., "vitric" or "zeolitic," for which associated rock properties will be assigned) within UZ model layers tsw39, ch1, ch2, ch3, ch4, ch5, and ch6. These boundaries were selected using the results of the RPM3.1 (DTN: MO9910MWDISMRP.002 [DIRS 145731]) $\mathrm{K}_{\mathrm{s}}$ plots (Section 5.2, Assumption 2), measured rock-property data for boreholes within the UZ model area (Section 5.2, Assumption 3 ), and the location of faults with significant vertical offset (Section 5.2, Assumption 4). A summary of how vitric/zeolitic boundaries were defined for each UZ model layer is presented below; additional details can be found in the scientific notebook by Hinds and Dobson (2004 [DIRS 170886], pp. 25 to 34, 63 to 67).

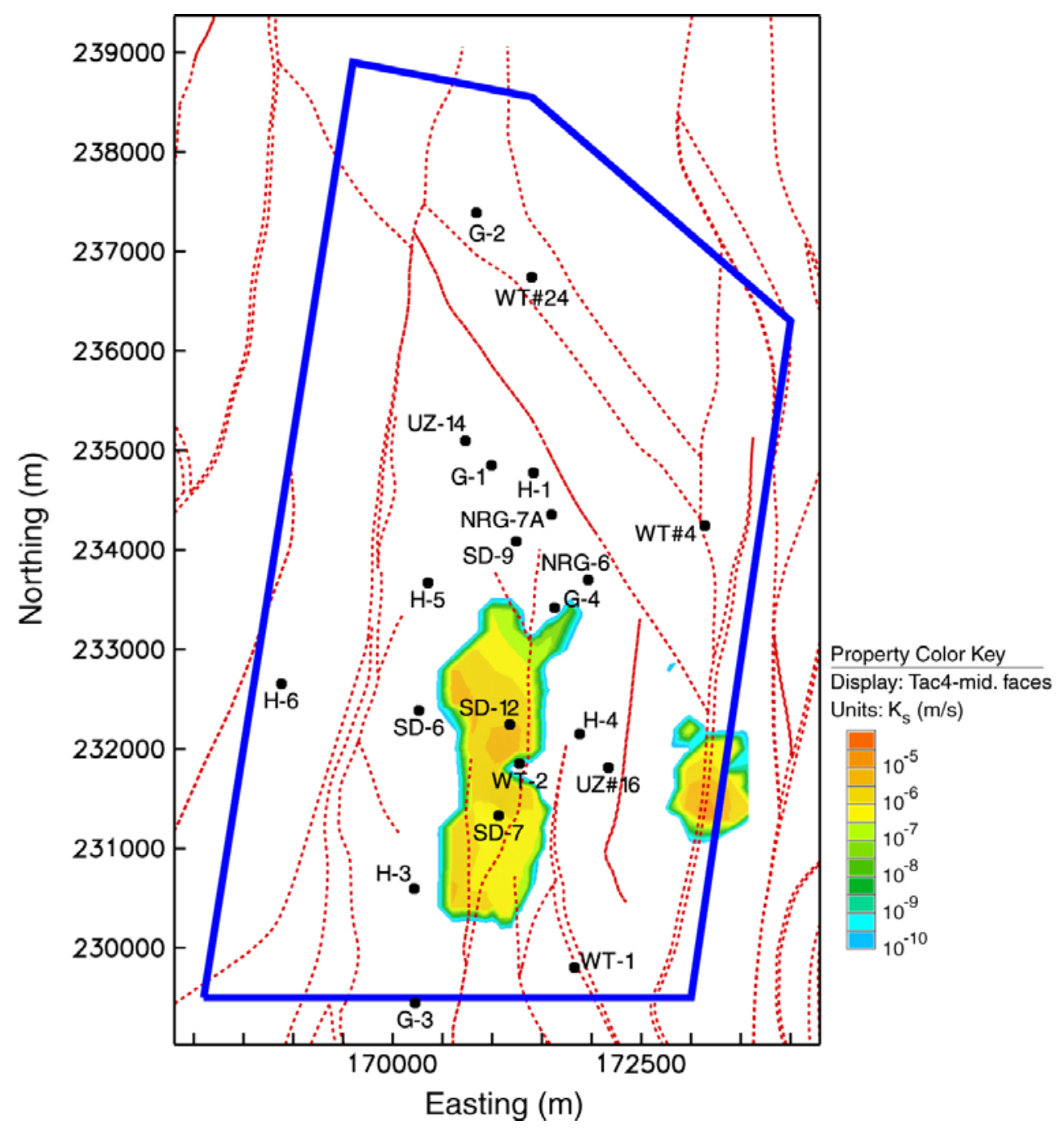

DTN: MO9910MWDISMRP.002 (Rock Properties Model 3.1) [DIRS 145731].

NOTE: Values less than $10^{-10} \mathrm{~m} / \mathrm{s}$ given by white. $\mathrm{K}_{\mathrm{s}}$ Contour Units are $\mathrm{m} / \mathrm{s}$.

Figure 6-4. Distribution of $K_{s}$ from ISM3.1 Rock Properties Model, Upper 1/4 of Layer Tac (UZ Model Layer "ch2") 


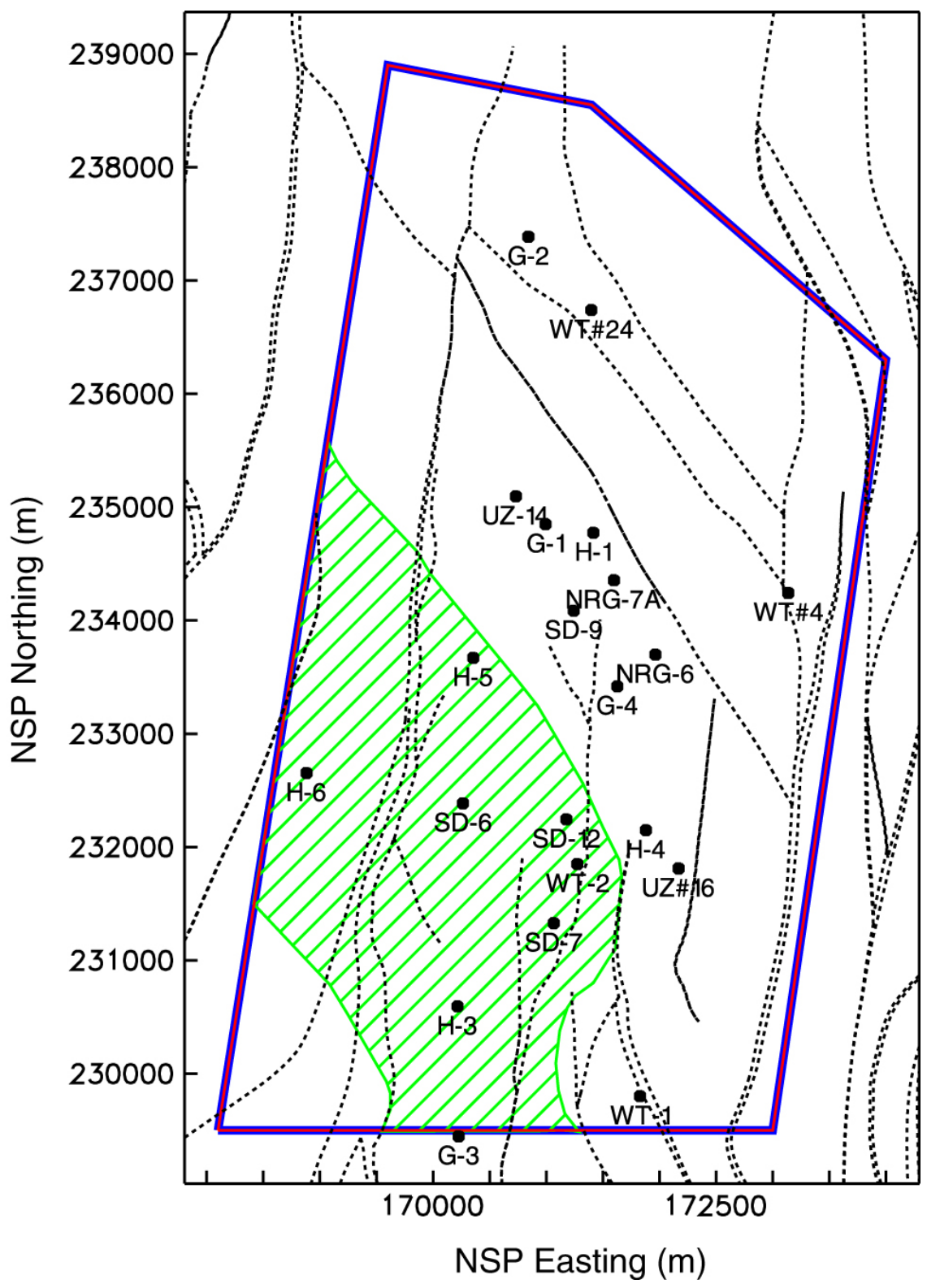

DTN: $\quad$ SN0112T0501399.004 (Rock Properties Model 2000 (Non-Q)) [DIRS 159524].

NOTE: Hachured area within UZ model boundary indicates vitric tuff.

Figure 6-5. Alteration Probability Contour (0.5) Plot from RPM2000, Upper 1/4 of Layer Tac (UZ Model Layer "ch2") 


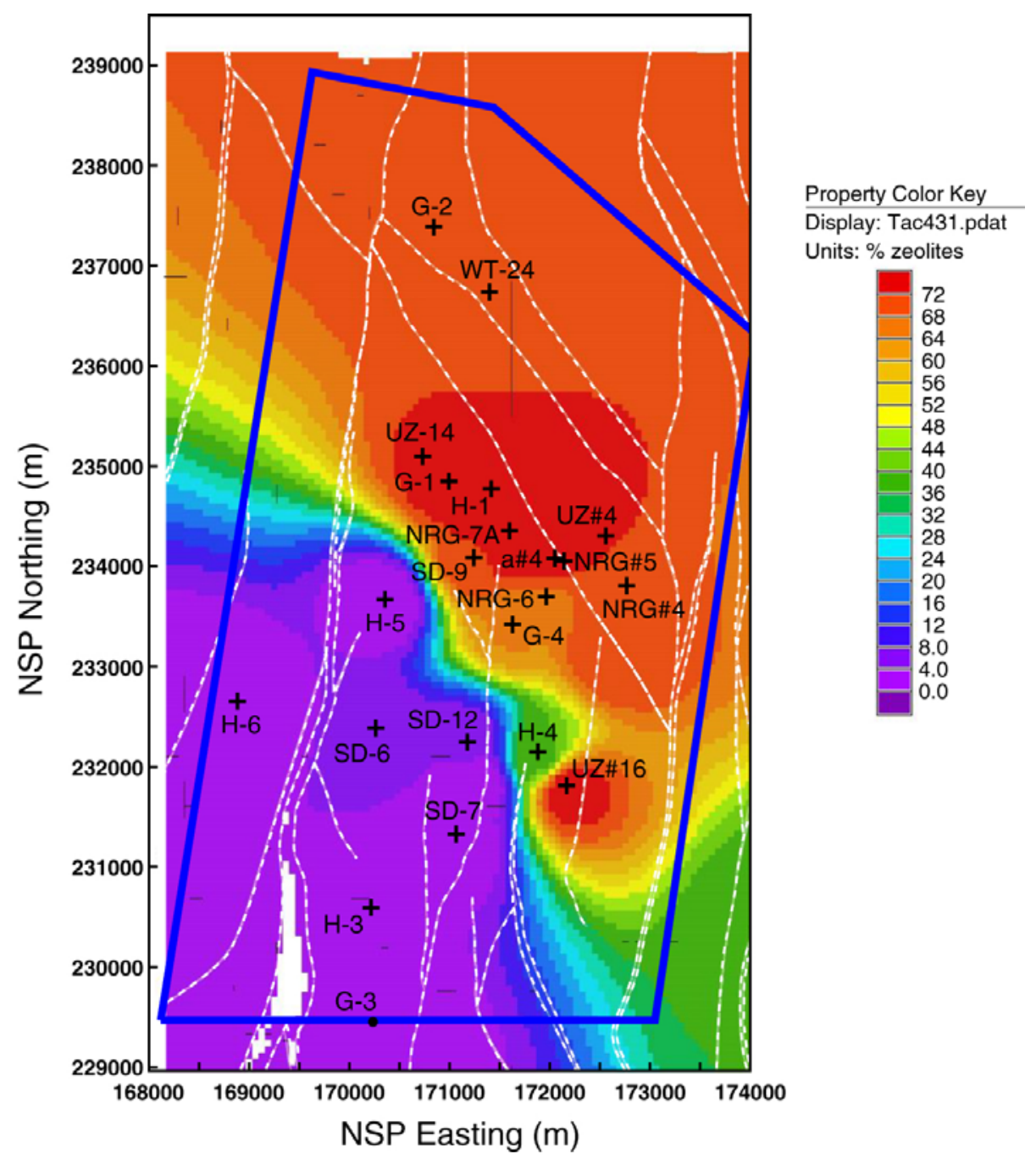

DTN: MO9910MWDISMMM.003 (Mineralogic Model 3.1) [DIRS 119199].

NOTE: Vitric region denoted by purple.

Figure 6-6. Percent Zeolite Distribution from ISM3.1 Mineralogic Model, Upper 1/4 of Layer Tac (UZ Model Layer "ch2") 

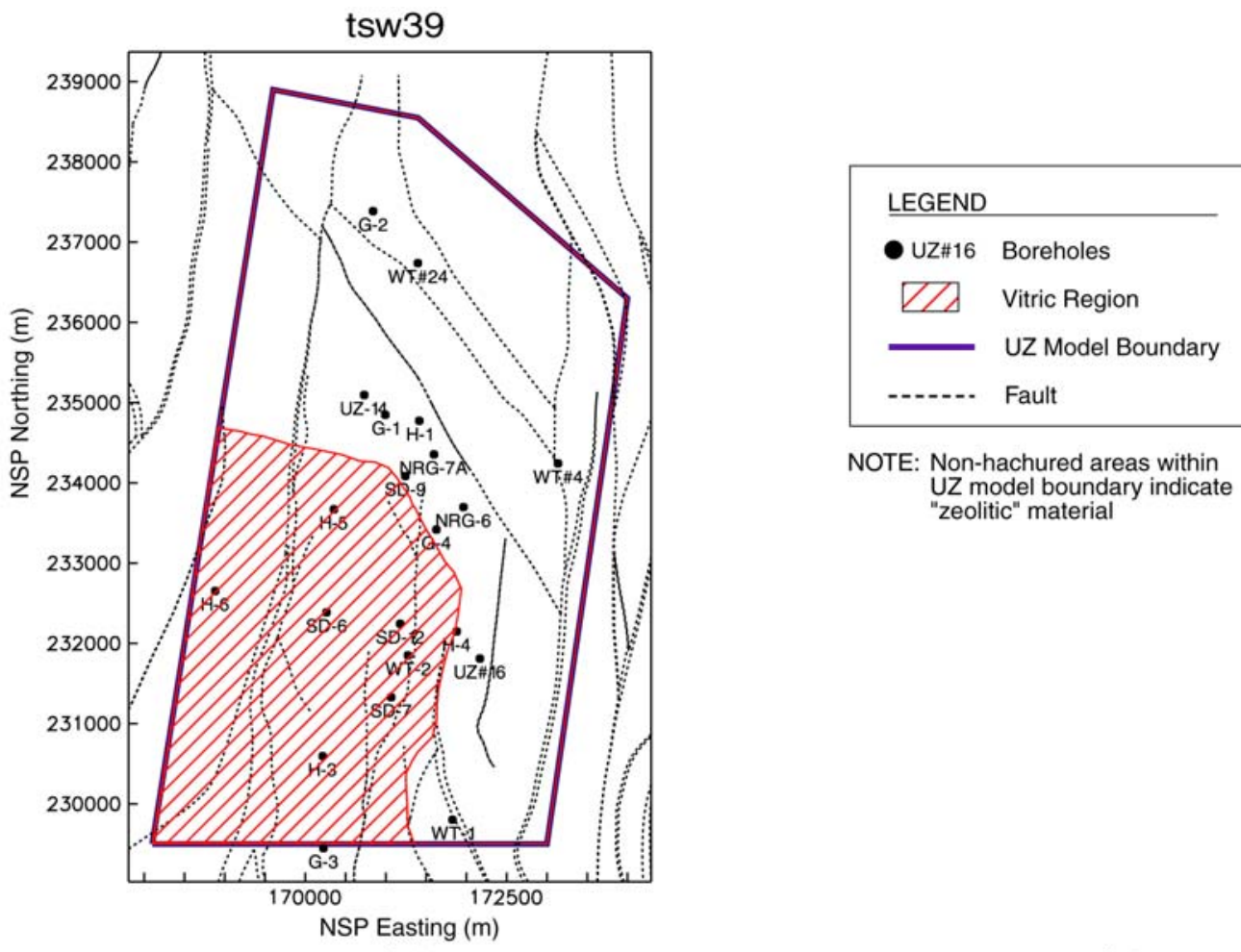

NOTE: Non-hachured areas within UZ model boundary indicate "zeolitic" material
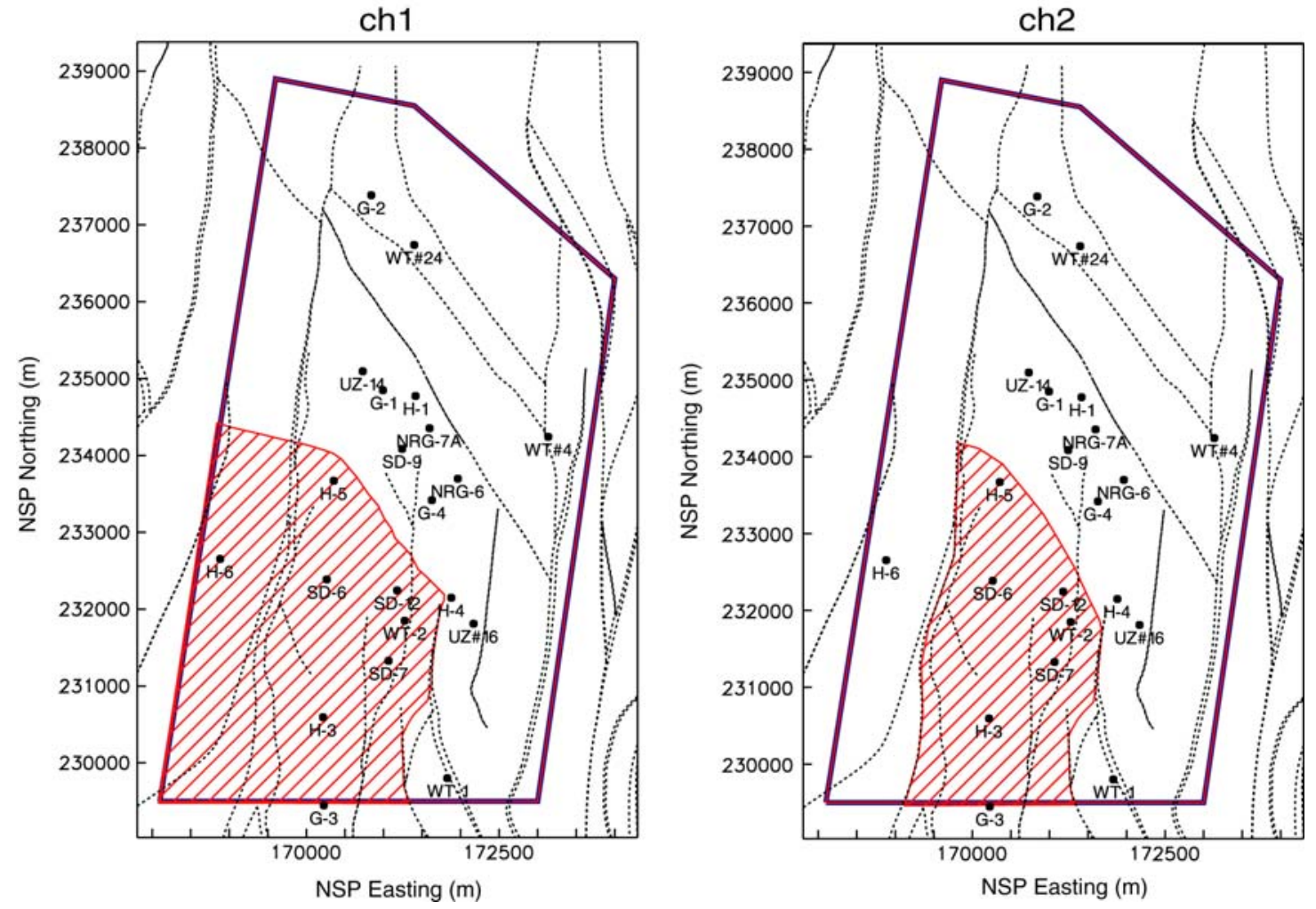

Output-DTN: LB0208HYDSTRAT.001.

Figure 6-7. Extent of Vitric Region in Fiscal Year 2002 UZ Model Layers tsw39, ch1 and ch2 

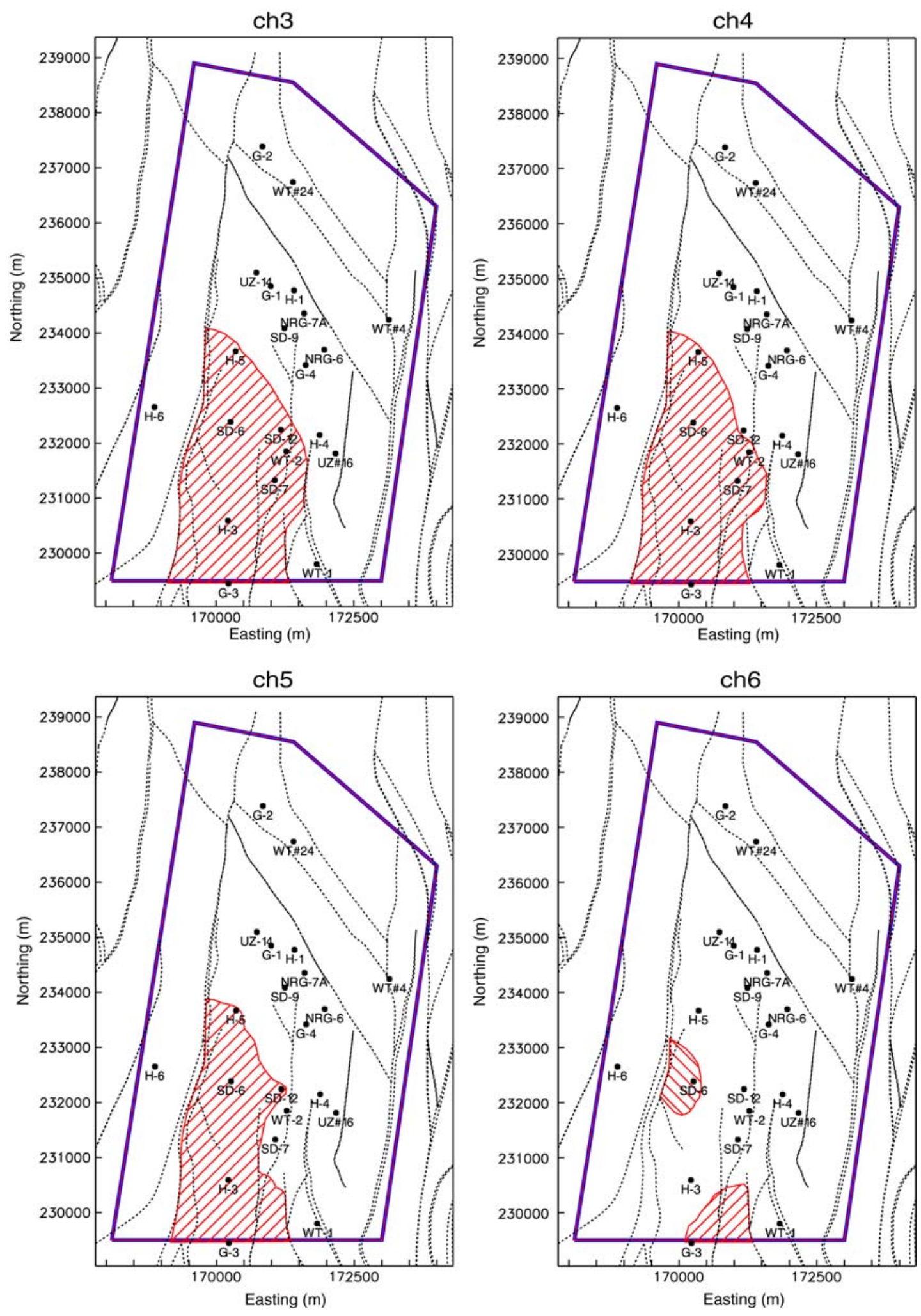

Output-DTN: LB0208HYDSTRAT.001.

NOTE: See Figure 6-7 for figure legend.

Figure 6-8. Extent of Vitric Region in Fiscal Year 2002 UZ Model Layers ch3, ch4, ch5 and ch6 


\section{Tsw39 (Tptpv2)}

Because RPM3.1 (DTN: MO9910MWDISMRP.002 [DIRS 145731]) cannot be easily used to evaluate $\mathrm{K}_{\mathrm{s}}$ values for the unit Tptpv2, rock-property data from boreholes SD-6, SD-7, SD-9, SD-12, UZ-14, UZ-16, NRG-7a, and WT-24 (DTN: LB0207REVUZPRP.002 [DIRS 159672]; see Hinds and Dobson 2004 [DIRS 170886], pp. 63 to 66 and p. 93 for details) were the primary input used to define the vitric and zeolitic regions for layer tsw39. Tuffs were characterized as vitric when the following properties were observed: relatively low saturation (less than approximately 90 percent), relatively high $\mathrm{K}_{\mathrm{s}}$ (greater than approximately $10^{-10} \mathrm{~m} / \mathrm{s}$ ), and a difference between oven-dried and relative-humidity porosities of less than 5 percent (Section 5.2, Assumptions 2 and 3). An evaluation of these rock properties within this unit for the boreholes listed above suggests that the boreholes SD-6, SD-7, SD-9 and SD-12 contain vitric tuffs, UZ-14, UZ-16, and WT-24 contain zeolitic tuffs, and that NRG-7a has samples with both vitric and zeolitic properties. However, to reconcile the presence of perched water above this unit in boreholes SD-9 and NRG-7a [Hydrogeology of the Unsaturated Zone, North Ramp Area of the Exploratory Studies Facility, Yucca Mountain, Nevada (Rousseau et al. 1999 [DIRS 102097], pp. 170 to 171)], these boreholes were assigned to lie near the boundary, but within the zeolitic region. In general, the vitric-zeolitic boundary for this unit is similar in shape to that determined for the underlying ch1 unit. The Dune Wash fault system was used to bound a portion of the eastern margin of the vitric zone.

\section{Ch1 (Tptpv1 + Tpbt1)}

The vitric region is initially defined by RPM3.1 (DTN: MO9910MWDISMRP.002 [DIRS 145731]) $\mathrm{K}_{\mathrm{s}}$ data and rock-property data from boreholes SD-6, SD-7, SD-12, G-3, H-3, H-5, H-6, and WT-2. Rock-property data for SD-6 (DTN: GS980808312242.014 [DIRS 106748]) within this unit (corresponding to a depth interval of 463.3-475.8 m) report low saturations (29-51 percent), and differences in oven-dried and relative-humidity porosities less than 5 percent, indicating that the ch1 interval in this borehole is vitric. Two of the three hydraulic conductivity values reported for this borehole (DTN: GS98090831224.038 [DIRS 107154]) are greater than $10^{-10} \mathrm{~m} / \mathrm{s}$, consistent with the vitric interpretation. The Dune Wash fault system was used to bound a portion of the eastern margin of the vitric zone.

\section{Ch2 (upper $1 / 4$ of Tac)}

The vitric region is initially defined by RPM3.1 (DTN: MO9910MWDISMRP.002 [DIRS 145731]) $\mathrm{K}_{\mathrm{s}}$ data and rock-property data from boreholes SD-6, SD-7, SD-12, G-3, H-3, H-5, H-6, and WT-2. Rock-property data for SD-6 (DTN: GS980808312242.014 [DIRS 106748]) within this unit (corresponding to a depth interval of 475.8-483.6 m) report low saturations (less than 70 percent, average 35 percent), and differences in oven-dried and relative-humidity porosities less than 5 percent, indicating that the ch2 interval in this borehole is vitric. The three hydraulic conductivity values reported for this borehole (DTN: GS98090831224.038 [DIRS 107154]) are greater than $10^{-10} \mathrm{~m} / \mathrm{s}$, consistent with the vitric interpretation. The Dune Wash fault system was used to bound a portion of the eastern margin of the vitric zone, and the Solitario Canyon fault, which downdrops the region to the west by over $200 \mathrm{~m}$ (Figure C3-2), was assumed to form the western boundary of the vitric zone for 
this unit, thus resulting in assigning the H-6 borehole as zeolitic (consistent with the results of RPM3.1 (DTN: MO9910MWDISMRP.002 [DIRS 145731])).

\section{Ch3 (mid-upper $1 / 4$ of Tac)}

The vitric region is initially defined by RPM3.1 (DTN: MO9910MWDISMRP.002 [DIRS 145731]) $K_{s}$ data and rock-property data from boreholes SD-6, SD-7, SD-12, G-3, H-3, H-5, H-6, and WT-2. Rock-property data for SD-6 (DTN: GS980808312242.014 [DIRS 106748]) within this unit (corresponding to a depth interval of 483.6-491.5 m) report low saturations (25-30 percent), and differences in oven-dried and relative-humidity porosities of less than 5 percent, indicating that the ch3 interval in this borehole is vitric. The Dune Wash fault system was used to bound a portion of the eastern margin of the vitric zone, and the Solitario Canyon fault, which downdrops the region to the west by over $200 \mathrm{~m}$ (Figure C3-2), was assumed to form the western boundary of the vitric zone for this unit, thus resulting in assigning the H-6 borehole as zeolitic (consistent with the results of RPM3.1 (DTN: MO9910MWDISMRP.002 [DIRS 145731])).

\section{Ch4 (mid-lower $1 / 4$ of Tac)}

The vitric region is initially defined by RPM3.1 (DTN: MO9910MWDISMRP.002 [DIRS 145731]) $\mathrm{K}_{\mathrm{s}}$ data and rock-property data from boreholes SD-6, SD-7, G-3, H-3, H-5, H-6, and WT-2. Rock-property data for SD-6 (DTN: GS980808312242.014 [DIRS 106748]) within this unit (corresponding to a depth interval of 491.5-499.3 m) report low saturations (25-43 percent), and differences in oven-dried and relative-humidity porosities less than 5 percent, indicating that the ch4 interval in this borehole is vitric. The hydraulic conductivity value $\left(2.31 \times 10^{-5} \mathrm{~m} / \mathrm{s}\right)$ reported for this borehole (DTN: GS98090831224.038 [DIRS 107154]) is greater than $10^{-10} \mathrm{~m} / \mathrm{s}$, consistent with the vitric interpretation. While SD-12 lies within the vitric region as defined by RPM3.1 (DTN: MO9910MWDISMRP.002 [DIRS 145731]), rock-property data (DTN: GS960808312231.004 [DIRS 108985]) for samples from this borehole within the ch4 interval (depths of 458.9-473.2 m) indicate elevated saturation values (92-100 percent), suggesting that this borehole lies within the zeolitic zone. The Dune Wash fault system was used to bound a portion of the eastern margin of the vitric zone, and the Solitario Canyon fault, which downdrops the region to the west by over $200 \mathrm{~m}$ (Figure C3-2), was assumed to form the western boundary of the vitric zone for this unit, thus resulting in assigning the H-6 borehole as zeolitic (consistent with the results of RPM3.1 (DTN: MO9910MWDISMRP.002 [DIRS 145731])).

\section{Ch5 (lower $1 / 4$ of Tac)}

The vitric region is initially defined by RPM3.1 (DTN: MO9910MWDISMRP.002 [DIRS 145731]) $\mathrm{K}_{\mathrm{s}}$ data and rock-property data from boreholes SD-6, SD-12, G-3, H-3, and H-5. No rock-property data are available for SD-6 (DTN: GS980808312242.014 [DIRS 106748]) within this unit (corresponding to a depth interval of 499.3-507.2 m). While SD-7 lies within the vitric region as defined by RPM3.1 (DTN: MO9910MWDISMRP.002 [DIRS 145731]), rock-property data (DTN: GS951108312231.009 [DIRS 108984]) for samples from this borehole within the ch5 interval (depths of 465.4-477.7 $\mathrm{m}$ ) indicate elevated saturation values (87-100 percent, average 97 percent) and differences in oven-dried and relative-humidity 
porosities typically greater than 5 percent, suggesting that this borehole lies within the zeolitic zone. The Dune (West 1) fault system was used to bound a portion of the eastern margin of the vitric zone, and the Solitario Canyon fault was assumed to form the western boundary of the vitric zone for this unit.

\section{Ch6 (Tacbt)}

The vitric region of ch6 is defined by the observed distribution of the vitric region in the overlying ch5 layer, rock-property data from borehole SD-6, and the indication from the corroborative data sources MM3.1 (DTN: MO9910MWDISMMM.003 [DIRS 119199]) and RPM2000 (DTN: SN0112T0501399.004 [DIRS 159524]) that the area around G-3 (located just outside of the southern UZ model area boundary) is also vitric. RPM3.1 (DTN: MO9910MWDISMRP.002 [DIRS 145731] does not suggest the presence of a vitric region for ch6. Rock-property data for SD-6 (DTN: GS980808312242.014 [DIRS 106748]) within this unit show low saturations (54-67 percent), and differences in oven-dried and relative-humidity porosities less than 5 percent in one of two samples, indicating that the ch6 interval in this borehole is vitric. The hydraulic conductivity value $\left(1.2 \times 10^{-9} \mathrm{~m} / \mathrm{s}\right)$ reported for borehole SD-6 (DTN: GS98090831224.038 [DIRS 107154]) is greater than $10^{-10} \mathrm{~m} / \mathrm{s}$, consistent with the vitric interpretation. The Solitario Canyon fault was assumed to form the western boundary of the vitric zone for this unit.

\subsection{DUAL-PERMEABILITY GRID GENERATION}

The software program 2kgrid8.for V1.0 (LBNL 2002 [DIRS 154787]) generates dual-k numerical grids for heterogeneous, fractured rocks. The 2kgrid8.for V1.0 generates a dual-k grid using (a) a primary single-continuum mesh (ECM grid) with 8-character element names, and (b) fracture properties for multiple hydrogeological units. The program is adapted from the software macro DKMgenerator V1.0 (LBNL 1999 [DIRS 140702]). The 2kgrid8.for V1.0 software is designed to handle three types of fractured media:

1. A set of parallel, infinite fractures (Type \#1, 1-D fracture continuum) with uniform spacing within each hydrogeological unit

2. Two sets of parallel, infinite, orthogonal fractures (Type \#2, 2-D fracture continuum) with the same spacing within each hydrogeological unit

3. Three sets of parallel, infinite, orthogonal fractures (Type \#3, 3-D fracture continuum) with the same spacing within each hydrogeological unit.

Volumes of fracture and matrix elements are computed with 2kgrid8.for V1.0 using the following formulas:

$$
\mathrm{V}_{\mathrm{f}}=\Phi_{\mathrm{f}} \mathrm{V}_{\mathrm{n}}
$$

and

$$
\mathrm{V}_{\mathrm{m}}=\left(1-\Phi_{\mathrm{f}}\right) \mathrm{V}_{\mathrm{n}}
$$


where $V_{f}$ and $V_{m}$ are volumes of fracture and matrix elements, respectively, for the dual-k grid, $\mathrm{V}_{\mathrm{n}}$ is the volume of element $\mathrm{n}$ of the primary mesh from which a dual-k grid is being generated, and $\Phi_{\mathrm{f}}$ is the fracture porosity or fractional volume of fractures within the bulk rock.

The connection information in the dual-permeability grid is determined as follows:

- Global fracture-fracture and matrix-matrix connection data are kept the same as the connections in the primary mesh for the corresponding gridblocks. This implies that permeabilities used for both fracture and matrix systems are the "continuum" values for both, relative to the grid connections for the primary mesh.

- Inner-connection distances between fractures and matrix within a primary gridblock are calculated as:

$$
\begin{gathered}
D_{f}=0 \\
D_{m}=\frac{D}{6} \quad \text { for Type \#1 fractures } \\
D_{m}=\frac{D}{8} \quad \text { for Type \#2 fractures } \\
D_{m}=\frac{D}{10} \quad \text { for Type \#3 fractures }
\end{gathered}
$$

and

$$
\mathrm{D}=\frac{1}{\mathrm{~F}}
$$

where $D_{f}$ is the distance from the fracture center to the surface of a matrix block; $D_{m}$ is the calculated distance from the fracture/matrix interface to the matrix node, based on the quasi-steady state assumption ("The Behavior of Naturally Fractured Reservoirs" [Warren and Root 1963 (DIRS 100611), p. 247] and GMINC - A Mesh Generator for Flow Simulations in Fractured Reservoirs [Pruess 1983 (DIRS 100605), Table 1]); D is the fracture spacing; and $\mathrm{F}$ is the fracture frequency within the unit.

The interface area (A) between fractures and matrix blocks is estimated by:

$$
\mathrm{A}=\mathrm{A}_{\mathrm{fm}} \mathrm{V}_{\mathrm{n}}
$$


where $A_{f m}$ is a volume-area factor, which represents the total fracture-matrix interface area per unit volume of rock, determined from site fracture characterization studies. Fracture properties incorporated in the UZ model are listed in Table 4-2. Only Type \#1 fractures were used in the generation of dual-k numerical grids.

The program 2kgrid8.for V1.0 must first be compiled using a FORTRAN compiler to create the executable file for the operating platform. Three input files are required to run 2kgrid8.for V1.0. These files are called 2kgrid.dat, connec.dat, and framtr.dat, and contain the following information:

1. The 2kgrid.dat file contains the two parts (ELEME and CONNE data blocks) from the primary single-continuum mesh using the same formats.

2. The connec.dat file contains connection indexes generated from the primary single-continuum mesh using the same formats.

3. The framtr.dat file contains fracture properties (DTN: LB0205REVUZPRP.001 [DIRS 159525] and DTN: LB0207REVUZPRP.001 [DIRS 159526]) with the following format and data (where (i) represents 1 up to the total number of rock types):

Format (A5,5X,4(E10.3))

urock(i), volf(i), xxx, dspac(i), afm_v(i)

urock(i) rock type name as rock(i)

volf(i) porosity or volume fraction of fractures within bulk rock

xxx aperture, not used

dspac(i) fracture frequency

afm_v(i) a volume-area factor, representing the total fracture-matrix area per unit volume rock, as determined from site fracture characterization studies.

Execution of "2kgridv1" creates three output files:

1. The 2kgrid.out file contains information from the primary mesh and new dual-k meshes for grid verification purposes.

2. The eleme.dat file contains "ELEME" data blocks for the new dual-k grid.

3. The conne.dat contains "CONNE" data blocks for the new dual-k grid.

\subsection{GRID VERIFICATION}

This report presents the grids to represent the geological framework model, refined from borehole data for the unique representation of Yucca Mountain. Because alternative geologic models were not developed in the geologic framework model report (BSC 2004 [DIRS 170029], 
Section 6.4.1), no alternative grids are presented in this report (see Section 4.1). The grids are intended for use by the UZ model for site-scale flow and transport processes. Numerical grids are fixed objects, or frameworks, that alone do not capture physical processes or phenomena occurring at Yucca Mountain. As such, the process of "model validation," in the usual sense, does not apply. However, the process of grid "verification"-an evaluation of how accurately the numerical grid represents the geologic and hydrogeologic input-does apply, and is discussed in this section.

The parameters generated for each numerical grid include gridblock material names, gridblock volumes and locations, connection lengths and interface areas between gridblocks, and direction of absolute permeability for each connection. Because of the number and size of the numerical grids developed for UZ model activities, it is not practical to verify each parameter for each gridblock generated. Consequently, a subset of gridblocks from each mesh is taken, and the associated parameters are verified to ensure the accuracy and representativeness of the mesh. The criteria by which the numerical grids are evaluated are not as rigorous as, for example, those specified for engineering design. This is because of the simplified approximation and large uncertainty inherent in modeling studies, where variations in modeling results up to an order of magnitude may be considered acceptable.

For the 1-D numerical grids (Output-DTN: LB02081DKMGRID.001), which consist of columns of gridblocks at borehole locations only, gridblock material names and elevations are verified through comparison with stratigraphic information from GFM2000 (see Appendix B for details). For the 2-D cross-sectional grids through borehole UZ-7a (Output-DTN: LB02081DKMGRID.001), gridblock material names and elevations are verified through visual comparison with stratigraphic and structural information from GFM2000 exported surface horizons (see Appendix $\mathrm{C}$ for details). For the 3-D UZ model grids (Output-DTN: LB03023DKMGRID.001) for calibration and calculation of flow fields, gridblock material names and elevations are verified through comparisons at borehole locations with the GFM2000 file contacts00el.dat (see Appendix A, GFM2000 files) and through visual comparison with stratigraphic and structural information from GFM2000 exported surface horizons (see Appendix C for details).

A spot check involving hand calculation of gridblock volumes, connection lengths, and interface areas between gridblocks showed consistency with calculated results for all UZ model grids generated. A spot check of the direction of connectivity confirmed vertical connections for all connections within gridblock columns (except for columns associated with nonvertical faults, where the $x-y$ locations of grid nodes can vary with depth). These spot checks are documented in the scientific notebook by Hinds and Dobson (2004 [DIRS 170886], p. 93).

An additional test of the 3-D grid was performed through the use of a TOUGH2 V1.4 (LBNL 2000 [DIRS 146496]) simulation. For this fully saturated isothermal $\left(25^{\circ} \mathrm{C}\right)$ simulation, all gridblocks were assigned the same rock properties and an initial fluid pressure of 500 bars. Several large volume gridblocks at the base of the grid were assigned constant pressures, and the remainder of the grid was allowed to attain equilibrium pressure conditions over time. Thus, for an ideally configured grid, there should be a linear relation between gridblock elevations and steady-state pressures. Small deviations from this relation were observed for the gridblocks in inclined fault columns, where vertical connections between gridblocks deviate from $90^{\circ}$. The 
shift in pressure for a given elevation for these gridblocks is a function of the relative deviation from vertical for the fault columns, with more inclined faults exhibiting a greater deviation from the predicted pressure. A more detailed discussion of this simulation is presented in Appendix C.

\section{Corroborative Studies}

Sensitivity studies that examine the effect of grid resolution (i.e., gridblock size) on flow and transport simulation results were documented in FY97 ("Grid Generation and Analysis" [Haukwa and Wu 1997 (DIRS 107934)]; "Modeling Study of Moisture Flow Using a Refined Grid Model” [Haukwa et al. 1997 (DIRS 101243)]) and FY98 (UZ Modeling and Synthesis [Zhang 2000 (DIRS 159531), pp. 52 to 56 and 66 to 72)]) UZ models, and are summarized below as corroborative material for this report.

FY97 UZ Model Sensitivity Study-Both coarse and refined 2-D, cross-sectional grids of the UZ at Yucca Mountain were developed by Haukwa and Wu (1997 [DIRS 107934], pp. 4-12 to 4-13) to address concerns over the use of appropriate numerical grid resolution in UZ moisture flow modeling. The cross sections were developed along a north-south (N-S) transect through the repository area, extending from borehole G-2 in the north to borehole G-3 in the south. The coarse grid used an average horizontal spacing of $50 \mathrm{~m}$ within the repository area and $100 \mathrm{~m}$ outside the repository area. The fine grid used a horizontal spacing as small as $6 \mathrm{~m}$ within the repository area and as high as $50 \mathrm{~m}$ outside the repository area. The coarse grid was comprised of 23 vertical layers; the refined grid had 61 layers (Haukwa et al. 1997 [DIRS 101243], pp. 12-2 to 12-3). Identical layer-averaged rock properties were used in both grids. From comparison of flow simulation results using the coarse and refined grids, it was concluded by Haukwa et al. (1997 [DIRS 101243], p. 12 to 16) that the coarser lateral grid resolution was sufficient for ambient site-scale flow modeling purposes.

Results indicated that moisture flow occurs predominantly in fractures (and thus is vertical) (Haukwa et al. 1997 [DIRS 101243], p. 12-4), except where zeolites are present, suggesting that modeling results are less sensitive to lateral gridblock dimensions than to vertical changes in grid resolution, unless a sudden change in rock hydrogeologic properties occurs at a layer contact, resulting in significant lateral diversion. Below the repository horizon, lateral diversion is most likely to occur above zeolites in the CHn. Calculated saturation and percolation flux distribution could be adequately resolved by adding a few grid layers at the PTn-TSw interface and at the vitric-zeolitic interfaces within the $\mathrm{CHn}$, since these are transitional areas where rock properties change rapidly over short distances.

The current (FY02) 3-D UZ model is vertically resolved with about 57 layers in the repository footprint; about 26 of these layers are above the repository horizon, 5 layers are within the repository horizon, and about 26 layers lie between the repository horizon and the water table). The transitional areas at the PTn-TSw and vitric-zeolitic interfaces are generally captured by several thin layers.

FY98 UZ Model Sensitivity Study - In this study, the influence of gridblock size on flow and transport simulation results was examined along an east-west (E-W) cross section through borehole SD-9. Four meshes, each with a different nominal gridblock size, were developed along 
the east-west transect (for details, refer to UZ Modeling and Synthesis [Zhang 2000 (DIRS 159531), pp. 52 to 56 and 66 to 72]). Three simulation scenarios were considered in this study. In the first simulation scenario (Scenario \#1), no modifications are made to the calibrated FY98 hydrogeologic property sets to represent perched water. In the second simulation scenario (Scenario \#2), FY98 calibrated perched-water hydrogeologic properties are used. In the third simulation scenario (Scenario \#3), perched-water properties are used, but fracture flow is ignored in zeolitic units (except in fault zones). Both conservative and reactive tracers are considered in the transport simulations for each of the three scenarios.

Under the conditions prescribed in Scenario \#1 (no perched water), the effect of gridblock size is minimal. Results from the coarsest of the four cross-sectional grids (which has a nominal horizontal spacing of $112 \mathrm{~m}$ and a maximum layer thickness of $60 \mathrm{~m}$ ) compared with the results from the finest of the four cross-sectional grids (which has a nominal horizontal spacing of $28 \mathrm{~m}$ and a maximum layer thickness of $15 \mathrm{~m}$ ) show an approximate 20 percent difference in the time at which half of the tracer mass (both conservative and reactive) reaches the water table.

Under the conditions prescribed in Scenario \#2 (perched water), model results for the coarsest mesh and finest mesh show differences of about 10 percent in the time at which half of the tracer mass reaches the water table for conservative tracers. For reactive tracers, results for the coarsest mesh differ from those for the finest mesh by a factor of two.

Under the conditions prescribed in Scenario \#3 (perched water, no fractures in zeolitic units), the effect of gridblock size is once again minimal. Results from the coarsest of the four cross-sectional grids compared with the results from the finest of the four cross-sectional grids show an approximate 20 percent difference in the time at which half of the conservative tracer mass reaches the water table, as well as an approximate 15 percent difference in the time at which half of the reactive tracer mass reaches the water table.

The results of this FY98 modeling study suggest that the numerical grid resolution used in the FY02 site-scale UZ model grids, at least within the repository area, is appropriate for capturing important flow and transport phenomena.

\subsection{LIMITATIONS AND UNCERTAINTIES}

The numerical grids developed in this report are intended for use in mountain-scale flow and transport modeling of the Yucca Mountain UZ system. A model of a complex system such as Yucca Mountain must be used with recognition of its limitations. For the site-scale UZ model, a key limitation is imposed by numerical grid resolution. Since computational time rapidly increases with grid size (i.e., number of gridblocks and connections), the use of large refined grids is currently limited by both simulation time and computational processing requirements. Refining an entire 3-D model with gridblocks having dimensions roughly equivalent to the expected drift spacing in the repository and using comparably refined vertical resolution would increase current grid sizes by more than an order of magnitude. Thus, it is not feasible at the mountain scale to characterize flow behavior on horizontal scales less than a few tens of meters. Current lateral resolution (up to $300 \mathrm{~m}$ in areas outside the repository boundary) can sometimes lead to high aspect ratios within very thin layers. This may lead to inaccuracies when trying to 
calculate lateral flow components; however, fracture spacing and orientation data suggest that groundwater flow is primarily downward, except within the altered tuffs.

Previous modeling studies at Yucca Mountain have established that sufficient vertical grid resolution is critical to capturing important flow and transport processes, such as lateral flow (Wu et al. 2002 [DIRS 161058]; BSC 2001 [DIRS 155950], Sections 3.3.3.4.2 and 3.3.4.8.1). Wu et al. (2002 [DIRS 161058]) evaluated the effect of grid refinement on percolation fluxes and noted that simulations using a vertical grid spacing of $10 \mathrm{~m}$ within the PTn were unable to resolve the effects of lateral flow. In contrast, the use of a more refined grid with a maximum vertical spacing of $2 \mathrm{~m}$ within the PTn could capture the capillary barrier effects of ptn21 and ptn23, resulting in significant lateral flow. The results of this sensitivity study were used to design the current numerical grids by employing a variable maximum vertical grid spacing with enhanced grid resolution within the PTn (See Section 6.6 for details).

The impact of utilizing nonorthogonal grids on TH modeling at Yucca Mountain was evaluated by Haukwa et al. ("Modeling Thermal-Hydrological Response of the Unsaturated Zone at Yucca Mountain, Nevada, to Thermal Load at a Potential Repository” [2003 (DIRS 165165)]). With a nonorthogonal grid, cross-term contributions in the numerical discretization are neglected because of vertical separation of laterally connected nodes. A comparison of simulations conducted using orthogonal and nonorthogonal grids for the Yucca Mountain UZ system (where represented layers typically have dips less than $10^{\circ}$; see Section 6.6) indicated little impact on both steady-state and transient solutions, because the cross-term connections contribute less than 6 percent to the total flux. As mentioned in Section 6.8 and Appendix C, the use of non-vertical columns for inclined faults does lead to some deviations in the flow behavior for the affected grid blocks.

The accuracy of UZ model grids depends largely on the accuracy of the GFM2000 (DTN: MO0012MWDGFM02.002 [DIRS 153777]) and RPM3.1 (DTN: MO9910MWDISMRP.002 [DIRS 145731]) input data. Both of these models, which are assumed to provide a representative picture of subsurface geology and rock properties, are constructed with limited data resources. GFM2000 includes assumptions about the lateral continuity and thickness trends of layers at Yucca Mountain based on limited borehole data. The UZ model numerical grids attempt to match this layered approach as closely as possible to constrain UZ flow and transport processes. While the degree of lateral continuity of layers represented in GFM2000 is a valid interpretation, the impact of more lateral discontinuity resulting from the inclusion of small faults on flow could be significant, especially in areas where little or no information has been collected. However, these areas typically lie too far from the repository area to have any significant impact on repository performance.

The GFM2000 bedrock surface (s00bedrockRWC.2grd; listed in GFM2000 files in Appendix A) was used to define the upper boundary of the UZ model grids (see Section 6.4.2). The use of the bedrock surface thus results in the exclusion of alluvial cover from the model. In the area of the repository, bedrock is typically exposed at the surface, with alluvium confined to washes and other topographic lows (BSC 2004 [DIRS 170029]), Figure 6-10). Because alluvial cover is mostly absent above the repository, any insulating effects of this material are likely to be minimal. Sensitivity studies to test the effect of alluvial cover on thermal modeling are not within the scope of this report. 
Within RPM3.1 (DTN: MO9910MWDISMRP.002 [DIRS 145731]), the interpretation of saturated hydraulic conductivity $\left(\mathrm{K}_{\mathrm{s}}\right)$ distribution and mineral alteration at Yucca Mountain is also based on limited data and assumed correlations (e.g., using porosity as a surrogate for predicting $\mathrm{K}_{\mathrm{s}}$ ). The spatial heterogeneity of low-permeability alteration products such as zeolites has a profound impact on UZ flow and transport modeling, yet the nature of their distribution is not fully understood. Though currently represented per hydrogeologic layer (i.e., UZ model layers tsw39, ch1, ch2, ch3, ch4, ch5, and ch6), true mineral alteration and rock-property variation may not strictly follow a layered model. While a variety of geologic and rock property data were used to define vitric-zeolitic boundaries (see Sections 5.2 and 6.6.3), the location of vitric to zeolitic transitions are not concisely resolved.

Grid verification exercises show that UZ model layer thicknesses and elevations are reasonable representations of the hydrogeologic input data. Using visual cross-sectional comparisons with GFM2000 (DTN: MO0012MWDGFM02.002 [DIRS 153777]), UZ model layer contact elevations are shown to have some large (up to $50 \mathrm{~m}$ ) differences in areas immediately adjacent to inclined fault zones, reflecting the coarse lateral grid resolution used as well as certain limitations of the gridding software. The effect of the differences in layer contact elevations along faults on modeling results has yet to be determined, but is likely limited in extent to the area immediately surrounding the fault zones. Given the large uncertainties associated with fault zone hydrogeologic characteristics, additional hydrogeologic property data and analyses within fault zones would reduce uncertainty in this area.

There are some limitations relating to the modeling of faults in the UZ model grids. As noted earlier (Section 6.6.1), faults cannot be modeled as intersecting features. To simplify the model, subsidiary faults related to the Solitario Canyon fault ("Splay N," "Splay G," "Splay S," and the Solitario [west] faults) were omitted from the UZ model grids because of their proximity to the dipping Solitario Canyon fault (making them difficult to incorporate as separate features to the model). Faults observed within the ESF and ECRB that are not part of the GFM2000 (owing to either insufficient length or offset) are also not incorporated in the UZ model grid.

As mentioned in Section 6.6.2, the repository design used for the UZ model numerical grid generation (BSC 2002 [DIRS 159527]) was the most recent representation of the repository layout at the time the grids were generated. The repository layout may be subject to design modifications. The most recent revision of the repository layout (BSC 2004 [DIRS 164519]) does not include the lower block area (see Sections 4.1 and 6.6.2). If additional design changes are made, the numerical grids should be evaluated to ensure that sufficient grid resolution in the area of the repository exists.

\subsubsection{Water Table Uncertainty}

The water table by definition forms the base of the UZ (Sections 4.1, 6.2, and 6.4.2). The potentiometric-surface map as defined by USGS (2004 [DIRS 168473], Figure 6-1) was constrained by borehole water levels in the Yucca Mountain area (USGS 2004 [DIRS 168473], Table I-1). Contours for this map were hand-drawn to conform to the borehole water levels, assuming that the measured water level in WT-24 represents the regional water table, whereas the water levels in boreholes G-2 and WT-6 represent perched conditions. The water table is well constrained in the area near the ESF where abundant borehole data exist, but is poorly 
constrained to the north and west, where there are very few control points and the potentiometric surface has a higher gradient. Thus, any definition of the water table elevations will inevitably include some uncertainty, especially in the areas where few borehole constraints are available.

The water table is defined in the qualified DTN: GS010608312332.001 [DIRS 155307] through the use of borehole locations and their associated water table elevations and potentiometric map contours. The DTN: GS010608312332.001 [DIRS 155307] from USGS 2004 [DIRS 168473] contains the ARCINFO files pot_contours.e00 and wells.e00. The layer "GWL_SSPAC" in the Vulcan GFM2000 Representation database (DTN: MO0110MWDGFM26.002 [DIRS 160565]) was derived by digitizing the contours depicted on the potentiometric surface map included in $F Y$ 01 Supplemental Science and Performance Analyses, Volume 1: Scientific Bases and Analyses (BSC 2001 [DIRS 155950], Figure 12.3.1.2-2), which appears to be identical to that presented in USGS (2004 [DIRS 168473], Figure 6-1). The data defining this layer (contours and borehole coordinates) were then extracted and the resulting data set ( $\left.g w l \_s s p a c 2 . a s c\right)$ was submitted to the Technical Data Management System as DTN: MO0212GWLSSPAX.000 (DIRS 161271). (See Attachment IV of Development of Numerical Grids for UZ Flow and Transport Modeling [BSC 2003 (DIRS 160109)] for details). This representation of the water table was qualified using the procedure AP-SIII.2Q, Qualification of Unqualified Data and the Documentation of Rationale for Accepted Data and the Data Qualification Plan found in the Technical Work Plan for: Performance Assessment Unsaturated Zone (BSC 2002 [DIRS 160819], Attachment III). The data qualification reviews for DTN: MO0212GWLSSPAX.000 [DIRS 161271] are presented in Attachment IV of Development of Numerical Grids for UZ Flow and Transport Modeling (BSC 2003 [DIRS 160109]).

The file gwl_sspac2.asc was used as input for the generation of the UZ water table reference horizon (see Section 6.4.2 for details). Data files in DTNs: GS010608312332.001 [DIRS 155307] and MO0212GWLSSPAX.000 [DIRS 161271] both contain water table contours, but these contours do not uniquely define a surface from which regularly spaced water table data could be obtained. Thus, the digitized potentiometric contour data and borehole water-level data must be used to create a numerical surface to facilitate production of a regularly spaced set of water table elevations.

The $x, y$ data contained in the ARCINFO files (DTN: GS010608312332.001 [DIRS 155307]) are given in Universal Transverse Mercator coordinates, whereas those from the gwl_sspac2.asc file (DTN: MO0212GWLSSPAX.000 [DIRS 161271]) are in NSP meters. The ARCINFO file pot_contours.e00 was modified using a text editor so that it could be read as a ".dat" file in EARTHVISION V5.1 (Dynamic Graphics 2000 [DIRS 167994]). The coordinate transformation utility of EARTHVISION V5.1 was used to convert the Universal Transverse Mercator coordinates to NSP coordinates. Elevation values were then assigned to each point on the basis of visual comparison to the potentiometric map in the report, Water-Level Data Analysis for the Saturated Zone Site-Scale Flow and Transport Model (USGS 2004 [DIRS 168473], Figure 6-1). The contour line locations were then compared with those extracted from the Vulcan database, and significant deviations in water table elevations between the data sets were observed in areas north (up to $60 \mathrm{~m}$ ) and northwest (up to $30 \mathrm{~m}$ ) of the ESF within the UZ model grid area. These variations may result from errors associated with the digitization of the contour lines. 
The data from these two sources were imported into EARTHVISION V5.1 (Dynamic Graphics 2003 [DIRS 171007]) to construct gridded surfaces to permit more rigorous comparison of the data (Hinds and Dobson 2004 [DIRS 170886], pp. 110 to 115). Borehole water table data included in the input file converted from Vulcan were appended to the modified ARCINFO file (which contained only water table contour data), with the only modification being that SD-7 was removed from the input data set, as it was considered to be unreliable in the report, Water-Level Data Analysis for the Saturated Zone Site-Scale Flow and Transport Model (USGS 2004 [DIRS 168473], Table I-3). Using the 2-D minimum tension gridding utility in EARTHVISION V5.1, the data were coarsely gridded and then finely gridded, using the same steps as outlined in Section 6.4.2 that were employed to create the water table utilized for numerical grid generation. The contoured water table surfaces created in EARTHVISION V5.1 using the two data sets are displayed in Figure 6-9.

(a)

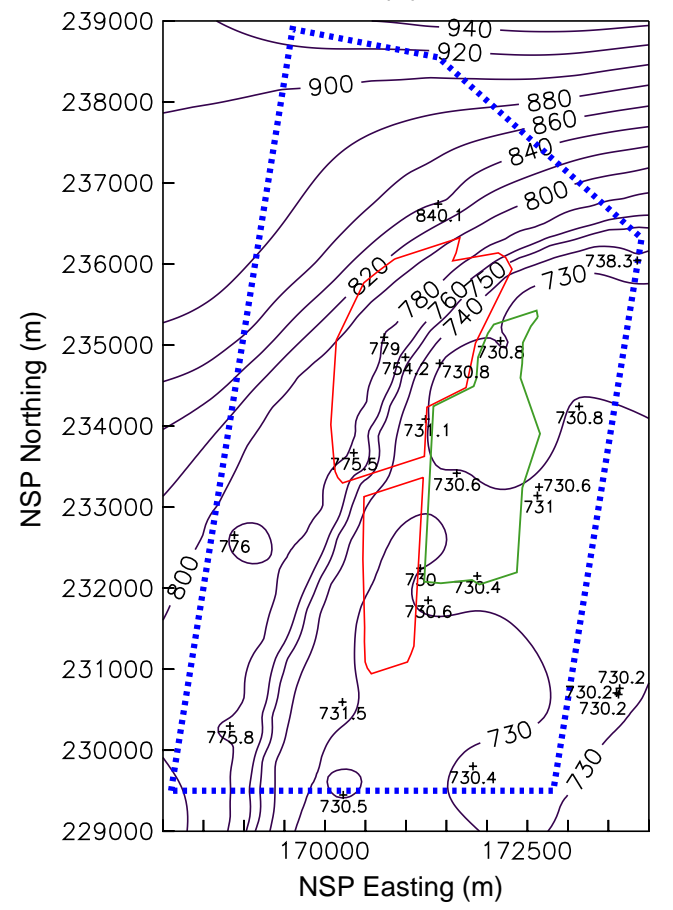

(b)

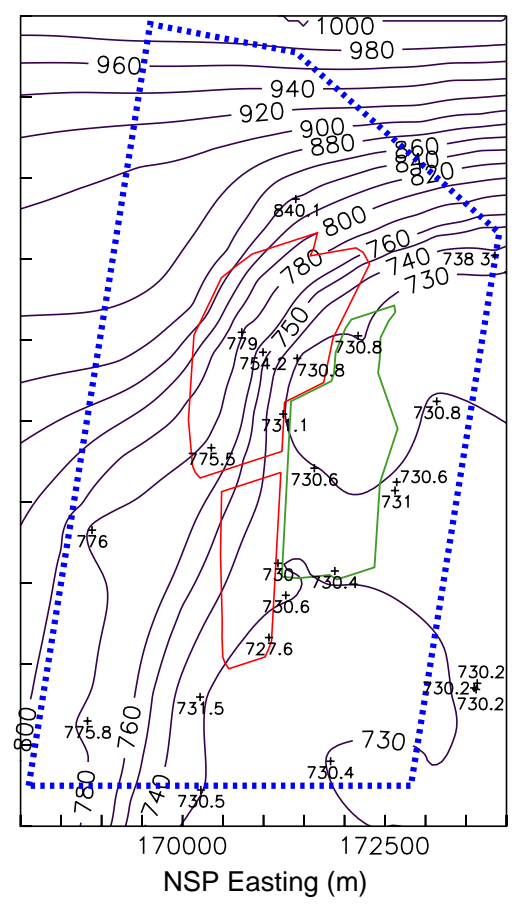

\begin{tabular}{|c|c|c|}
\hline LEGEND & & \\
\hline 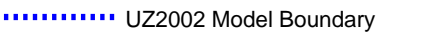 & $-900-$ & Water Table Elevation Contours (m) \\
\hline 2002 Repository Boundary & +727.6 & $\begin{array}{l}\text { Boreholes with Water Table } \\
\text { Elevations }(\mathrm{m})\end{array}$ \\
\hline
\end{tabular}

DTNs: (a) GS010608312332.001 [DIRS 155307]

(b) MO0212GWLSSPAX.000 [DIRS 161271].

NOTE: Part (a) depicts surface created using water table data from DTN: GS010608312332.001 and part (b) depicts surface created using water table data from DTN: MO0212GWLSSPAX.000. 2002 Repository Lower Block will not be used in any LA calculations.

Figure 6-9. Comparison of EARTHVISION V5.1 Gridded Potentiometric Surfaces 
Because neither data set uniquely defines a water table that could be used to extract a set of regularly spaced data needed for creating the numerical grids, creating a numerically defined surface in EARTHVISION V5.1 through gridding of the borehole water table elevations and potentiometric surface contour lines was necessary. The two-step process used to create the fine-spaced grid (see Section 6.4.2) does result in small changes in the appearance of the contoured surface, such as the creation of a small ridge in the potentiometric surface where the water table is around $730 \mathrm{~m}$ elevation. Such features are artifacts of the irregularly spaced input data and the use of 2-D minimum tension gridding, and result in minor shifts in the water table. As mentioned in Section 6.4.2, the resulting regularly spaced data set was edited to have a minimum water table elevation of $730 \mathrm{~m}$, and thus the final numerical grids generated by WINGRIDDER V2.0 (LBNL 2002 [DIRS 154785]) have a lower boundary no lower than $730 \mathrm{~m}$. Both contoured surfaces are consistent with the measured borehole water table elevations; however, significant differences exist between the locations of the contour lines used to define the potentiometric surface. These differences translate into significant deviations (up to $60 \mathrm{~m}$ ) in the water table elevations in the areas to the north and west, where there is a pronounced gradient to the water table and few borehole constraints. In general, the water table elevations as indicated by DTN: MO0212GWLSSPAX.000 [DIRS 161271] (the data set used to define the base of the UZ model grids) are higher than the corresponding elevations from DTN: GS010608312332.001 [DIRS 155307], resulting in a shorter distance for radionuclide transport through the UZ. 


\section{INTENTIONALLY LEFT BLANK}




\section{CONCLUSIONS}

Data from the GFM2000 geological model (DTN: MO0012MWDGFM02.002 [DIRS 153777]) were integrated with HGUs defined by Flint (1998 [DIRS 100033]) and adjusted using rock-property data, contained in ISM3.1 and from boreholes, to create integral finite-difference numerical grids for the UZ at Yucca Mountain. The layer subdivision and assignment of material properties resulted in numerical grids that are appropriate for UZ flow and transport modeling.

Results from the development of numerical grids (Tables 6-1 and 7-1) to simulate the UZ at Yucca Mountain include:

- One primary mesh and one dual-k mesh consisting of 1-D columns at borehole locations (Output-DTN: LB02081DKMGRID.001) used for developing calibrated hydrogeologic property sets for the UZ at Yucca Mountain.

- One primary mesh and one dual-k mesh comprising a 2-D cross section through borehole UZ-7a (Output-DTN: LB02081DKMGRID.001) used to calibrate fault hydrogeologic properties in the UZ at Yucca Mountain.

- One primary mesh and one dual-k mesh (Output-DTN: LB03023DKMGRID.001) used for 3-D UZ model calibration and to generate 3-D UZ flow fields for Performance Assessment.

These grids were verified for accuracy by inspection of gridblock material names, volumes, location, interface areas, and connection length and direction. The grids were also verified against known stratigraphy in reference boreholes and the GFM2000 (DTN: MO0012MWDGFM02.002 [DIRS 153777]). The results show that the resulting 1-D, 2-D, and 3-D grids accurately reflect the stratigraphy and structural features of GFM2000, with contact elevations and unit thicknesses usually within $5 \mathrm{~m}$ of those of GFM2000. Larger deviations may occur in the vicinity of faults with large vertical offsets or with nonvertical fault slopes.

- Corroborative sensitivity studies show that the grids developed are valid and appropriate for UZ flow and transport modeling. The FY02 UZ model grids incorporate closer spacing of layers (maximum of $5 \mathrm{~m}$ ) for the PTn units (where lateral flow may occur), the repository, and the unit ch1, thus allowing for adequate resolution of flow and transport phenomena within the UZ.

\subsection{LIMITATIONS AND UNCERTAINTIES}

The numerical grids developed in this report are only intended for use in mountain-scale flow and transport modeling of the Yucca Mountain UZ system, a limitation imposed by the spatial configuration and resolution of these grids. Grid uncertainty depends in large part on the accuracy of the direct input data (Section 4.1) utilized to create the grids, namely: (1) the geologic framework model (DTN: MO0012MWDGFM02.002 [DIRS 153777]) used to create the grid layers and faults; (2) rock property data used to delineate vitric and zeolitic subunits; 
(3) the definition of the water table, which forms the base of the UZ model area, and; (4) the configuration of the repository. These and other limitations and uncertainties are discussed in greater detail in Sections 6.9 and 6.9.1.

\subsection{SATISFACTION OF ACCEPTANCE CRITERIA}

The following information describes how this analysis addresses the acceptance criteria in the Yucca Mountain Review Plan, Final Report (NRC 2003 [DIRS 163274], Sections 2.2.1.3.6.3 and 2.2.1.3.7.3). Only those acceptance criteria that are applicable to this report (see Section 4.2) are discussed. In most cases, the applicable acceptance criteria are not addressed solely by this report; rather, the acceptance criteria are fully addressed when this report is considered in conjunction with other analysis and model reports that describe flow and transport in the unsaturated zone.

\section{Acceptance Criteria from Section 2.2.1.3.6.3, Flow Paths in the Unsaturated Zone}

\section{Acceptance Criterion 1: System Description and Model Integration Are Adequate.}

Subcriterion (1): The development and construction of the numerical grids described in this report adequately incorporate important physical phenomena such as fault geometries, stratigraphy, fracture hydrogeologic property data, and vitric/zeolitic boundaries as described in Sections 4.1, 5, and 6.2 through 6.6. Consistent and appropriate assumptions discussed in Sections 5.1 and 5.2 were adopted to model the geologic and hydrologic data integrated in the grids.

Subcriterion (2): The key aspects of the geology and hydrology for the UZ model area at Yucca Mountain that may affect flow paths in the unsaturated zone have been incorporated into numerical grids that were generated for UZ flow and transport modeling. Lithostratigraphic and fault geometry data from the geologic framework model (GFM2000) (DTN: MO0012MWDGFM02.002 [DIRS 153777]) were used, together with the HGU definitions of Flint (1998 [DIRS 100033]), to create 2-and 3-D grids that resolve the hydrogeologic layers and faults (Sections 6.3 and 6.4). For units that have spatially variably hydrogeologic properties resulting from alteration (the lowermost Topopah Spring Tuff and the upper section of the Calico Hills Tuff), vitric and zeolitic subunits were identified through the use of rock property data from the rock properties model 3.1 (DTN: MO9910MWDISMRP.002 [DIRS 145731]) and selected boreholes (Section 6.6.3). Fracture hydrogeologic property data were used to generate dual-permeability meshes (Section 6.7) for use by downstream users for hydrogeologic property calibrations and 3-D UZ site-scale modeling (see Table 1-2 in Section 1). Conditions and assumptions supporting the abstraction of flow paths in the UZ are readily identified in Sections 5.1, 5.2, and 6.3 through 6.7.

Subcriterion (3): The numerical grid prepared for the site-scale 3-D model used to support the abstraction of flow paths in the unsaturated zone uses input from, and is therefore consistent with, the assumptions, technical bases, data, and models of the geologic framework model and the rock properties model. Both of these models are used as input for other abstractions. The descriptions and technical bases are traceable to site data through the geologic framework model and rock properties model and through extensive citations of borehole data and USGS data. The 
USGS (Flint 1998 [DIRS 100033], p. 1, Table 1) identified HGUs that are used to define the layering scheme used for the UZ model grids (Section 6.3).

Subcriterion (9): This report was developed in accordance with the QARD, which commits to NUREGs 1297 (Peer Review for High-Level Nuclear Waste Repositories: Generic Technical Position [Altman et al. 1988 (DIRS 103597)]) and 1298 (Qualification of Existing Data for High-Level Nuclear Waste Repositories: Generic Technical Position [Altman et al. 1988 (DIRS 103750)]). Moreover, compliance with the DOE procedures, which are designed to ensure compliance with the QARD, is verified by audits by QA and other oversight activities. Accordingly, the guidance in NUREGs 1297 and 1298 (Altman et al. 1988 [DIRS 103597 and DIRS 103750]) has been followed as appropriate.

\section{Acceptance Criterion 2: Data Are Sufficient for Model Justification.}

Subcriterion (1): The direct data inputs utilized in this report are appropriate for this study because they represent the key elements (geologic framework, hydrologic properties, UZ boundary, and repository layout) required for numerical grids used for UZ modeling at Yucca Mountain (Section 6.1). Data from the geologic framework model and rock properties model used in the development of these grids are adequately justified in the reports describing those models. Other data integrated specifically in this process are saturation, porosity, and hydraulic conductivity data obtained from a variety of boreholes within the UZ model domain. Sections 4.1, and 6.2 through 6.7 describe and adequately justify how the data were used, interpreted, and appropriately synthesized into the parameters.

Subcriterion (2): Table 4-1 provides references to the sources of geology, hydrology, and geochemistry data used in this report. Each of these data sets consist of data qualified in accordance to the requirements of the QARD, or as in the case of the repository layout, are design drawings prepared in accordance with governing procedures.

Subcriterion (6): As noted in Section 2, approved QA procedures identified in the TWP (BSC 2004 [DIRS 169654], Section 4) have been used to conduct and document the activities described in this scientific analysis report. Per Section 6.1.1, the latest procedures were used in the report development. The software used in this study, listed in Table 3-1, was obtained from Software Configuration Management, was appropriate for the intended application, and was used only within the range of validation in accordance with applicable software procedures.

Subcriterion (7): A summary of the numerical grids developed in this report for use in calibrating hydrogeologic properties and simulating flow and transport properties is presented in Section 6.1, Table 6-1. This table provides a summary description for each of the grids that shows that they are complete and incorporate relevant site characteristics. Details of the generation of the grids and incorporation of site data are presented in Sections 6.2 through 6.7. Section 6.8 summarizes results from corroborative studies that support the use of fairly coarse numerical grids to model flow and transport processes. 
Acceptance Criterion 3: Data Uncertainty Is Characterized and Propagated Through the Model Abstraction.

Subcriterion (1): Technically defensible parameters and bounding assumptions are employed in the development of these grids as described in Sections 5.1, 5.2, and 6.1 through 6.7. The results of previous modeling studies suggest that the numerical grid resolution used in the site-scale UZ model grids is appropriate for capturing important flow and transport phenomena within the proposed repository area. Parameters are primarily developed from site-specific physical data and conservative assumptions are adopted for the data and models employed. Therefore, use of these grids does not result in an under-representation of the risk estimate.

Subcriterion (4): Boundary conditions for the grids developed by this report are consistent with available data as described in Section 6.2. Parameter values are consistent with the initial and boundary conditions and the assumptions of the conceptual models for the Yucca Mountain site as verified by sensitivity studies that examine the effect of grid resolution (i.e., gridblock size) on flow and transport simulation results (Section 6.8).

Acceptance Criterion 4: Model Uncertainty Is Characterized and Propagated Through the Model Abstraction.

Subcriterion (1): Alternative sizes for the gridblocks were investigated and the final gridblock sizes reflect best scientific estimates of effective sizes that allow an accurate representation of site geological features. Uncertainties, limitations, and results of the grids developed in this report are discussed in Sections 6.9 and 7.1.

Subcriterion (3): Grid uncertainty depends primarily on the accuracy of the input data utilized to create the grids, namely: 1) the grid layers and faults from the geologic framework model; 2) rock property data used to delineate vitric and zeolitic subunits; 3 ) the definition of the water table, which forms the base of the UZ model area; and 4) the configuration of the proposed repository (Sections 6.9, 6.9.1, and 7.1). The geologic framework model and rock properties model reflect site data, field measurements and testing, laboratory experiments, and modeling studies. Because corroborative modeling studies suggest that the numerical grid resolution used in the site-scale grids is appropriate and the accuracy depends primarily on the input data, use of these grids should not result in an under-representation of the risk estimate (Sections 6.8, 6.9, and 7.1).

Acceptance Criteria from Section 2.2.1.3.7.3, Radionuclide Transport in the Unsaturated Zone

Acceptance Criterion 1: System Description and Model Integration Are Adequate.

Subcriterion (1): The development and construction of the numerical grids described in this report adequately incorporate important physical phenomena such as fault geometries, stratigraphy, fracture hydrogeologic property data, and vitric/zeolitic boundaries as described in Sections 4.1, 5, and 6.2 through 6.6. Spacing of the repository drifts is also considered in grid sizing (Section 6.1). Consistent and appropriate assumptions discussed in Sections 5.1 and 5.2 were adopted to model the geologic and hydrologic data integrated in the grids. 
Subcriterion (2): The key aspects of the geology and hydrology for the UZ model area at Yucca Mountain that may affect flow paths in the unsaturated zone have been incorporated into numerical grids that were generated for UZ flow and transport modeling. Lithostratigraphic and fault geometry data from the geologic framework model were used, together with HGU definitions, to create 2-and 3-D grids that resolve the hydrogeologic layers and faults (Sections 6.3 and 6.4). Vitric and zeolitic subunits were identified through the use of rock-property data from the rock properties model and selected boreholes (Section 6.6.3). Conditions and assumptions supporting the abstraction of flow paths in the UZ are readily identified in Sections 5.1, 5.2, and 6.3 through 6.7.

Subcriterion (3): The descriptions and technical bases for faults, stratigraphy, boreholes, grids generated, and geometries employed as given in Sections 6.1 through 6.8 provide transparent and traceable support for the abstraction of radionuclide transport in the unsaturated zone. The numerical grid prepared for the site-scale 3-D model uses input from, and is therefore consistent with, the assumptions, technical bases, data, and models of the geologic framework model and the rock properties model. Both of these models are used as input for other abstractions. The descriptions and technical bases are transparent and traceable to site data through the geologic framework model and rock properties model and through extensive citations of borehole data and USGS data. The USGS (Flint 1998 [DIRS 100033], p. 1, Table 1) identified HGUs that are used to define the layering scheme used for the UZ model grids (Section 6.3).

Subcriterion (4): Boundary conditions for the grids developed by this report are consistent with available data and conditions as described in Section 6.2 and are used to support the abstraction of radionuclide transport in the UZ and other related abstractions.

Subcriterion (5): Fractures, faults, stratigraphy, and topography and morphology (Table 1-1) are the features, events, and processes incorporated in these grids, which support the TSPA. Sufficient data and technical bases related to these features are provided in Sections 1, 4, and 6.2 through 6.7.

Subcriterion (6): This report was developed in accordance with the QARD, which commits to NUREGs 1297 and 1298 (Altman et al. 1988 [DIRS 103597 and DIRS 103750]). Moreover, compliance with the DOE procedures, which are designed to ensure compliance with the QARD, is verified by audits by QA and other oversight activities. Accordingly, the guidance in NUREGs 1297 and 1298 (Altman et al. 1988 [DIRS 103597 and DIRS 103750]) has been followed as appropriate.

\section{Acceptance Criterion 2: Data Are Sufficient for Model Justification.}

Subcriterion (1): The direct data inputs utilized in this report are appropriate for this study because they represent the key elements (geologic framework, hydrologic properties, UZ boundary, and repository layout) required for numerical grids used for UZ modeling at Yucca Mountain (Section 6.1). Data from the geologic framework model and rock properties model used in the development of these grids are adequately justified in the reports describing those models. 
Subcriterion (3): Table 4-1 provides references to the sources of geology, hydrology, and geochemistry data used in this report. Each of these data sets consist of data qualified in accordance to the requirements of the QARD, or as in the case of the repository layout, are design drawings prepared in accordance with governing procedures. These data reflect the Yucca Mountain site measurements and experiments, laboratory experiments, natural analogs, and process-level modeling studies (see documents listed in Section 4.1).

Acceptance Criterion 3: Data Uncertainty Is Characterized and Propagated Through the Model Abstraction.

Subcriterion (1): Technically defensible parameters and bounding assumptions are employed in the development of these grids as described in Sections 5.1, 5.2, and 6.1 through 6.7. These values are primarily developed from site-specific physical data and conservative assumptions are adopted for the data and models employed. Therefore, use of these grids does not result in an under-representation of the risk estimate.

Subcriterion (4): Uncertainty is adequately represented in parameter development for conceptual models employed in the grids through evaluation of how accurately the numerical grid represents the geologic and hydrogeologic input (Section 6.8). A subset of parameters from each mesh was selected and verified to ensure the accuracy and representativeness of the mesh. Sensitivity studies were also conducted to examine the effect of grid resolution (i.e., gridblock size) on flow and transport simulation results. These studies and verifications indicated that the mesh is appropriate to describe the Yucca Mountain repository area.

Acceptance Criterion 4: Model Uncertainty Is Characterized and Propagated Through the Model Abstraction.

Subcriterion (1): Alternative sizes for the gridblocks were investigated and the final gridblock sizes reflect best scientific estimates of effective sizes that allow an accurate representation of site geological features incorporated including faults and stratigraphy. Uncertainties, limitations, and results of the grids developed in this report are discussed in Sections 6.9 and 7.1.

Subcriterion (2): Grid uncertainty depends primarily on the accuracy of the input data utilized to create the grids, namely: 1) the grid layers and faults from the geologic framework model; 2) rock property data used to delineate vitric and zeolitic subunits; 3) the definition of the water table, which forms the base of the UZ model area; and 4) the configuration of the proposed repository (Sections 6.9, 6.9.1, and 7.1). Since modeling studies of the grids developed in this report indicate that the numerical grid resolution used in the site-scale grids is appropriate (Section 6.9), uncertainties will primarily reflect those of the input data.

Subcriterion (3): Grid uncertainty depends primarily on the accuracy of the input data utilized to create the grids, namely: 1) the grid layers and faults from the geologic framework model; 2) rock property data used to delineate vitric and zeolitic subunits; 3) the definition of the water table, which forms the base of the UZ model area; and 4) the configuration of the proposed repository (Sections 6.9, 6.9.1, and 7.1). The geologic framework model and rock properties model reflect site data, field measurements and testing, laboratory experiments, and modeling studies. Because corroborative modeling studies suggest that the numerical grid resolution used in the site-scale grids is appropriate and the uncertainty depends primarily on the input data, use 
of these grids should not result in an under-representation of the risk estimate (Sections 6.8, 6.9, and 7.1).

\subsection{RESTRICTIONS FOR SUBSEQUENT USE}

The UZ model numerical grids developed herein shall be used only for development of UZ hydrogeologic property sets, for UZ model calibration, and for development of UZ flow fields for Performance Assessment. These activities will involve the use of software from the TOUGH2 family of codes.

\subsection{TECHNICAL PRODUCT OUTPUT}

The technical product output files for this report have been submitted to the Technical Data Management System and are included in the following Output-DTNs in Table 7-1.

Table 7-1. Output DTNs from This Report

\begin{tabular}{|c|l|}
\hline \multicolumn{1}{|c|}{ DTN } & \multicolumn{1}{c|}{ Description } \\
\hline LB02081DKMGRID.001 & 1-D and 2-D UZ model calibration grid files \\
\hline LB0208HYDSTRAT.001 & Supporting files for the UZ model grid construction process \\
\hline LB02092DGRDVER.001 & Files for 2-D UZ model grid verification \\
\hline LB03023DKMGRID.001 & 3-D UZ model grid files \\
\hline
\end{tabular}




\section{INTENTIONALLY LEFT BLANK}




\section{INPUTS AND REFERENCES}

\subsection{DOCUMENTS CITED}

Altman, W.D.; Donnelly, J.P.; and Kennedy, J.E. 1988. Qualification of Existing

103750 Data for High-Level Nuclear Waste Repositories: Generic Technical Position. NUREG-1298. Washington, D.C.: U.S. Nuclear Regulatory Commission. TIC: 200652.

Altman, W.D.; Donnelly, J.P.; and Kennedy, J.E. 1988. Peer Review for High-Level 103597 Nuclear Waste Repositories: Generic Technical Position. NUREG-1297. Washington, D.C.: U.S. Nuclear Regulatory Commission. TIC: 200651.

Aurenhammer, F. 1991. "Voronoi Diagrams-A Survey of a Fundamental Geometric 160333 Data Structure.” ACM Computing Surveys, 23, (3), 345-405. New York, New York: Association for Computing Machinery. TIC: 240932.

BSC (Bechtel SAIC Company) 2001. Development of Numerical Grids for UZ Flow and Transport Modeling. ANL-NBS-HS-000015 REV 00 ICN 01. Las Vegas, Nevada: Bechtel SAIC Company. ACC: MOL.20020211.0002.

BSC 2001. FY 01 Supplemental Science and Performance Analyses, Volume 1:

Scientific Bases and Analyses. TDR-MGR-MD-000007 REV 00 ICN 01. Las Vegas, Nevada: Bechtel SAIC Company. ACC: MOL.20010801.0404; MOL.20010712.0062; MOL.20010815.0001.

BSC 2002. Repository Design, Repository/PA IED Subsurface Facilities Plan Sht. 159527 1 of 5, Sht. 2 of 5, Sht. 3 of 5, Sht. 4 of 5, and Sht. 5 of 5. DWG-MGR-MD-000003 REV A. Las Vegas, Nevada: Bechtel SAIC Company.

ACC: MOL.20020601.0194.

BSC 2002. Rock Properties Model Analysis Model Report. MDL-NBS-GS-000004 REV 00 ICN 03. Las Vegas, Nevada: Bechtel SAIC Company. ACC: MOL.20020429.0086.

BSC 2002. Technical Work Plan for: Performance Assessment Unsaturated Zone. TWP-NBS-HS-000003 REV 02. Las Vegas, Nevada: Bechtel SAIC Company. ACC: MOL.20030102.0108.

BSC 2003. Development of Numerical Grids for UZ Flow and Transport Modeling. ANL-NBS-HS-000015 REV 01. Las Vegas, Nevada: Bechtel SAIC Company. ACC: DOC.20030404.0005.

BSC 2004. Analysis of Hydrologic Properties Data. ANL-NBS-HS-000042, 170038 Rev. 00. Las Vegas, Nevada: Bechtel SAIC Company. 
BSC 2004. Calibrated Properties Model. MDL-NBS-HS-000003, Rev. 02.

Las Vegas, Nevada: Bechtel SAIC Company.

BSC 2004. D\&E / PA/C IED Subsurface Facilities. 800-IED-WIS0-00101-000-00A.

164519

Las Vegas, Nevada: Bechtel SAIC Company. ACC: ENG.20040309.0026.

BSC 2004. Features, Events, and Processes in UZ Flow and Transport.

170012

ANL-NBS-MD-000001, Rev. 03. Las Vegas, Nevada: Bechtel SAIC Company.

BSC 2004. Geologic Framework Model (GFM2000). MDL-NBS-GS-000002,

Rev. 02. Las Vegas, Nevada: Bechtel SAIC Company.

ACC: DOC.20040827.0008.

BSC 2004. Multiscale Thermohydrologic Model. ANL-EBS-MD-000049, Rev. 02. Las Vegas, Nevada: Bechtel SAIC Company.

BSC 2004. Q-List. 000-30R-MGR0-00500-000-000 REV 00. Las Vegas, Nevada: Bechtel SAIC Company. ACC: ENG.20040721.0007.

BSC 2004. Technical Work Plan for: Unsaturated Zone Flow Analysis and Model Report Integration. TWP-MGR-HS-000001 REV 00. Las Vegas, Nevada: Bechtel SAIC Company. ACC: DOC.20040701.0005.

BSC 2004. UZ Flow Models and Submodels. MDL-NBS-HS-000006, Rev. 02. Las Vegas, Nevada: Bechtel SAIC Company.

Buesch, D.C. and Spengler, R.W. 1999. “Correlations of Lithostratigraphic Features 107905 with Hydrogeologic Properties, a Facies-Based Approach to Model Development in Volcanic Rocks at Yucca Mountain, Nevada.” Proceedings of Conference on Status of Geologic Research and Mapping in Death Valley National Park, Las Vegas, Nevada, April 9-11, 1999. Slate, J.L., ed. Open-File Report 99-153. Pages 62-64. Denver, Colorado: U.S. Geological Survey. TIC: 245245.

Buesch, D.C.; Spengler, R.W.; Moyer, T.C.; and Geslin, J.K. 1996. Proposed Stratigraphic Nomenclature and Macroscopic Identification of Lithostratigraphic Units of the Paintbrush Group Exposed at Yucca Mountain, Nevada. Open-File Report 94-469. Denver, Colorado: U.S. Geological Survey.

ACC: MOL.19970205.0061.

Canori, G.F. and Leitner, M.M. 2003. Project Requirements Document. 166275 TER-MGR-MD-000001 REV 02. Las Vegas, Nevada: Bechtel SAIC Company. ACC: DOC.20031222.0006.

CRWMS M\&O (Civilian Radioactive Waste Management System Management and Operating Contractor) 2000. Conceptual and Numerical Models for UZ Flow and Transport. MDL-NBS-HS-000005 REV 00. Las Vegas, Nevada: CRWMS M\&O. ACC: MOL.19990721.0526. 
Czarnecki, J.B.; Nelson, P.H.; O'Brien, G.M.; Sass, J.H.; Thapa, B.; Matsumoto, Y.;

103371 and Murakami, O. 1995. "Testing in Borehole USW G-2 at Yucca Mountain: The Saga Continues.” Eos, 76, (46), 191-192. Washington, D.C.: American Geophysical Union. TIC: 240933.

Czarnecki, J.B.; O'Brien, G.M.; Nelson, P.H.; Sass, J.H.; Bullard, J.W.; and Flint, A.L. 1994. "Is There Perched Water Under Yucca Mountain in Borehole USW G-2?” Eos (Supplement), 75, (44), 249-250. Washington, D.C.: American Geophysical Union. TIC: 226992.

DOE (U.S. Department of Energy) 1995. Yucca Mountain Site Characterization Project Site Atlas 1995. Two volumes. Washington, D.C.: U.S. Department of Energy. ACC: MOL.19960311.0262.

Ervin, E.M.; Luckey, R.R.; and Burkhardt, D.J. 1994. Revised Potentiometric-Surface Map, Yucca Mountain and Vicinity, Nevada. Water-Resources Investigations Report 93-4000. Denver, Colorado: U.S. Geological Survey. ACC: NNA.19930212.0018.

Finsterle, S. 1999. ITOUGH2 User's Guide. LBNL-40040. Berkeley, California: 104367 Lawrence Berkeley National Laboratory. TIC: 243018.

Flint, L.E. 1998. Characterization of Hydrogeologic Units Using Matrix Properties, Yucca Mountain, Nevada. Water-Resources Investigations Report 97-4243. Denver, Colorado: U.S. Geological Survey. ACC: MOL.19980429.0512.

Haukwa, C. and Wu, Y.S. 1997. "Grid Generation and Analysis.” Chapter 4 of The Site-Scale Unsaturated-Zone Model of Yucca Mountain, Nevada, for the Viability Assessment. Bodvarsson, G.S., Bandurraga, T.M., and Wu, Y.S., eds. LBNL-40376. Berkeley, California: Lawrence Berkeley National Laboratory. ACC: MOL.19971014.0232.

Haukwa, C.; Wu, Y.; and Bodvarsson, G.S. 1997. "Modeling Study of Moisture 101243 Flow Using a Refined Grid Model.” Chapter 12 of The Site-Scale Unsaturated Zone Model of Yucca Mountain, Nevada, for the Viability Assessment. Bodvarsson, G.S.; Bandurraga, T.M.; and Wu, Y.S., eds. LBNL-40376. Berkeley, California: Lawrence Berkeley National Laboratory. ACC: MOL.19971014.0232.

Haukwa, C.B.; Wu, Y-S.; and Bodvarsson, G.S. 2003. "Modeling ThermalHydrological Response of the Unsaturated Zone at Yucca Mountain, Nevada, to Thermal Load at a Potential Repository.” Journal of Contaminant Hydrology, 62-63, 529-552. New York, New York: Elsevier. TIC: 254205.

Hinds, J. 2001. Unsaturated Zone Modeling \& Synthesis. Scientific Notebook YMP-LBNL-YSW-JH-2. ACC: MOL.20010725.0216. 
Hinds, J. and Dobson, P. 2004. YMP-LBNL-YSW-JH-3 Unsaturated Zone 170886 Modeling and Synthesis. Scientific Notebook: SN-LBNL-SCI-213-V1.

ACC: MOL.20040414.0156; MOL.20040414.0157.

LBNL (Lawrence Berkeley National Laboratory) 2002. User's Manual (UM) for

170551

WinGridder V2.0. Document Identifier: 10024-UM-2.0-00. Berkeley, California:

Lawrence Berkeley National Laboratory. ACC: MOL.20020705.0057.

Loeven, C. 1993. A Summary and Discussion of Hydrologic Data from the Calico

Hills Nonwelded Hydrogeologic Unit at Yucca Mountain, Nevada. LA-12376-MS.

101258

Los Alamos, New Mexico: Los Alamos National Laboratory.

ACC: NNA.19921116.0001.

Montazer, P. and Wilson, W.E. 1984. Conceptual Hydrologic Model of Flow in the

100161

Unsaturated Zone, Yucca Mountain, Nevada. Water-Resources Investigations Report 84-4345. Lakewood, Colorado: U.S. Geological Survey.

ACC: NNA.19890327.0051.

Moyer, T.C.; Geslin, J.K.; and Buesch, D.C. 1995. Summary of Lithologic Logging of New and Existing Boreholes at Yucca Mountain, Nevada, July 1994 to November 1994. Open-File Report 95-102. Denver, Colorado: U.S. Geological Survey.

TIC: 224224.

NRC (U.S. Nuclear Regulatory Commission) 2003. Yucca Mountain Review Plan, Final Report. NUREG-1804, Rev. 2. Washington, D.C.: U.S. Nuclear Regulatory Commission, Office of Nuclear Material Safety and Safeguards. TIC: 254568.

Pan, L. 2003. YMP-LBNL-GSB-LP-2 Unsaturated Zone Modeling \& Synthesis. Scientific Notebook SN-LBNL-SCI-103-V1. ACC: MOL.20010201.0437; MOL.20020716.0159; MOL.20030506.0295.

Pruess, K. 1983. GMINC - A Mesh Generator for Flow Simulations in Fractured Reservoirs. LBL-15227. Berkeley, California: Lawrence Berkeley Laboratory. ACC: NNA.19910307.0134.

Pruess, K. 1991. TOUGH2-A General-Purpose Numerical Simulator for 100413 Multiphase Fluid and Heat Flow. LBL-29400. Berkeley, California: Lawrence Berkeley Laboratory. ACC: NNA.19940202.0088.

Rautman, C.A. and McKenna, S.A. 1997. Three-Dimensional Hydrological and 163274 Thermal Property Models of Yucca Mountain, Nevada. SAND97-1730. Albuquerque, New Mexico: Sandia National Laboratories. ACC: MOL.19980311.0317. 
Rousseau, J.P.; Kwicklis, E.M.; and Gillies, D.C., eds. 1999. Hydrogeology of the

102097 Unsaturated Zone, North Ramp Area of the Exploratory Studies Facility, Yucca Mountain, Nevada. Water-Resources Investigations Report 98-4050. Denver, Colorado: U.S. Geological Survey. ACC: MOL.19990419.0335.

USGS (U.S. Geological Survey) 2004. Water-Level Data Analysis for the Saturated 168473 Zone Site-Scale Flow and Transport Model. ANL-NBS-HS-000034 REV 01 Errata 002. Denver, Colorado: U.S. Geological Survey. ACC: MOL.20020209.0058; MOL.20020917.0136; DOC.20040303.0006.

Wang, J.S. 2003. "Scientific Notebooks Referenced in Scientific Analysis Report 162380 U0000, Development of Numerical Grids for UZ Flow and Transport Modeling, ANL-NBS-HS-000015 REV01.” Memorandum from J.S. Wang (BSC) to File, March 04, 2003, with attachments. ACC: MOL.20030306.0526.

Warren, J.E. and Root, P.J. 1963. “The Behavior of Naturally Fractured 100611 Reservoirs.” Society of Petroleum Engineers Journal, 3, (3), 245-255. Dallas, Texas: Society of Petroleum Engineers. TIC: 233671.

Wu, Y-S. 2004. YMP-LBNL-YSW-3, Unsaturated Zone Modeling and Synthesis for the UZ PMR. Scientific Notebook SN-LBNL-SCI-199-V1.

ACC: MOL.20040119.0095.

Wu, Y-S.; Zhang, W.; Pan, L.; Hinds, J.; and Bodvarsson, G.S. 2002. “Modeling Capillary Barriers in Unsaturated Fractured Rock.” Water Resources Research, 38, (11), 35-1 through 35-12. Washington, D.C.: American Geophysical Union. TIC: 253854.

Zhang, W. 2000. UZ Modeling and Synthesis. Scientific Notebook YMP-LBNL-YSW-WZ-1 (SN-LBNL-SCI-115-V1). ACC: MOL.20001025.0166.

\subsection{CODES, STANDARDS, REGULATIONS, AND PROCEDURES}

10 CFR 63. Energy: Disposal of High-Level Radioactive Wastes in a Geologic 156605 Repository at Yucca Mountain, Nevada. Readily available.

AP-2.22Q, Rev. 1, ICN 1. Classification Analyses and Maintenance of the Q-List. Washington, D.C.: U.S. Department of Energy, Office of Civilian Radioactive Waste Management. ACC: DOC.20040714.0002.

AP-SIII.2Q, Rev. 1, ICN 0. Qualification of Unqualified Data and the Documentation of Rationale for Accepted Data. Washington, D.C.: U.S. Department of Energy, Office of Civilian Radioactive Waste Management. ACC: MOL.20021105.0164. 
AP-SIII.9Q, Rev. 1, ICN 6. Scientific Analyses. Washington, D.C.: U.S. Department of Energy, Office of Civilian Radioactive Waste Management. ACC: DOC.20040805.0003

DOE/RW-0333P, Rev. 16. Quality Assurance Requirements and Description. Washington, D.C.: U.S. Department of Energy, Office of Civilian Radioactive Waste Management. ACC: DOC.20040823.0004.

IEEE/ASTM SI 10-1997. Standard for Use of the International System of Units (SI): 151762 The Modern Metric System. New York, New York: Institute of Electrical and Electronics Engineers. TIC: 240989.

\subsection{SOURCE DATA, LISTED BY DATA TRACKING NUMBER}

GS010608312332.001. Potentiometric-Surface Map, Assuming Perched Conditions 155307 North of Yucca Mountain, in the Saturated Site-Scale Model. Submittal date: 06/19/2001.

GS951108312231.009. Physical Properties, Water Content, and Water Potential for 108984 Borehole USW SD-7. Submittal date: 09/26/1995.

GS960808312231.004. Physical Properties, Water Content and Water Potential for 108985 Samples from Lower Depths in Boreholes USW SD- 7 and USW SD-12. Submittal date: 08/30/1996.

GS980808312242.014. Physical Properties of Borehole Core Samples and Water 106748 Potential Measurements Using the Filter Paper Technique for Borehole Samples from USW SD-6. Submittal date: 08/11/1998.

GS980908312242.038. Physical Properties and Saturated Hydraulic Conductivity Measurements of Lexan-Sealed Samples from USW SD-6. Submittal date: 09/22/1998.

LB0205REVUZPRP.001. Fracture Properties for UZ Model Layers Developed from 159525 Field Data. Submittal date: 05/14/2002.

LB0207REVUZPRP.001. Revised UZ Fault Zone Fracture Properties. Submittal 159526 date: $07 / 03 / 2002$.

LB0207REVUZPRP.002. Matrix Properties for UZ Model Layers Developed from Field and Laboratory Data. Submittal date: 07/15/2002.

MO0012MWDGFM02.002. Geologic Framework Model (GFM2000). Submittal date: $12 / 18 / 2000$.

MO0106RIB00038.001. Water-Level Data and the Potentiometric Surface.

Submittal date: 06/22/2001. 
MO0109HYMXPROP.001. Matrix Hydrologic Properties Data. Submittal date: 155989 09/17/2001.

MO0110MWDGFM26.002. Vulcan GFM2000 Representation. Submittal date:

160565 10/18/2001.

MO0212GWLSSPAX.000. ASCII File, Extracted from DTN:

MO0110MWDGFM26.002, Which Includes 1) Contours Digitized from DTN:

GS010608312332.001 and 2) Water Levels from DTNS: MO0106RIB00038.001 and GS010608312332.001. Submittal date: 12/23/2002.

MO0407SEPFEPLA.000. LA FEP List. Submittal date: 07/20/2004.

MO9910MWDISMMM.003. ISM3.1 Mineralogic Models. Submittal date:

MO9910MWDISMRP.002. ISM3.1 Rock Properties Models. Submittal date: 10/06/1999.

SN0112T0501399.004. Three-Dimensional Rock Property Models (RPM2000). Submittal date: 12/04/2001.

\subsection{OUTPUT DATA, LISTED BY DATA TRACKING NUMBER}

LB02081DKMGRID.001. 2002 UZ 1-D and 2-D Calibration Grids. Submittal date: 08/26/2002.

LB03023DKMGRID.001. UZ 3-D Site Scale Model Grids.

Submittal date: 02/26/2003.

LB0208HYDSTRAT.001. 2002 UZ Model Grid Components.

Submittal date: 08/26/2002.

LB02092DGRDVER.001. Files for 2D Grid Verification.

Submittal date: 09/30/2002.

\subsection{SOFTWARE CODES}

Dynamic Graphics 2000. Software Code: EARTHVISION. V5.1. SGI/IRIX 6.5.

167994 10174-5.1-00.

Dynamic Graphics 2003. Software Code: EARTHVISION. V 5.1. SGI, IRIX 6.2. 171007 10174-5.1-00. 
LBNL 2000. Software Code: TOUGH2. V1.4. Sun Workstation and 146496 DEC/ALPHA. 10007-1.4-01.

LBNL 2002. Software Code: WINGRIDDER. V2.0. PC. 10024-2.0-00. 154785

LBNL 2002. Software Routine: 2kgrid8.for. V1.0. DEC-Alpha, PC. 10503-1.0- 154787 00 . 
APPENDIX A

ELECTRONIC GFM2000, ISM3.1, RPM2000, AND ROCK- AND FRACTURE-PROPERTY DATA FILES USED TO DEVELOP UZ MODEL NUMERICAL GRIDS 
This appendix contains a list of files used to develop the numerical model grids.

\section{GFM2000 Files}

\section{Isochores}

ia00cLDRWC.2grd

ia00cpv3RWC.2grd

ia00cpv2RWC.2grd

ia00cpv1RWC.2grd

ia00bt4RWC.2grd

ia00tpyRWC.2grd

ia00bt3RWC.2grd

ia00tppRWC.2grd

ia00bt2RWC.2grd

ia00trv3RWC.2grd

ia00trv2RWC.2grd

ia00trv1RWC.2grd

ia00trnRWC.2grd

ia00trltfRWC.2grd

ia00tpulRWC.2grd

ia00tpmnRWC.2grd

ia00tpllRWC.2grd

ia00tplnRWC.2grd

ia00tpv3RWC.2grd

ia00tpv2RWC.2grd

ia00tpv1RWC.2grd

ia00bt1RWC.2grd

ia00tacRWC.2grd

ia00tacbtRWC.2grd

ia00prowuvRWC.2grd

ia00prowucRWC.2grd

ia00prowmdRWC.2grd

ia00prowlcRWC.2grd

ia00prowlvRWC.2grd

ia00prowbtRWC.2grd

ia00bulluvRWC.2grd

ia00bullucRWC.2grd

ia00bullmdRWC.2grd

ia00bulllcRWC.2grd

ia00bulllvRWC.2grd

ia00bullbtRWC.2grd

ia00tramuvRWC.2grd

ia00tramucRWC.2grd

ia00trammdRWC.2grd

ia00tramlcRWC.2grd

ia00tramlvRWC.2grd

ia00trambtRWC.2grd

\section{Faults}

foobowex.dat

f00solEX.dat

f00solwestEX.dat

f00soljfatEX.dat

f00splaygEX.dat

f00splaynEX.dat

f00splaysEX.dat

fOOsundanceEX.dat

footoeex.dat

fo0severEX.dat

f00paganyEX.dat

foOdrillEX.dat

fooghostEX.dat

fOOghostwEX.dat

fooduneEX.dat

foodunexEX.dat

fo0dunew1EX.dat

fooimbex.dat

f00exileEX.dat
Surface Horizons:

s00bedrockRWC.2grd

s00TpсpEXuncut.2grd

s00Tptpv3EXuncut.2grd

Other:

boreholepaths.dat contacts00el.dat

(DTN: MO0012MWDGFM02.002 [DIRS 153777]) 


\section{ISM3.1 Files}

mineralsM.pdat*

(DTN: MO9910MWDISMMM.003 [DIRS 119199])

CHnKsatEtype.out

(DTN: MO9910MWDISMRP.002 [DIRS 145731])

CHnZksStrat.3grd

(DTN: MO9910MWDISMRP.002 [DIRS 145731])

ISM31.seq

(DTN: MO9910MWDISMRP.002 [DIRS 145731])

*Data considered for corroborative purposes.

\section{RPM2000 Files}

CHn_hmap_etype.out* （DTN: SN0112T0501399.004 [DIRS 159524])

\section{Rock and Fracture Property Data}

General borehole rock property data

(DTN: LB0207REVUZPRP.002 [DIRS 159672])

(DTN: MO0109HYMXPROP.001

[DIRS 155989])

Rock fracture property data

(DTN: LB0205REVUZPRP.001 [DIRS 159525])

Fault fracture property data

(DTN: LB0207REVUZPRP.001 [DIRS 159526])

\section{Specific Borehole Rock Property Data}

$\begin{array}{lll}\text { Borehole } & \text { DTN and Q-status } & \text { Description } \\ \text { SD-6 } & \text { GS980808312242.014 [DIRS 106748] qualified } & \text { saturation, porosity } \\ \text { SD-6 } & \text { GS980908312242.038 [DIRS 107154] qualified } & \text { hydraulic conductivity } \\ \text { SD-7 } & \text { GS951108312231.009 [DIRS 108984] qualified } & \text { saturation, porosity } \\ \text { SD-12 } & \text { GS960808312231.004 [DIRS 108985] qualified } & \text { saturation, porosity }\end{array}$




\section{APPENDIX B}

DEVELOPMENT OF NUMERICAL GRIDS FOR 1-D HYDROGEOLOGIC-PROPERTY-SET INVERSIONS 
UZ model numerical grids developed for the FY02 1-D hydrogeologic-property-set inversions are comprised of numerous 1-D columns centered at borehole coordinates, or in the case of boreholes closer than $80 \mathrm{~m}$ to each other, the midpoint location between the two boreholes (Hinds and Dobson 2004 [DIRS 170886], p. 71). Layer subdivision within these 1-D columns is based on a combination of borehole stratigraphic picks identified in the GFM2000 file, contacts00el.dat (DTN: MO0012MWDGFM02.002 [DIRS 153777]), and hydrogeologic unit boundaries defined by Flint (1998 [DIRS 100033]).

The mesh files identified by output-DTN: LB02081DKMGRID.001 and created for use in 1-D hydrogeologic property set inversions and calibration for the UZ model include:

- The primary ECM mesh, Boreholes.mesh

- The ECM mesh Boreholes_NF.mesh with rock (rather than fault) matrix properties used for fault grid nodes, in turn used for generation of the dual-k mesh

- The dual-k mesh mesh_1d.dkm for transient (pneumatic) and steady-state simulations based on the Boreholes_NF.mesh file and the fracture values given in Table 4-2.

The detailed steps describing the generation of these files are documented in scientific notebooks (Pan 2003 [DIRS 170887], pp. 134 to 140 and 145 to 151; Wu 2004 [DIRS 170888], pp. 85 to 91). Table B-1 summarizes the layer contact elevation input to the 1-D inversion grids based on the GFM2000 (DTN: MO0012MWDGFM02.002 [DIRS 153777]) file contacts00el.dat. Note that the GFM2000 borehole elevations, which have been converted from feet to meters, are also adjusted in the same manner as described in Section 6.4.1 of this report to correspond with Flint's HGUs (1998 [DIRS 100033]). The corresponding elevations for each of these hydrogeologic unit contacts as determined from the UZ model grid file Boreholes.mck, is also given to provide a means of verifying the accuracy of the UZ model results (Hinds and Dobson 2004 [DIRS 170886], pp. 67 to 69).

A total of 45 borehole locations were cross-checked. Note that in most cases, the differences in contact elevations are less than $5 \mathrm{~m}$. There are several cases where deviations exceed this amount. A number of boreholes (e.g., UZ-7a, H-6, NRG\#7, UZ\#4/5) had greater than $5 \mathrm{~m}$ discrepancies for the elevation of the uppermost unit present. These differences (primarily at the bedrock surface) arise from channel erosion that produces surfaces with large local variations in slope and elevation. Although the nearest GFM2000 data point may be only meters to a few tens of meters away, the highly variable surface elevations may result in the observed mismatches in the upper contact surfaces. These differences are restricted to the upper unit only, and thus should not have a significant impact on UZ model flow and transport modeling results.

Two boreholes (b\#1 and N11) exhibit poor matches for most of the contact elevations, with an abrupt shift in elevations occurring below a given unit contact. Both of these boreholes are near faults, and differences in how faults were modeled in GFM2000 and the UZ model grids may explain these discrepancies. In the case of N11, where there is a difference of over $50 \mathrm{~m}$ in most of the contact elevations, the borehole lies on the west side of the Solitario Canyon fault in the GFM2000 representation, but is situated on the east side of this fault in the UZ model grid. The difference in contact elevations is similar to the observed vertical offset on the fault. The 
N11 borehole is located approximately $2 \mathrm{~km}$ north of the repository footprint (Figure 6-2), and thus this discrepancy should have little impact on UZ flow and transport models for the repository area. Because of the observed differences between GFM2000 (DTN: MO0012MWDGFM02.002 [DIRS 153777]) and UZ model grid contact elevations, the b\#1 and N11 boreholes were not used for 1-D rock property calibration calculations. 
Table B-1. Comparison of Borehole Layer Contact Elevations from GFM2000 and UZ Model Grid

NOTE: A subset of these boreholes was used in 1-D property set inversions. Depths given in meters.

${ }^{a}$ GFM2000 data for b\#1.

HGU=hydrogeologic unit; UZ=unsaturated zone 
Table B-1. Comparison of Borehole Layer Contact Elevations from GFM2000 and UZ Model Grid (Continued)

\begin{tabular}{|c|c|c|c|c|c|c|c|c|c|c|c|c|}
\hline \multirow{2}{*}{$\begin{array}{c}\text { UZ Model } \\
\text { Unit }\end{array}$} & \multirow{2}{*}{$\begin{array}{c}\text { GFM2000 } \\
\text { Unit }\end{array}$} & \multirow[b]{2}{*}{ HGU } & \multicolumn{2}{|c|}{ USW H-3 } & \multicolumn{2}{|c|}{ USW H-4 } & \multicolumn{2}{|c|}{ USW H-5 } & \multicolumn{2}{|c|}{ USW H-6 } & \multicolumn{2}{|c|}{ UE\#25 NRG\#4 } \\
\hline & & & GFM2000 & UZGrid & GFM2000 & UZGrid & GFM2000 & UZGrid & GFM2000 & UZGrid & GFM2000 & UZGrid \\
\hline tcw11 & Tpcr & CCR, CUC & 1483.467 & 1482.424 & & & 1478.89 & 1477.951 & 1292.962 & 1303.709 & 1249.988 & 1249.887 \\
\hline tcw12 & Трср & CUL, CW & 1466.207 & 1465.925 & 1248.766 & 1248.831 & 1445.3 & 1444.681 & 1244.194 & 1244.537 & 1246.108 & 1245.239 \\
\hline tcw13 & Tpcpv3,2 & CMW & 1370.747 & 1371.286 & 1195.761 & 1196.322 & 1355.75 & 1355.991 & 1241.146 & 1241.459 & 1153.058 & 1152.775 \\
\hline ptn21 & Tpcpv1 & CNW & 1365.199 & 1365.668 & 1192.378 & 1192.874 & 1350.874 & 1351.079 & 1222.858 & 1223.221 & 1151.534 & 1151.223 \\
\hline ptn22 & Tpbt4+upper Tpy & BT4 & 1361.542 & 1361.983 & 1189.939 & 1190.416 & 1345.54 & 1345.763 & absent & absent & 1146.962 & 1146.662 \\
\hline ptn23 & mid Tpy & TPY & absent & absent & absent & absent & absent & absent & 1218.286 & absent & absent & absent \\
\hline ptn24 & lower Tpy+Tpbt3 & BT3 & 1360.353 & 1360.77 & 1188.415 & 1188.841 & 1342.492 & 1340.3 & 1217.371 & 1217.639 & 1142.086 & 1141.823 \\
\hline ptn25 & Tpp & TPP & 1356.36 & absent & 1182.929 & 1183.442 & 1335.329 & 1335.52 & 1213.714 & 1214.006 & 1135.685 & 1135.431 \\
\hline ptn26 & Tpbt2+Tptrv3,2 & BT2 & 1356.36 & 1356.737 & 1180.49 & 1181.028 & 1323.442 & 1323.615 & 1201.522 & 1201.762 & 1110.386 & 1110.143 \\
\hline tsw31 & Tptrv1 & TC & 1347.826 & 1348.126 & 1172.261 & 1172.831 & 1307.592 & 1307.783 & 1199.522 & 1199.762 & 1102.157 & 1101.87 \\
\hline tsw32 & Tptrn & TR & 1345.826 & 1346.126 & 1170.261 & 1170.831 & 1305.592 & 1305.783 & 1177.442 & 1177.645 & 1100.157 & 1099.87 \\
\hline tsw33 & Tptrl+Tpul & TUL & 1322.862 & 1323.116 & 1134.161 & 1134.673 & 1265.53 & 1265.736 & 1103.071 & 1103.359 & 1048.664 & 1048.393 \\
\hline tsw34 & Tptpmn & TMN & 1276.167 & 1276.471 & 1073.201 & 1073.696 & 1177.747 & 1178.021 & 1059.79 & 1060.018 & & \\
\hline tsw35 & Tptpll & TLL & 1224.961 & 1225.293 & 1034.491 & 1035.049 & 1147.267 & 1147.494 & 967.74 & 968.0029 & & \\
\hline tsw36 & upper Tptpln & TM2 & 1163.452 & 1163.756 & 947.928 & 948.4726 & 1036.93 & 1037.192 & 944.1688 & 944.4087 & & \\
\hline tsw37 & lower Tptpln & TM1 & 1134.171 & 1134.473 & 907.6944 & 908.251 & 1010.107 & 1010.321 & 932.3832 & 932.6117 & & \\
\hline tsw38 & Tptpv3 & PV3 & 1119.53 & 1119.832 & 887.5776 & 888.1402 & 996.696 & 996.8859 & 902.8176 & 903.0982 & & \\
\hline tsw39 & Tptpv2 & $\mathrm{PV} 2$ & 1084.783 & 1085.145 & 880.2624 & 880.734 & 973.2264 & 973.4256 & 899.16 & 899.4235 & & \\
\hline ch1 & Tptpv1+Tpbt1 & BT1, BT1a & 1074.725 & 1075.087 & 868.68 & 869.2362 & 969.264 & 969.4739 & 888.7968 & 889.0499 & & \\
\hline $\operatorname{ch} 2$ & upper $1 / 4$ Tac & $\mathrm{CH}$ & 1056.742 & 1057.069 & 847.344 & 848.0614 & 959.2056 & 959.3875 & 881.0244 & 881.2959 & & \\
\hline ch3 & mid $1 / 4$ Tac & $\mathrm{CH}$ & 1053.922 & 1054.238 & 827.913 & 828.6188 & 945.8782 & 946.072 & 873.252 & 873.542 & & \\
\hline ch4 & mid $1 / 4 \mathrm{Tac}$ & $\mathrm{CH}$ & 1051.103 & 1051.407 & 808.482 & 809.1762 & 932.5508 & 932.7565 & 865.4796 & 865.788 & & \\
\hline $\operatorname{ch} 5$ & lower 1/4 Tac & $\mathrm{CH}$ & 1048.283 & 1048.575 & 789.051 & 789.7336 & 919.2235 & 919.441 & 857.7072 & 858.0341 & & \\
\hline ch6 & Tacbt & BT & 1045.464 & 1045.744 & 769.62 & 770.2909 & 905.8961 & 906.1255 & 842.4672 & 842.7937 & & \\
\hline pp4 & Prowuv & PP4 & $\mid 1027.786$ & $\mid 1028.084$ & 752.8865 & 753.6395 & 886.0841 & 886.3395 & 828.1416 & 828.495 & & \\
\hline pp3 & Prowuc & PP3 & 1020.775 & 1021.054 & 742.188 & 743.0525 & 879.348 & 879.5576 & 813.816 & 814.126 & & \\
\hline pp2 & Prowmd+Prow & PP2 & 983.5896 & 983.8958 & & & 843.3816 & 843.6558 & 788.5176 & 788.8992 & & \\
\hline pp1 & Prowlv+Prowbt+Bulluv & PP1 & 964.692 & 964.9361 & & & 829.6656 & 829.9347 & & & & \\
\hline bf3 & Bulluc+Bullmd+Bulllc & BF3 & 897.636 & 897.8414 & & & & & & & & \\
\hline bf2 & Bulllv+Bullbt+Tramuv & BF2 & 752.856 & 753.1556 & & & & & & & & \\
\hline
\end{tabular}

Source DTN: MO0012MWDGFM02.002 (GFM2000) [DIRS 153777]; output-DTN: LB02081DKMGRID.001.

$\mathrm{HGU}=$ hydrogeologic unit; UZ=unsaturated zone 
Table B-1. Comparison of Borehole Layer Contact Elevations from GFM2000 and UZ Model Grid (Continued)

\begin{tabular}{|c|c|c|c|c|c|c|c|c|c|c|c|c|}
\hline \multirow{2}{*}{$\begin{array}{c}\text { UZ Model } \\
\text { Unit }\end{array}$} & \multirow{2}{*}{$\begin{array}{c}\text { GFM2000 } \\
\text { Unit }\end{array}$} & \multirow[b]{2}{*}{ HGU } & \multicolumn{2}{|c|}{ UE\#25 NRG\#5 } & \multicolumn{2}{|c|}{ UE\#25 NRG-6 } & \multicolumn{2}{|c|}{ UE\#25 NRG-7a } & \multicolumn{2}{|c|}{ USW SD-6 } & \multicolumn{2}{|c|}{ USW SD-7 } \\
\hline & & & GFM2000 & UZGrid & GFM2000 & UZGrid & GFM2000 & UZGrid & GFM2000 & UZGrid & GFM2000 & UZGrid \\
\hline tcw11 & Tpcr & CCR, CUC & & & & & & & 1495.349 & 1495.412 & & \\
\hline tcw12 & Tрср & CUL, CW & 1241.007 & 1239.184 & 1277.722 & 1283.19 & 1277.569 & 1291.754 & 1472.299 & 1472.224 & 1363.98 & 1362.601 \\
\hline tcw13 & Tpcpv3,2 & CMW & 1206.307 & 1206.628 & 1261.659 & 1261.554 & 1239.347 & 1234.845 & 1368.979 & 1369.086 & 1271.016 & 1271.179 \\
\hline ptn21 & Tpcpv1 & CNW & 1201.278 & 1201.715 & 1258.763 & 1258.603 & 1233.221 & 1229.901 & 1364.59 & 1364.668 & 1267.663 & 1267.791 \\
\hline ptn22 & Tpbt4+upper Tpy & BT4 & 1199.205 & 1199.598 & 1251.814 & 1251.722 & 1229.045 & 1225.738 & 1360.505 & 1360.602 & 1264.676 & 1264.795 \\
\hline ptn23 & mid Tpy & TPY & absent & absent & 1245.433 & 1244.768 & absent & absent & absent & absent & absent & absent \\
\hline ptn24 & lower Tpy+Tpbt3 & BT3 & 1197.925 & 1198.265 & 1240.394 & 1240.869 & 1227.247 & 1224.024 & 1356.451 & 1356.551 & 1263.213 & 1263.303 \\
\hline ptn25 & Tpp & TPP & 1194.237 & 1194.494 & 1230.478 & 1230.335 & 1223.802 & absent & 1349.045 & 1349.14 & 1259.434 & 1259.514 \\
\hline ptn26 & Tpbt2+Tptrv3,2 & BT2 & 1180.247 & 1180.591 & 1204.021 & 1203.916 & 1222.675 & 1220.493 & 1346.363 & 1346.453 & 1255.471 & 1255.592 \\
\hline tsw31 & Tptrv1 & TC & 1168.359 & 1168.713 & 1192.621 & 1192.461 & 1213.531 & absent & 1335.115 & 1335.18 & 1246.236 & 1246.327 \\
\hline tsw32 & Tptrn & TR & 1166.359 & 1166.713 & 1190.621 & 1190.461 & 1211.531 & 1209.552 & 1333.115 & 1333.18 & 1244.236 & 1244.327 \\
\hline tsw33 & Tptrl+Tpul & TUL & 1116.787 & 1117.237 & 1137.148 & 1136.969 & 1174.151 & 1172.198 & 1302.715 & 1302.787 & 1217.676 & 1217.75 \\
\hline tsw34 & Tptpmn & TMN & 1030.224 & 1030.781 & 1057.351 & 1057.121 & & & 1235.354 & 1235.444 & 1155.954 & 1156.091 \\
\hline tsw35 & Tptpll & TLL & 1000.658 & 1002.85 & 1015.411 & 1015.292 & & & 1192.073 & 1192.177 & 1119.134 & 1119.219 \\
\hline tsw36 & upper Tptpln & TM2 & & & 904.0368 & 903.9169 & & & 1097.585 & 1097.692 & 1053.084 & 1053.035 \\
\hline tsw37 & lower Tptpln & TM1 & & & 869.127 & 869.2099 & & & 1066.902 & 1067.005 & 1020.166 & 1020.158 \\
\hline tsw38 & Tptpv3 & PV3 & & & 851.6722 & 851.8564 & & & 1051.56 & 1051.661 & 1003.706 & 1003.719 \\
\hline tsw39 & Tptpv2 & PV2 & & & 838.8096 & 838.919 & & & 1037.234 & 1037.334 & 972.312 & 972.4217 \\
\hline ch1 & Tptpv1+Tpbt1 & BT1, BT1a & & & 833.4451 & 833.5818 & & & 1032.053 & 1032.144 & 965.3016 & 965.3709 \\
\hline ch2 & upper $1 / 4$ Tac & $\mathrm{CH}$ & & & 826.3128 & 826.387 & & & 1019.556 & 1019.646 & 935.5531 & 935.7576 \\
\hline ch3 & mid 1/4 Tac & $\mathrm{CH}$ & & & & & & & 1011.707 & 1011.792 & 923.2392 & 923.4592 \\
\hline $\operatorname{ch} 4$ & mid $1 / 4$ Tac & $\mathrm{CH}$ & & & & & & & 1003.859 & 1003.938 & 910.9253 & 911.1608 \\
\hline ch5 & lower $1 / 4$ Tac & $\mathrm{CH}$ & & & & & & & 996.0102 & 996.0834 & 898.6114 & 898.8624 \\
\hline ch6 & Tacbt & BT & & & & & & & 988.1616 & 988.2292 & 886.2974 & 886.564 \\
\hline pp4 & Prowuv & PP4 & & & & & & & 972.6168 & 972.6871 & 869.7468 & 869.9841 \\
\hline pp3 & Prowuc & PP3 & & & & & & & 965.0273 & 965.0948 & 862.1268 & 862.45 \\
\hline pp2 & Prowmd+Prow & PP2 & & & & & & & 924.7632 & 924.841 & 826.008 & 826.324 \\
\hline pp1 & Prowlv+Prowbt+Bulluv & PP1 & & & & & & & 913.7904 & 913.8426 & 793.3944 & 793.756 \\
\hline bf3 & Bulluc+Bullmd+Bulllc & BF3 & & & & & & & 848.4413 & 848.5061 & & \\
\hline bf2 & Bulllv+Bullbt+Tramuv & BF2 & & & & & & & & & & \\
\hline
\end{tabular}


Table B-1. Comparison of Borehole Layer Contact Elevations from GFM2000 and UZ Model Grid (Continued)

\begin{tabular}{|c|c|c|c|c|c|c|c|c|c|c|c|c|}
\hline \multirow{2}{*}{$\begin{array}{c}\text { UZ } \\
\text { Model } \\
\text { Unit }\end{array}$} & \multirow{2}{*}{$\begin{array}{c}\text { GFM2000 } \\
\text { Unit }\end{array}$} & \multirow[b]{2}{*}{ HGU } & \multicolumn{2}{|c|}{ USW SD-9 } & \multicolumn{2}{|c|}{ USW SD-12 } & \multicolumn{2}{|c|}{ UE\#25 UZ\#4/5 } & \multicolumn{2}{|c|}{ UE\#25 UZ-6 } & \multicolumn{2}{|c|}{ USW UZ-1/14 } \\
\hline & & & GFM2000 & UZGrid & GFM2000 & UZGrid & GFM2000 & UZGrid & GFM2000 & UZGrid & GFM $2000^{\circ}$ & UZGrid \\
\hline tcw11 & Tpcr & CCR, CUC & & & & & & & 1501.446 & 1500.024 & & \\
\hline tcw12 & Трср & CUL, CW & 1303.02 & 1301.601 & 1323.746 & 1319.003 & 1189.33 & 1194.513 & 1480.806 & 1480.864 & & \\
\hline tcw13 & Tpсpv3,2 & CMW & 1285.585 & 1285.393 & 1250.747 & 1250.691 & 1179.454 & 1178.984 & 1384.706 & 1382.479 & & \\
\hline ptn21 & Tpcpv1 & CNW & 1279.703 & 1279.489 & 1245.718 & 1245.633 & 1177.442 & 1176.162 & \begin{tabular}{|l|}
1372.819 \\
\end{tabular} & 1372.966 & & \\
\hline ptn22 & Tpbt4+upper Tpy & BT4 & 1275.131 & 1274.913 & 1243.371 & absent & 1171.042 & 1170.298 & 1369.619 & 1369.766 & 1339.6 & 1338.763 \\
\hline ptn23 & mid Tpy & TPY & 1268.447 & 1268.24 & absent & absent & 1163.474 & 1163.726 & absent & absent & 1334.733 & 1332.634 \\
\hline ptn24 & lower Tpy+Tpbt3 & BT3 & 1265.447 & 1265.24 & 1242.67 & 1242.548 & 1160.474 & 1160.726 & 1368.186 & 1368.322 & 1332.733 & 1330.592 \\
\hline ptn25 & Tpp & TPP & 1255.624 & 1255.428 & 1238.921 & 1238.791 & 1148.212 & 1148.619 & 1364.254 & 1364.416 & 1320.58 & 1317.966 \\
\hline ptn26 & Tpbt2+Tptrv3,2 & BT2 & 1233.952 & 1233.767 & 1234.989 & 1234.878 & 1108.253 & 1108.838 & 1362.608 & 1362.807 & 1278.427 & 1276.032 \\
\hline tsw31 & Tptrv1 & $\mathrm{TC}$ & 1221.181 & 1221 & 1224.839 & 1224.731 & 1096.061 & 1096.891 & 1352.398 & 1352.604 & 1265.595 & 1263.237 \\
\hline tsw32 & Tptrn & TR & 1219.181 & 1219 & 1222.839 & 1222.731 & 1094.061 & 1094.891 & 1350.398 & 1350.604 & 1263.595 & 1261.237 \\
\hline tsw33 & Tptrl+Tpul & TUL & 1165.86 & 1165.689 & 1190.732 & 1190.622 & & & 1326.185 & 1326.38 & 1220.637 & 1217.538 \\
\hline tsw34 & Tptpmn & TMN & 1080.516 & 1080.378 & 1121.451 & 1121.398 & & & 1264.31 & 1264.554 & 1133.769 & 1131.36 \\
\hline tsw35 & Tptpll & TLL & 1045.22 & 1045.081 & 1083.899 & 1083.817 & & & 1221.943 & 1222.135 & 1099.326 & 1096.919 \\
\hline tsw36 & upper Tptpln & TM2 & 942.7464 & 942.5479 & 998.982 & \begin{tabular}{|l|}
998.8207 \\
\end{tabular} & & & 1138.733 & 1139.025 & 1004.838 & 1001.555 \\
\hline tsw37 & lower Tptpln & TM1 & 906.9832 & 906.7829 & 955.7817 & 955.6774 & & & 1109.675 & \begin{tabular}{|l|l}
1109.94 \\
\end{tabular} & 976.1666 & 973.3775 \\
\hline tsw38 & Tptpv3 & PV3 & 889.1016 & 888.9004 & 934.1815 & 934.1058 & & & 1095.146 & 1095.398 & 961.8309 & 959.2885 \\
\hline tsw39 & Tptpv2 & PV2 & 870.6917 & 870.5053 & 925.068 & 925.0046 & & & 1081.126 & 1081.264 & 937.7822 & 935.5172 \\
\hline ch1 & Tptpv1+Tpbt1 & BT1, BT1a & 868.4666 & 868.2757 & 916.0764 & 915.9899 & & & 1068.019 & 1068.212 & 930.1622 & 927.9533 \\
\hline ch2 & upper 1/4 Tac & $\mathrm{CH}$ & 851.9465 & 851.7716 & 893.5212 & 893.4719 & & & 1056.437 & 1056.566 & 918.8236 & 916.2651 \\
\hline ch3 & mid 1/4 Tac & $\mathrm{CH}$ & 830.2676 & 830.1 & 879.1956 & 879.1375 & & & 1049.792 & 1049.948 & 897.96 & 895.2167 \\
\hline ch4 & mid 1/4 Tac & $\mathrm{CH}$ & 808.5887 & 808.4284 & 864.87 & 864.8032 & & & \begin{tabular}{|l|}
1043.148 \\
\end{tabular} & 1043.329 & 877.0965 & 874.1683 \\
\hline ch5 & Iower 1/4 Tac & $\mathrm{CH}$ & 786.9098 & 786.7568 & 850.5444 & 850.4688 & & & 1036.503 & 1036.711 & 856.2329 & 853.1199 \\
\hline ch6 & Tacbt & $\mathrm{BT}$ & 765.2309 & 765.0852 & 836.2188 & 836.1344 & & & 1029.858 & 1030.093 & 835.3694 & 832.0715 \\
\hline pp4 & Prowuv & PP4 & 748.0706 & 747.9223 & 821.3141 & 821.1733 & & & 1016.203 & 1016.409 & 818.2396 & 814.8519 \\
\hline pp3 & Prowuc & PP3 & 733.4402 & 733.2986 & 812.5968 & 812.5241 & & & 1009.498 & 1009.693 & 798.4581 & 795.0506 \\
\hline pp2 & Prowmd+Prow & PP2 & & & 779.0688 & 778.9805 & & & 968.0448 & 968.2735 & 787.8206 & 784.2032 \\
\hline pp1 & Prowlv+Prowbt+Bulluv & PP1 & & & 755.2944 & 755.2224 & & & 943.9656 & 944.2452 & & \\
\hline bf3 & Bulluc+Bullmd+Bulllc & BF3 & & & & & & & & & & \\
\hline bf2 & Bulllv+Bullbt+Tramuv & BF2 & & & & & & & & & & \\
\hline
\end{tabular}

Source DTN: MO0012MWDGFM02.002 (GFM2000) [DIRS 153777], output-DTN: LB02081DKMGRID.001.

NOTE: A subset of these boreholes was used in 1-D property set inversions. Depths given in meters.

${ }^{b}$ GFM2000 data for UZ\#4

${ }^{c}$ GFM2000 data for UZ-14

HGU=hydrogeologic unit; UZ=unsaturated zone 
Table B-1. Comparison of Borehole Layer Contact Elevations from GFM2000 and UZ Model Grid (Continued)

\begin{tabular}{|c|c|c|c|c|c|c|c|c|c|c|c|c|}
\hline $\begin{array}{c}\text { UZ Model } \\
\text { Unit }\end{array}$ & $\begin{array}{l}\text { GFM2000 } \\
\text { Unit }\end{array}$ & HGU & \multicolumn{2}{|c|}{ UE-25 UZ\#16 } & \multicolumn{2}{|c|}{ USW UZ-N11 } & \multicolumn{2}{|c|}{ USW UZ-N31/32 } & \multicolumn{2}{|c|}{ USW UZ-N33 } & \multicolumn{2}{|c|}{ USW UZ-N37 } \\
\hline tcw11 & Tpcr & CCR, CUC & & & 1591.754 & 1590.4 & & & & & & \\
\hline tcw13 & Tpcpv3,2 & CMW & 1176.894 & 1176.393 & 1584.594 & 1527.931 & 1238.098 & 1238.968 & 1316.096 & 1315.646 & 1223.65 & 1224.214 \\
\hline ptn21 & Tpcpv1 & CNW & 1173.175 & 1172.661 & 1583.223 & 1526.528 & 1234.592 & 1234.821 & 1313.2 & 1312.708 & 1220.084 & 1220.49 \\
\hline ptn22 & Tpbt4+upper Tpy & BT4 & 1170.828 & 1170.255 & 1578.132 & 1524.853 & 1232.886 & 1233.371 & 1306.617 & 1306.123 & 1218.072 & 1218.335 \\
\hline ptn26 & Tpbt2+Tptrv3,2 & BT2 & 1162.263 & 1161.761 & & & 1219.048 & 1220.769 & & & & \\
\hline tsw31 & Tptrv1 & $\mathrm{TC}$ & 1149.888 & 1149.557 & & & 1206.581 & 1209.008 & & & & \\
\hline tsw32 & Tptrn & TR & 1147.888 & 1147.557 & & & 1205.667 & 1207.008 & & & & \\
\hline tsw33 & Tptrl+Tpul & TUL & 1110.752 & 1110.504 & & & & & & & & \\
\hline tsw34 & Tptpmn & TMN & 1053.694 & 1053.462 & & & & & & & & \\
\hline tsw35 & Tptpll & TLL & 1015.898 & 1015.648 & & & & & & & & \\
\hline ch1 & Tptpv1+Tpbt1 & BT1, BT1a & 860.7552 & 860.3443 & & & & & & & & \\
\hline ch2 & upper $1 / 4$ Tac & $\mathrm{CH}$ & 854.964 & 854.3603 & & & & & & & & \\
\hline ch3 & mid 1/4 Tac & $\mathrm{CH}$ & 835.2739 & 834.6529 & & & & & & & & \\
\hline ch4 & mid 1/4 Tac & $\mathrm{CH}$ & 815.5838 & \begin{tabular}{|l|}
814.9455 \\
\end{tabular} & & & & & & & & \\
\hline ch5 & lower $1 / 4$ Tac & $\mathrm{CH}$ & 795.8938 & 795.2381 & & & & & & & & \\
\hline ch6 & Tacbt & BT & 776.2037 & 775.5308 & & & & & & & & \\
\hline pp4 & Prowuv & PP4 & 767.1816 & \begin{tabular}{|l|}
766.3932 \\
\end{tabular} & & & & & & & & \\
\hline pp3 & Prowuc & PP3 & 763.3106 & 762.4906 & & & & & & & & \\
\hline pp2 & Prowmd+Prow & PP2 & 740.9688 & \begin{tabular}{|l|}
740.0902 \\
\end{tabular} & & & & & & & & \\
\hline pp1 & $\begin{array}{l}\text { Prowlv+Prowbt+Bullu } \\
\mathrm{v}\end{array}$ & PP1 & & & & & & & & & & \\
\hline bf3 & Bulluc+Bullmd+Bulllc & BF3 & & & & & & & & & & \\
\hline
\end{tabular}

O Source DTN: MO0012MWDGFM02.002 (GFM2000) [DIRS 153777]; output-DTN: LB02081DKMGRID.001

NOTE: A subset of these boreholes was used in 1-D property set inversions. Depths given in meters.

dGFM2000 data for N32

HGU=hydrogeologic unit; UZ=unsaturated zone 
Table B-1. Comparison of Borehole Layer Contact Elevations from GFM2000 and UZ Model Grid (Continued)

\begin{tabular}{|c|c|c|c|c|c|c|c|c|c|c|c|c|}
\hline \multirow{2}{*}{$\begin{array}{l}\text { UZ Model } \\
\text { Unit }\end{array}$} & \multirow{2}{*}{$\begin{array}{l}\text { GFM2000 } \\
\text { Unit }\end{array}$} & \multirow[b]{2}{*}{ HGU } & \multicolumn{2}{|c|}{ USW UZ-N53/54 } & \multicolumn{2}{|c|}{ USW UZ-N55 } & \multicolumn{2}{|c|}{ USW WT-1 } & \multicolumn{2}{|c|}{ USW WT-2 } & \multicolumn{2}{|c|}{ USW WT-7 } \\
\hline & & & GFM2000 & UZGrid & GFM2000 & UZGrid & GFM2000 & UZGrid & GFM2000 & UZGrid & GFM2000 & UZGrid \\
\hline tcw11 & Tpcr & CCR, CUC & & & & & & & & & & \\
\hline tcw12 & Tpсp & CUL, CW & 1227.43 & 1229.417 & 1241.45 & 1240.629 & 1192.073 & 1181.052 & 1282.903 & 1297.756 & 1184.758 & 1195.65 \\
\hline tcw13 & Tpcpv3,2 & CMW & 1188.872 & 1189.809 & 1187.501 & 1188.169 & 1080.821 & 1081.838 & 1242.365 & 1242.33 & 1092.098 & 1096.113 \\
\hline ptn21 & Tpcpv1 & CNW & 1184.819 & 1186.203 & 1183.538 & 1184.155 & 1074.115 & 1075.147 & 1235.659 & 1235.841 & 1088.746 & 1092.733 \\
\hline ptn22 & Tpbt4+upper Tpy & BT4 & 1182.106 & 1183.028 & 1179.302 & 1180.216 & 1069.848 & 1070.891 & 1232.002 & 1232.137 & 1084.326 & 1088.3 \\
\hline ptn23 & mid Tpy & TPY & absent & absent & absent & absent & absent & absent & absent & absent & absent & absent \\
\hline ptn24 & lower Tpy+Tpbt3 & BT3 & 1179.728 & 1180.797 & 1176.254 & 1177.255 & 1068.629 & 1069.64 & 1231.087 & 1231.072 & 1082.802 & 1086.783 \\
\hline ptn25 & Tpp & TPP & absent & absent & absent & absent & absent & absent & absent & absent & absent & absent \\
\hline ptn26 & Tpbt2+Tptrv3,2 & BT2 & 1174.882 & 1175.823 & 1173.907 & 1174.418 & 1065.276 & 1066.249 & 1225.906 & 1226.111 & 1077.773 & 1081.723 \\
\hline tsw31 & Tptrv1 & TC & 1162.324 & 1163.564 & 1167.079 & 1166.659 & 1053.694 & 1054.672 & 1215.847 & 1216.156 & 1065.276 & 1069.231 \\
\hline tsw32 & Tptrn & TR & & & 1166.287 & 1164.659 & 1051.694 & 1052.672 & 1213.847 & 1214.156 & 1063.276 & 1067.231 \\
\hline tsw33 & Tptrl+Tpul & TUL & & & & & 1025.957 & 1026.927 & 1185.367 & 1184.726 & 1039.978 & 1043.926 \\
\hline tsw34 & Tptpmn & TMN & & & & & 977.7984 & 978.7964 & 1121.359 & 1120.757 & 981.7608 & 985.726 \\
\hline tsw35 & Tptpll & TLL & & & & & 930.5544 & 931.6222 & 1079.602 & 1079.452 & 904.6464 & 908.6525 \\
\hline tsw36 & upper Tptpln & TM2 & & & & & 839.4192 & 840.6009 & 992.124 & 992.2496 & 864.4128 & 868.3616 \\
\hline tsw37 & lower Tptpln & TM1 & & & & & 816.6608 & 817.8055 & 958.596 & 958.5879 & 824.5856 & 828.5462 \\
\hline tsw38 & Tptpv3 & PV3 & & & & & 805.2816 & 806.4078 & 941.832 & 941.7571 & 804.672 & 808.6385 \\
\hline tsw39 & Tptpv2 & PV2 & & & & & 793.6992 & 794.7491 & 928.4208 & 928.2658 & 785.1648 & 789.0901 \\
\hline ch1 & Tptpv1+Tpbt1 & BT1, BT1a & & & & & 784.2504 & 785.3049 & 915.924 & 915.8546 & 782.4216 & 786.3244 \\
\hline ch2 & upper $1 / 4$ Tac & $\mathrm{CH}$ & & & & & 779.3736 & 780.3893 & 899.16 & 898.901 & & \\
\hline ch3 & mid $1 / 4$ Tac & $\mathrm{CH}$ & & & & & 765.6576 & 766.6763 & 883.7676 & 883.5388 & & \\
\hline ch4 & mid 1/4 Tac & $\mathrm{CH}$ & & & & & 751.9416 & 752.9632 & 868.3752 & 868.1765 & & \\
\hline ch5 & lower $1 / 4$ Tac & $\mathrm{CH}$ & & & & & 738.2256 & 739.2502 & 852.9828 & 852.8143 & & \\
\hline $\operatorname{ch} 6$ & Tacbt & BT & & & & & & & 837.5904 & 837.452 & & \\
\hline pp4 & Prowuv & PP4 & & & & & & & absent & absent & & \\
\hline pp3 & Prowuc & PP3 & & & & & & & 815.34 & 815.3688 & & \\
\hline pp2 & Prowmd+Prow & PP2 & & & & & & & 781.2024 & 781.2358 & & \\
\hline pp1 & $\begin{array}{l}\text { Prowlv+Prowbt+Bullu } \\
\text { v }\end{array}$ & PP1 & & & & & & & 754.38 & 754.3675 & & \\
\hline bf3 & Bulluc+Bullmd+Bulllc & BF3 & & & & & & & & & & \\
\hline bf2 & Bulllv+Bullbt+Tramuv & BF2 & & & & & & & & & & \\
\hline
\end{tabular}

\& Source DTN: MO0012MWDGFM02.002 (GFM2000) [DIRS 153777]; output-DTN: LB02081DKMGRID.001

NOTE: A subset of these boreholes was used in 1-D property set inversions. Depths given in meters

GFM2000 data for N54

$\mathrm{HGU}=$ hydrogeologic unit; UZ=unsaturated zone 


\begin{tabular}{|c|c|c|c|c|c|c|}
\hline \multirow{2}{*}{$\begin{array}{c}\text { UZ Model } \\
\text { Unit }\end{array}$} & \multirow{2}{*}{$\begin{array}{c}\text { GFM2000 } \\
\text { Unit }\end{array}$} & \multirow[b]{2}{*}{ HGU } & \multicolumn{2}{|c|}{ UE-25 WT\#18 } & \multicolumn{2}{|c|}{ USW WT-24 } \\
\hline & & & GFM2000 & UZGrid & GFM2000 & UZGrid \\
\hline tcw11 & Tpcr & CCR, CUC & 1336.246 & 1335.836 & 1493.518 & 1492.268 \\
\hline tcw12 & Трср & CUL, CW & 1310.106 & 1309.962 & 1469.098 & 1468.345 \\
\hline tcw13 & Tpcpv3,2 & CMW & 1240.536 & 1240.952 & 1427.988 & 1428.093 \\
\hline ptn21 & Tpcpv1 & CNW & 1235.05 & 1235.45 & 1415.796 & 1415.992 \\
\hline ptn22 & Tpbt4+upper Tpy & BT4 & 1232.611 & 1232.983 & 1408.603 & 1408.822 \\
\hline ptn23 & mid Tpy & TPY & 1221.537 & 1221.926 & 1399.184 & 1399.395 \\
\hline ptn24 & lower Tpy+Tpbt3 & BT3 & 1214.425 & 1214.821 & 1390.802 & 1391.022 \\
\hline ptn25 & Tpp & TPP & 1184.758 & 1185.218 & 1349.045 & 1349.198 \\
\hline ptn26 & Tpbt2+Tptrv3,2 & BT2 & 1137.818 & 1138.332 & 1292.565 & 1292.599 \\
\hline tsw31 & Tptrv1 & TC & 1122.578 & 1123.119 & 1281.074 & 1281.107 \\
\hline tsw32 & Tptrn & TR & 1120.578 & 1121.119 & 1279.074 & 1279.107 \\
\hline tsw33 & Tptrl+Tpul & TUL & 1068.324 & 1068.839 & 1231.087 & 1231.096 \\
\hline tsw34 & Tptpmn & TMN & 1007.669 & 1007.687 & 1142.482 & 1142.494 \\
\hline tsw35 & Tptpll & TLL & 979.6272 & 980.1595 & 1108.954 & 1109.128 \\
\hline tsw36 & upper Tptpln & TM2 & absent & absent & 998.22 & 998.5361 \\
\hline tsw37 & lower Tptpln & TM1 & absent & absent & 987.044 & 987.4208 \\
\hline tsw38 & Tptpv3 & PV3 & 878.7384 & 879.184 & 981.456 & 981.8631 \\
\hline tsw39 & Tptpv2 & PV2 & 859.536 & 859.9577 & 969.0202 & 969.4164 \\
\hline ch1 & Tptpv1+Tpbt1 & BT1, BT1a & 851.0016 & 851.4074 & 966.155 & 966.5284 \\
\hline ch2 & upper 1/4 Tac & $\mathrm{CH}$ & 842.4672 & 842.8865 & 954.3898 & 954.7154 \\
\hline ch3 & mid 1/4 Tac & $\mathrm{CH}$ & & & & \\
\hline ch4 & mid 1/4 Tac & $\mathrm{CH}$ & & & & \\
\hline ch5 & lower $1 / 4$ Tac & $\mathrm{CH}$ & & & & \\
\hline $\operatorname{ch} 6$ & Tacbt & BT & & & & \\
\hline pp4 & Prowuv & PP4 & & & & \\
\hline pp3 & Prowuc & PP3 & & & & \\
\hline pp2 & Prowmd+Prow & PP2 & & & & \\
\hline pp1 & Prowlv+Prowbt+Bulluv & PP1 & & & & \\
\hline bf3 & Bulluc+Bullmd+Bulllc & BF3 & & & & \\
\hline bf2 & Bulllv+Bullbt+Tramuv & BF2 & & & & \\
\hline
\end{tabular}

Source DTN: MO0012MWDGFM02.002 (GFM2000) [DIRS 153777]; output-DTN: LB02081DKMGRID.001.

NOTE: A subset of these boreholes was used in 1-D property set inversions. Depths given in meters.

HGU=hydrogeologic unit; UZ=unsaturated zone 


\section{INTENTIONALLY LEFT BLANK}


APPENDIX C GRID VERIFICATION 
This appendix describes the verification activities associated with the 1-D, 2-D, and 3-D UZ model grids.

\section{C1. GRIDBLOCK ATTRIBUTE VERIFICATION}

Because the total number of gridblocks within the 3-D UZ model grids is quite large, a subset of gridblocks from the model is evaluated to ensure the accuracy of the calculated gridblock volumes, connection lengths, and interface areas. These verification activities are described in the scientific notebook by Hinds and Dobson (2004 [DIRS 170886], p. 93).

Spot checks of the 1-D and 2-D mesh files were conducted to verify that the proper gridblock connections were created in mesh generation. For all 1-D and 2-D grid columns examined, gridblocks had the correct gridblock volumes and vertical connections with the adjoining gridblocks within the column $(\mathrm{BETAX}=-1)$. The lateral connections between gridblocks in adjoining columns for the 2-D mesh file were also spot-checked. These checks revealed that the examined gridblocks were laterally connected to neighboring blocks (in adjoining columns) and had the same assigned rock properties, with two exceptions. These exceptions were: (1) the neighboring column, or the column under investigation, was a fault block (fault blocks have different properties assigned to them), and (2) the rock type might be absent in the adjacent column, in which case the lateral connection was made with the stratigraphically closest rock type. Note that connections between gridblocks within columns associated with nonvertical (inclined) faults may be nonvertical, because the $\mathrm{x}, \mathrm{y}$ locations of grid nodes within these columns can vary with depth.

\section{C2. CONTACT ELEVATION VERIFICATION}

Model layer contact elevations for 45 grid columns were compared against the observed stratigraphic contact elevations contained in the GFM2000 (DTN: MO0012MWDGFM02.002 [DIRS 153777]) file contacts00el.dat. Given an estimated maximum error in layer contact elevations at column centers of about $5 \mathrm{~m}$ (see first paragraph of Section 6.6), a grid validation criterion of plus-or-minus $5 \mathrm{~m}$ for layer contact elevations in grid columns corresponding to borehole locations was established. Differences in layer contact elevations (values from UZ model calibration grid subtracted from values from contacts00el.dat) are plotted in Figures C2-1 and C2-2. Line discontinuities indicate missing, or pinched out, layers for that particular location. 


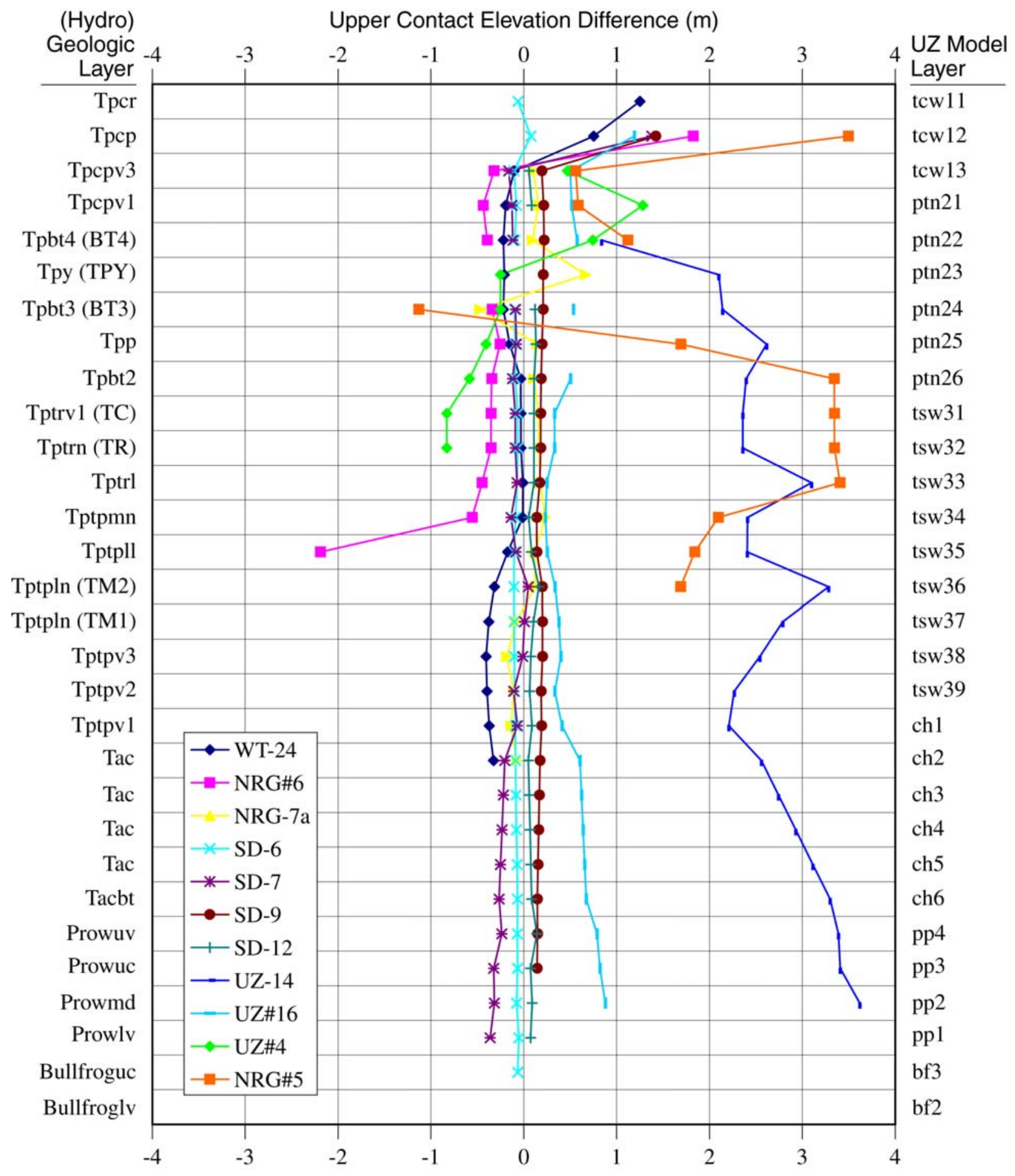

Output DTN: LB02081DKMGRID.001.

Source: DTN MO0012MWDGFM02.002 (GFM2000) [DIRS 153777].

NOTE: A negative value means the UZ model layer contact elevation is higher than the stratigraphic pick.

Figure C2-1. Upper Contact Elevation Differences at Selected Borehole Locations (GFM2000 file contacts00el.dat Minus UZ Model Grid) 


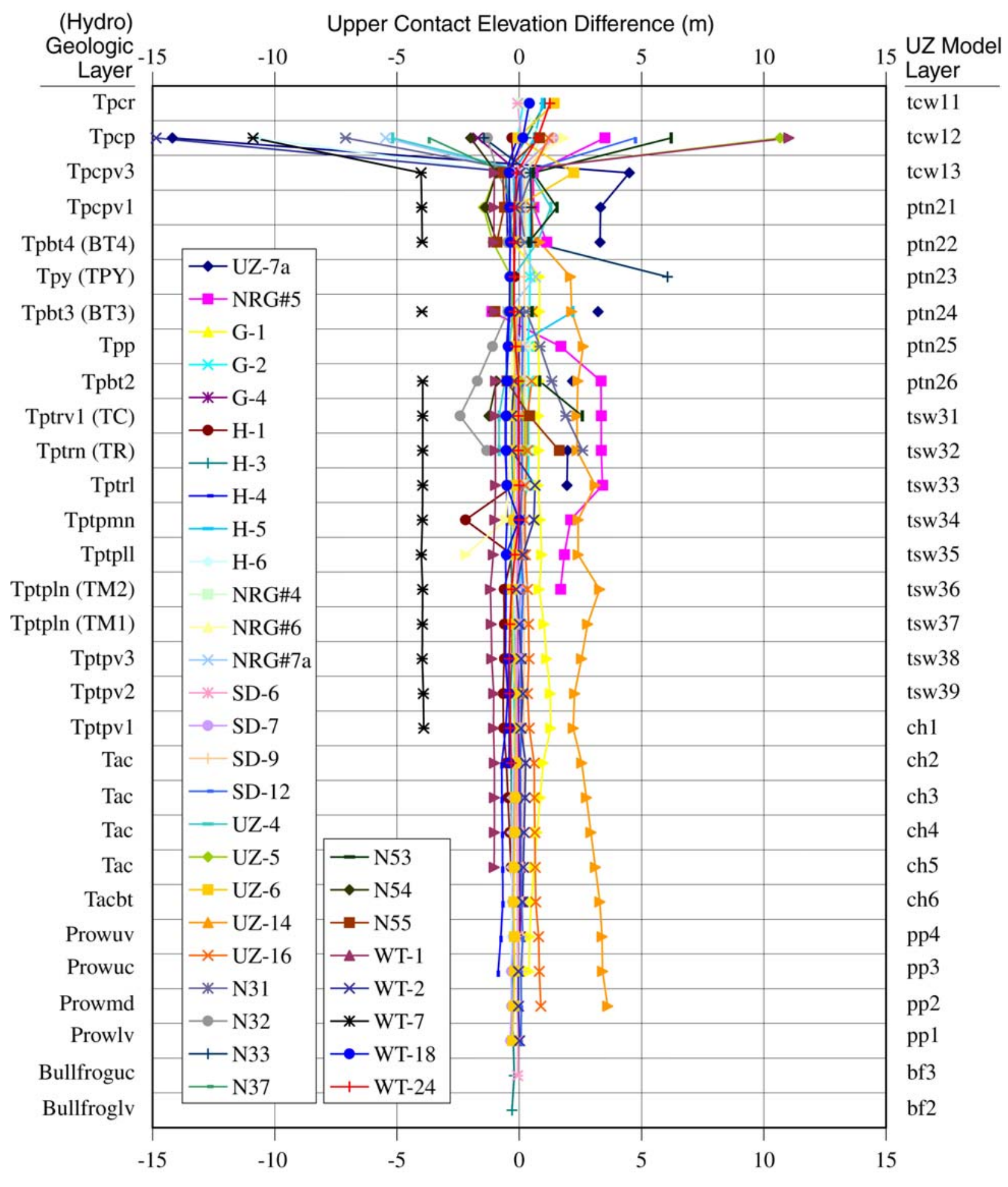

Output: DTN LB02081DKMGRID.001.

Source: DTN MO0012MWDGFM02.002 (GFM2000) [DIRS 153777].

NOTE: A negative value means the UZ model layer contact elevation is higher than the stratigraphic pick.

Figure C2-2. Upper Contact Elevation Differences at All Borehole Locations (GFM2000 file contacts00el.dat Minus UZ Model Grid) 
Note that in most cases, the differences in contact elevations are less than $5 \mathrm{~m}$. There are several cases where deviations exceed this amount. A number of boreholes (e.g., UZ-7a, H-6, NRG\#7, $\mathrm{UZ \# 4/5)} \mathrm{had} \mathrm{greater} \mathrm{than} 5 \mathrm{~m}$ discrepancies for the elevation of the uppermost unit present. These differences (primarily at the bedrock surface) arise from channel erosion that produces surfaces with large local variations in slope and elevation. Although the nearest GFM2000 data point may be only meters to a few tens of meters away, the highly variable surface elevations may result in the observed mismatches in the upper contact surfaces. These differences are restricted to the upper unit only, and thus should not have a significant impact on UZ model flow and transport modeling results.

Two boreholes (b\#1 and N11) exhibit poor matches for most of the contact elevations, with an abrupt shift in elevations occurring below a given unit contact. Both of these boreholes are near faults, and differences in how faults were modeled in GFM2000 and the UZ model grids may explain these discrepancies. In the case of N11, where there is a difference of over $50 \mathrm{~m}$ in most of the contact elevations, the borehole lies on the west side of the Solitario Canyon fault in the GFM2000 representation, but is situated on the east side of this fault in the UZ model grid. The difference in contact elevations is similar to the observed vertical offset on the fault. The N11 borehole is located approximately $2 \mathrm{~km}$ north of the repository footprint (Figure 6-2), and thus this discrepancy should have little impact on UZ flow and transport models for the repository area. Because of the differences between GFM2000 (DTN: MO0012MWDGFM02.002 [DIRS 153777]) and UZ model grid contact elevations, the b\#1 and N11 boreholes were not used for 1-D rock property calibration calculations.

\section{C3. 2-D CROSS SECTION VERIFICATION}

To verify the accuracy of the 2-D east-west cross section (Figures C3-1 and C3-2), ten selected adjacent pairs of grid columns were compared to a series of GFM2000 cross sections constructed using the location of each pair of grid column nodes as ends of the cross sections (Hinds and Dobson 2004 [DIRS 170886], pp. 94-99). The apparent vertical offset between adjacent columns as seen in Figure C3-2 is an artifact of the visualization generated by WINGRIDDER V2.0 (LBNL 2002 [DIRS 154785]), and does not reflect how the layers are connected in the numerical grids (see Section 6.6 for more details). Cross sections constructed using EARTHVISION V5.1 (Dynamic Graphics 2003 [DIRS 171007]) and the following geologic framework model surfaces (see Table C3-1) were compared with the correlative UZ model grid columns (Figures C3-3 to C3-5). The corresponding pairs of column coordinates used for each of the traverses are listed in Table C3-2.

Using these traverse endpoints and the stacked GFM2000 surfaces listed in Table C3-2, ten 2-D cross sections were created. The results of this comparison are shown below. Figures C3-1 and C3-2 depict the 2-D plan-view grid design and an east-west cross section from the UZ model grid (file EWUZ7a_profile.eps from output DTN: LB02081DKMGRID.001), and illustrate the location of each of the column pairs used to construct the 10 traverses. Figures C3-3 to C3-5 depict each of the GFM2000 traverse cross sections, sandwiched between the corresponding UZ model columns. 
Table C3-1. UZ Model Layers and GFM2000 Surfaces

\begin{tabular}{|l|l|}
\hline \multicolumn{1}{|c|}{ File Name } & \multicolumn{1}{|c|}{ Corresponding UZ Model Layers } \\
\hline REF00bedrock.m.2grd & tcw11 \\
\hline REF00tpcp.m.2grd & tcw12, tcw13 \\
\hline s00Tpcpv1EX.m.2grd & ptn21, ptn22, ptn23, ptn24 \\
\hline s00PahEX.m.2grd & ptn25, ptn26 \\
\hline s00Tptrv1EX.m.2grd & tsw31, tsw32 \\
\hline s00TptrlEX.m.2grd & tsw33 \\
\hline s00TptpmnEX.m.2grd & tsw34 \\
\hline s00TptpllEX.m.2grd & tsw35 \\
\hline s00TptplnEX.m.2grd & tsw36, tsw37 \\
\hline s00Tptpv3EX.m.2grd & tsw38 \\
\hline s00Tptpv2EX.m.2grd & tsw39, ch1 \\
\hline s00CalicoEX.m.2grd & ch2, ch3, ch4, ch5, ch6 \\
\hline s00ProwuvEX.m.2grd & pp4, pp3, pp2 \\
\hline s00ProwlvEX.m.2grd & pp1 \\
\hline s00BullfrogucEX.m.2grd & bf3 \\
\hline s00BullfroglvEX.m.2grd & bf2 \\
\hline s00TramucEX.m.2grd & tr3 \\
\hline Gwl_sspac_60.96.2grd & base of UZ \\
\hline Output_DTN:_B02092DGRDVER.001.
\end{tabular}

Output DTN: LB02092DGRDVER.001.

UZ=Unsaturated Zone

Table C3-2. Cross Section Traverse Columns

\begin{tabular}{|l|l|l|l|l|l|l|}
\hline $\begin{array}{c}\text { Traverse } \\
\text { No. }\end{array}$ & $\begin{array}{l}\text { ID of W } \\
\text { Column }\end{array}$ & \multicolumn{1}{|c|}{$\begin{array}{c}\text { W Column } \\
\text { Easting }\end{array}$} & $\begin{array}{c}\text { W Column } \\
\text { Northing }\end{array}$ & $\begin{array}{c}\text { ID of E } \\
\text { Column }\end{array}$ & $\begin{array}{c}\text { E Column } \\
\text { Easting }\end{array}$ & $\begin{array}{c}\text { E Column } \\
\text { Northing }\end{array}$ \\
\hline 1 & $\mathrm{q} 40$ & 168882.0938 & 232653.5 & $\mathrm{a} 63$ & 169150 & 232650 \\
\hline 2 & $\mathrm{e} 64$ & 170094.6094 & 232454.7344 & $\mathrm{q} 44$ & 170263.7031 & 232385.9062 \\
\hline 3 & $\mathrm{i} 24$ & 170539.8438 & 232295.8125 & $\mathrm{i} 29$ & 170564.875 & 232218.7812 \\
\hline 4 & $\mathrm{i} 40$ & 170614.9375 & 232064.7031 & $\mathrm{i} 41$ & 170769.0156 & 232114.7656 \\
\hline 5 & $\mathrm{i} 47$ & 170948.1094 & 232087.7812 & $\mathrm{i} 52$ & 170973.1406 & 232010.75 \\
\hline 6 & $\mathrm{i} 60$ & 171023.2031 & 231856.6875 & $\mathrm{i} 61$ & 171177.2812 & 231906.7344 \\
\hline $7^{\mathrm{a}}$ & $\mathrm{p} 3$ & 171338.0469 & 231868.3125 & $\mathrm{p} 2$ & 171388.5781 & 231860.8594 \\
\hline 8 & $\mathrm{q} 62$ & 171982.7969 & 231801.2969 & $\mathrm{q} 51$ & 172168.4062 & 231811.0938 \\
\hline $9^{\mathrm{b}}$ & $\mathrm{o} 2$ & 172299.2812 & 231776.0312 & $\mathrm{o} 1$ & 172358.8906 & 231769.2031 \\
\hline $10^{\mathrm{c}}$ & $\mathrm{a} 48$ & 172750 & 231750 & $\mathrm{q} 19$ & 173079.3906 & 231774.7656 \\
\hline
\end{tabular}

Output DTN: LB02081DKMGRID.001.

Source: DTN: MO0012MWDGFM02.002 (GFM2000) [DIRS 153777].

${ }^{a}$ Columns separated by Ghost Dance Fault

${ }^{b}$ Columns separated by Imbricate Fault

'Column q19 adjacent to Toe Fault

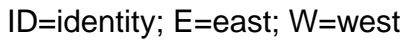




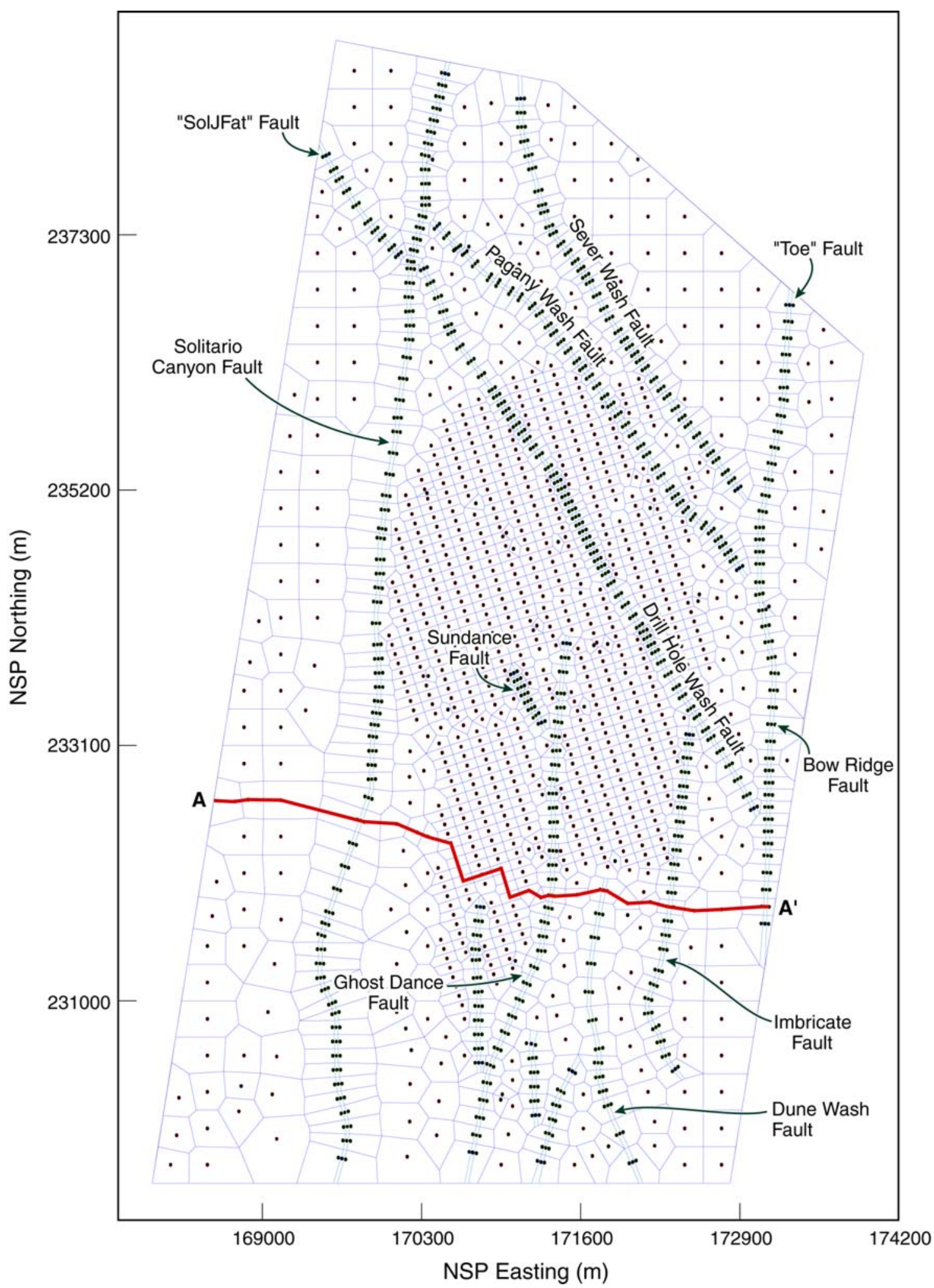

Output: DTN LB02081DKMGRID.001.

NOTE: Line A-A' indicates location of cross section shown in Figure C3-2.

Figure C3-1. 2-D (Plan-View) UZ Model Grid Design 


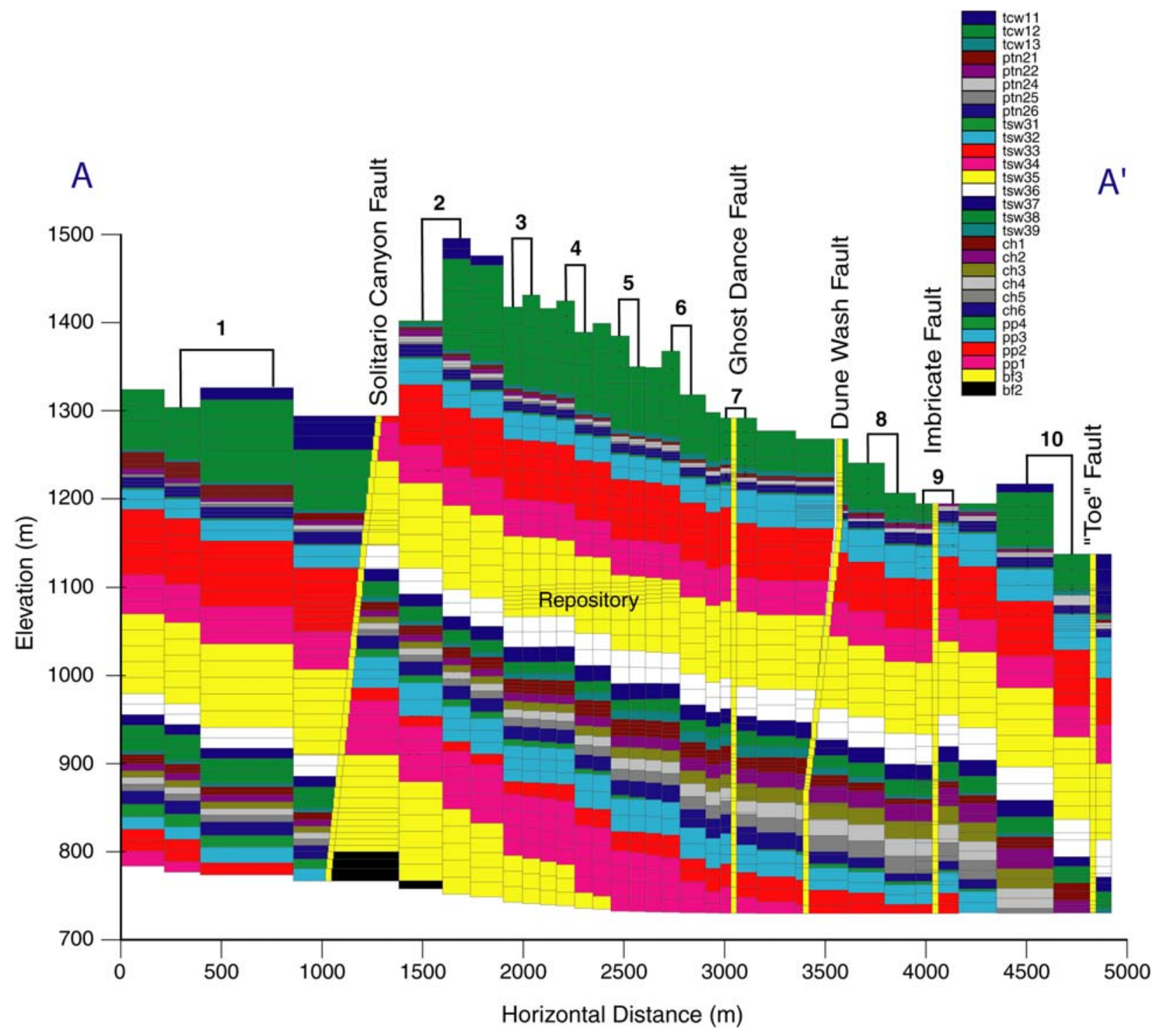

Output: DTN LB02081DKMGRID.001.

NOTE: UZ model layer ptn23 does not occur within this traverse. Numbered column pairs were used to construct the comparison plots (Figures C3-3 to C3-5) between the UZ model grid and GFM2000. Layer stratigraphy is the same as shown in the legend.

Figure C3-2. Two-dimensional Cross Section from the UZ Model Grid 


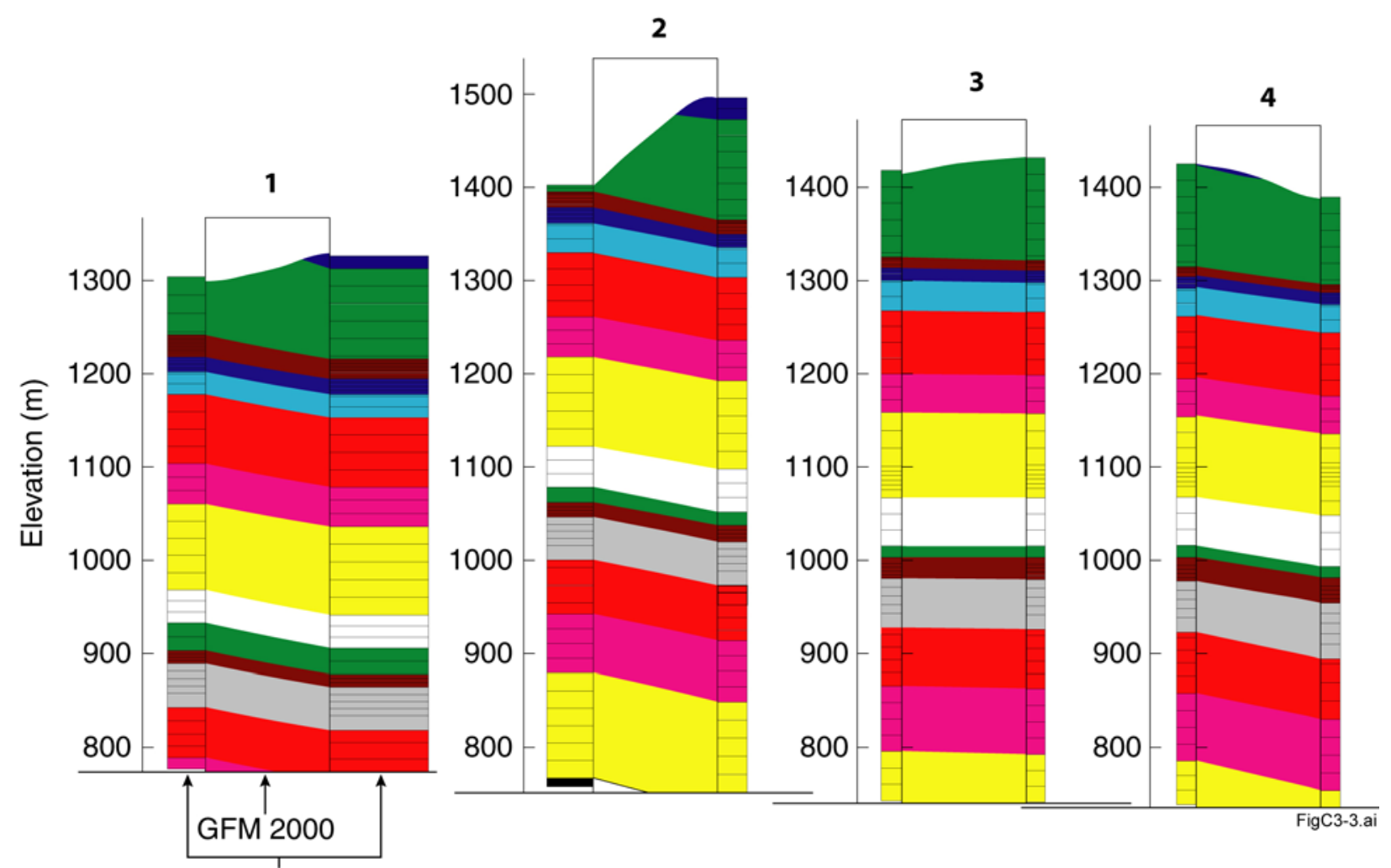

UZ Model Grid

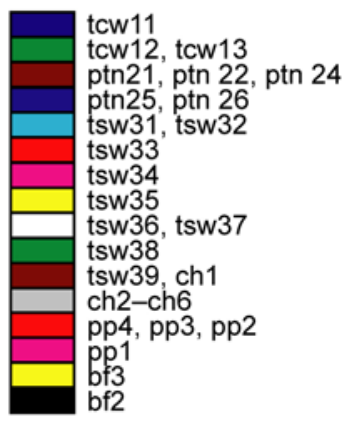

Output: DTN LB02081DKMGRID.001.

Source: DTN MO0012MWDGFM02.002 (GFM2000) [DIRS 153777].

NOTE: Layer stratigraphy is the same as shown in the legend.

Figure C3-3. Traverses 1-4 of 2-D Cross Section, Comparing Results of UZ Model and GFM2000 Grids 

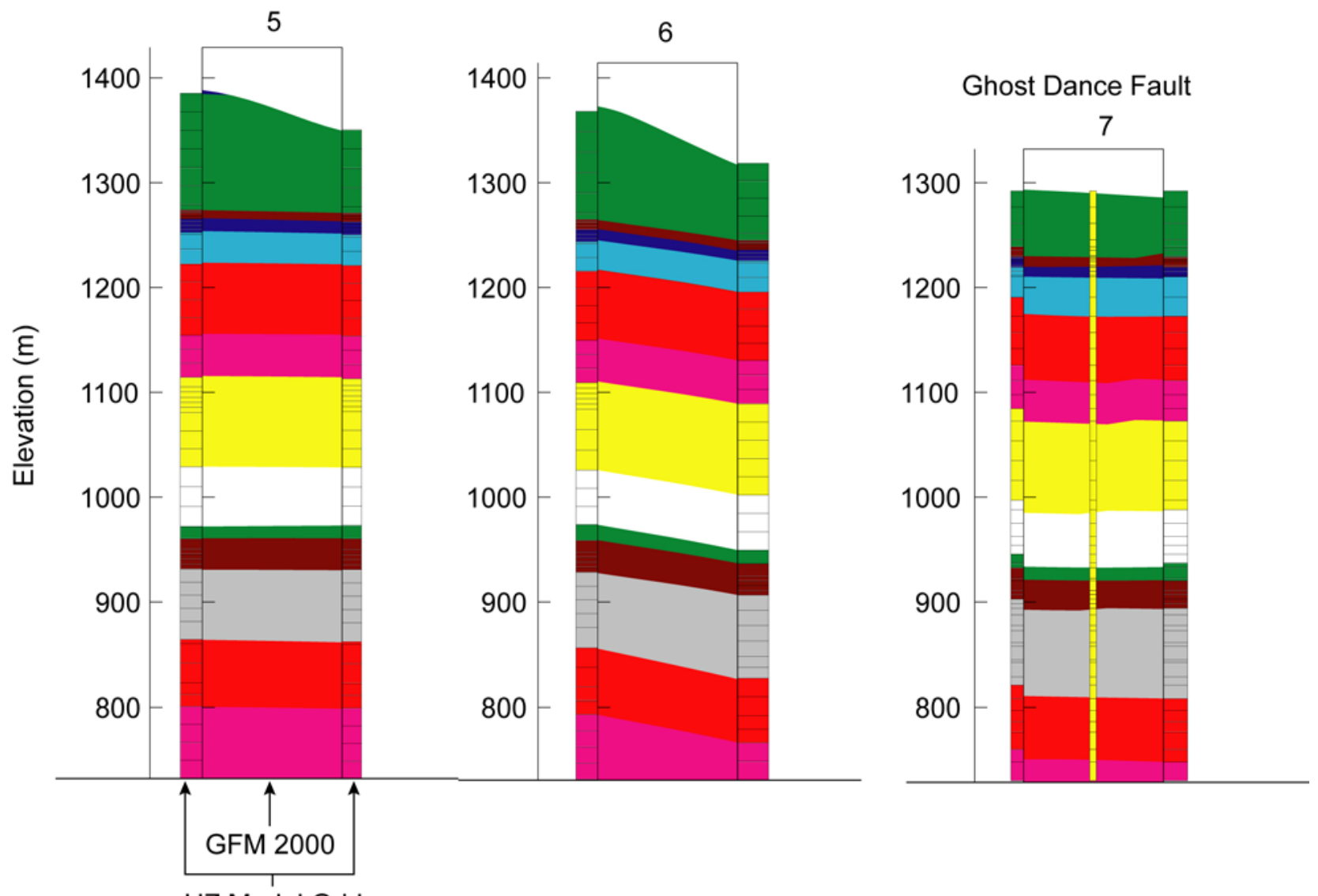

UZ Model Grid

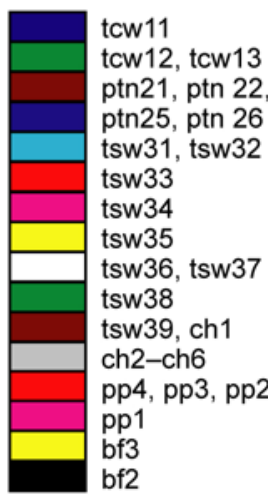

Output: DTN LB02081DKMGRID.001.

Source: DTN MO0012MWDGFM02.002 (GFM2000) [DIRS 153777].

NOTE: Layer stratigraphy is the same as shown in the legend.

Figure C3-4. Traverses 5-7 of 2-D Cross Section, Comparing Results of UZ Model and GFM2000 Grids 

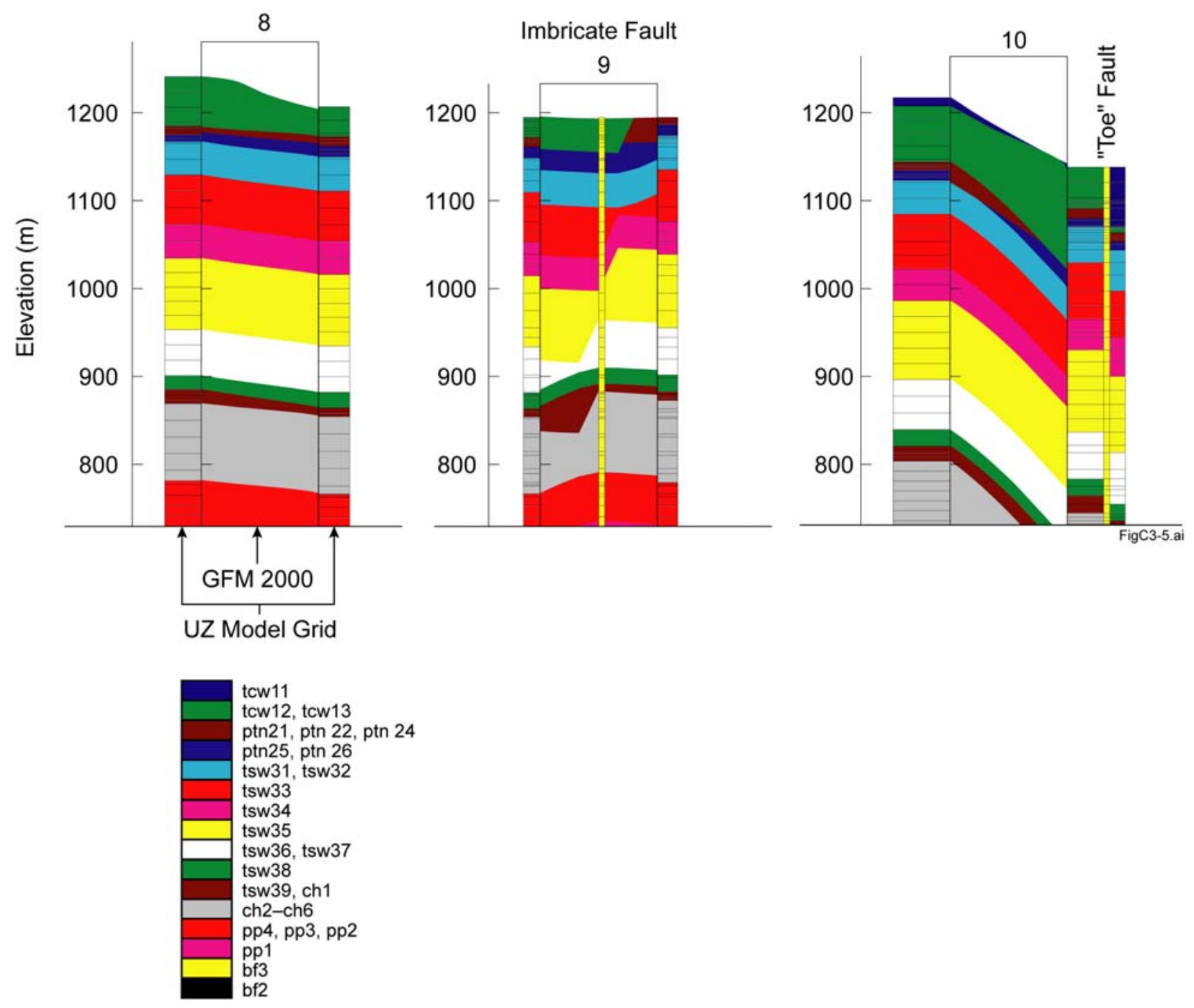

Output: DTN LB02081DKMGRID.001.

Source: DTN MO0012MWDGFM02.002 (GFM2000) [DIRS 153777].

NOTE: Layer stratigraphy is the same as shown in the legend.

Figure C3-5. Traverses 8-10 of 2-D Cross Section, Comparing Results of UZ Model and GFM2000 Grids

For Traverses 1-6 and 8, the matches between the unit contacts for the GFM2000 cross sections and the UZ model columns are extremely good, with minimal offset of units observed. These intervals are not intersected by faults, and thus a good match is expected.

Discrepancies between UZ model grid and GFM2000 unit contacts are observed for traverses $(7,9,10)$ that cross or are immediately adjacent to faults. Most of the GFM2000 unit thicknesses in Traverse 7 (where the Ghost Dance fault passes) correlate with their counterparts for the two UZ model columns; however, there are some differences in the location of the contact elevations. Differences that are more significant are observed in Traverses 9 and 10 . Substantial (approximately $50 \mathrm{~m}$ ) vertical offset is observed along the Imbricate fault, which cuts through 
Traverse 9, and discrepancies of up to 10-20 m are observed between the UZ model column and GFM2000 contacts. Even larger discrepancies are observed between the GFM2000 cross-section in Traverse 10 and the eastern UZ model column. This difference may result from the nearby presence of the Toe fault, which is modeled as a vertical feature by the UZ model, but as a dipping fault in GFM2000 (DTN: MO0012MWDGFM02.002 [DIRS 153777]).

The comparisons made using column centers around faults in the UZ model grid are affected by the closely spaced nature of the column nodes $(50-60 \mathrm{~m})$, similar to the data resolution $(61 \times 61 \mathrm{~m})$ of the GFM2000 grid (BSC 2004 [DIRS 170029], Section 6.4.2). The localization of contact elevation discrepancies between the GFM2000 and UZ model grids near faults results in part from the differences in the way that faults are represented in the two systems. The simplification of faults, as required by the use of vertical columns in the UZ model grids (Section 6.3), results in localized discrepancies between the two grids. However, as demonstrated by good matches observed in Traverses 1-6 and 8, the UZ model grids accurately portray the stratigraphic representation of geologic units within structural blocks.

\section{C4. 3-D MESH VERIFICATION}

To verify the accuracy of the 3-D mesh and its connections, test simulations using isothermal, saturated conditions were conducted on the ECM mesh using TOUGH2 V1.4 (LBNL 2000 [DIRS 146496]). The goal of these simulations was to look for improperly connected gridblocks that would be identified by anomalous points on a pressure-elevation plot. Under steady-state conditions, the observed fluid pressures should vary linearly as a function of gridblock elevation. A description of the simulations and their results are given in Hinds and Dobson 2004 (DIRS 170886], pp. 125 to 131), Wang 2003 ([DIRS 162380], pp. 17 to 28), and Wu 2004 (DIRS 170888]), pp. 237 to 238).

Initial conditions of $25^{\circ} \mathrm{C}, 500$ bars water pressure, and a single suite of rock properties were assigned to all of the gridblocks. Large volume gridblocks located at the base of the grid served as a constant pressure boundary and the remaining gridblocks in the mesh were allowed to come to pressure equilibrium with this boundary condition. The simulations were run for $0.316 \times 10^{18} \mathrm{~s}$ to ensure that a steady-state solution would be obtained (Wu 2004 ([DIRS 170888], p. 238).

Several modifications to some of the lateral connections in the 3-D mesh were made as a result of the simulation results. First, improper lateral connections between adjoining fault and repository columns were corrected (Wang 2003 [DIRS 162380], pp. 17 to 23). During further evaluation of the 3-D grid, it was discovered that anomalous pressures were associated with some matrix columns adjacent to fault columns (Hinds and Dobson 2004 [DIRS 170886], pp. 125 to 131; Wang 2003 [DIRS 162380], pp. 23 to 26). As mentioned in Section 6.3, some simplification of the GFM2000 faults was made in creating the UZ model grids, including the representation of the Solitario Canyon and Solitario Canyon (west) faults as a single fault. The gridblocks with the anomalous pressure-elevation relations exhibited fault-related stratigraphic offset with their neighboring columns. To ensure proper flow behavior in the grid, the columns with apparent fault-related offset were classified as "faults" while reconstructing the 3-D grid so that lateral connections between gridblocks in these columns and those in the adjacent columns were made with the closest lateral neighbor, and not with the same stratigraphic interval 
(UZ model layer). A total of 18 columns, all adjacent to faults, were adjusted in this manner (see Hinds and Dobson 2004 ([DIRS 170886], p. 129 for the locations of these columns). The pressure-elevation relation results from the test simulation conducted using the final 3-D mesh exhibited very little deviation from linearity (Figure C4-1).

A few small deviations were observed in this simulation were attributed to the presence of non-vertical connections associated with inclined fault columns. Larger pressure shifts were observed for gridblocks associated with faults with dips that had the largest deviation from vertical. This feature is a result of the non-orthogonal configuration of the 3-D grid (Hinds and Dobson 2004 [DIRS 170886], pp. 130 to 131). The changes in the 3-D mesh resulting from these test simulations (correcting improper lateral connections between adjoining fault and repository columns and reclassifying 18 matrix columns with apparent fault-related offsets as fault columns, as described above) were captured in the output DTN: LB03023DKMGRID.001. 


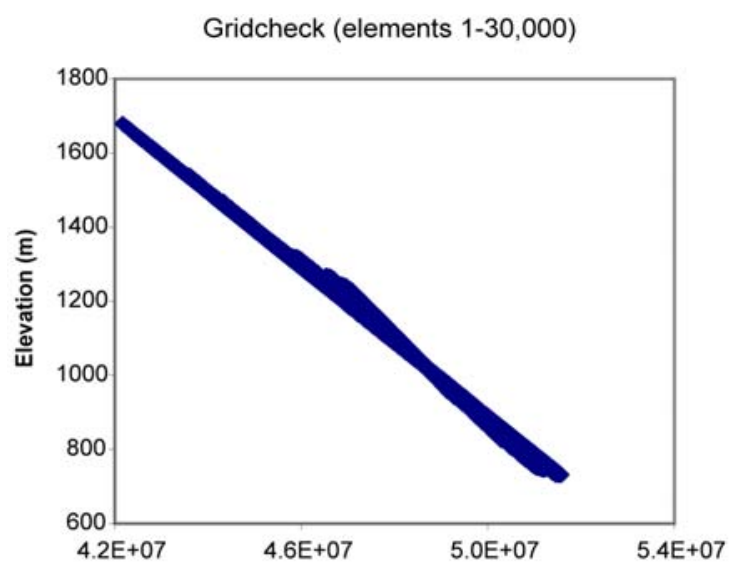

(a)

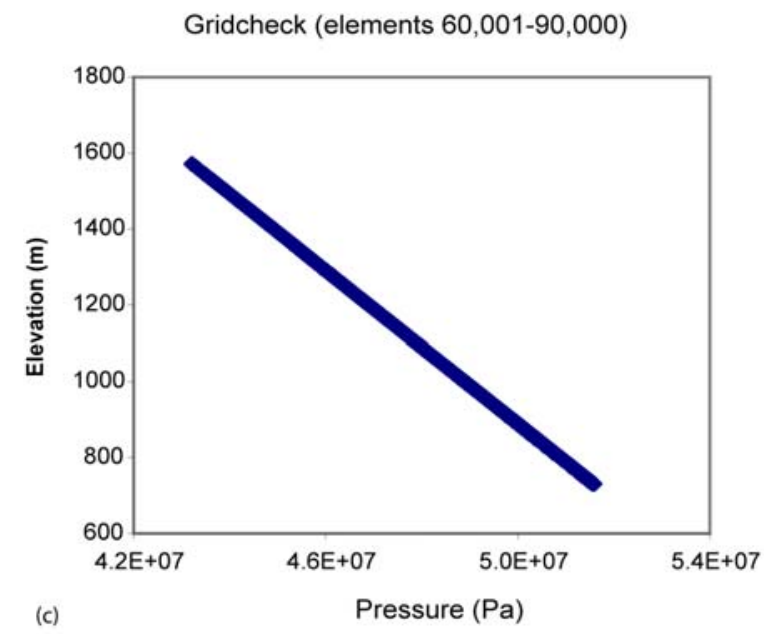

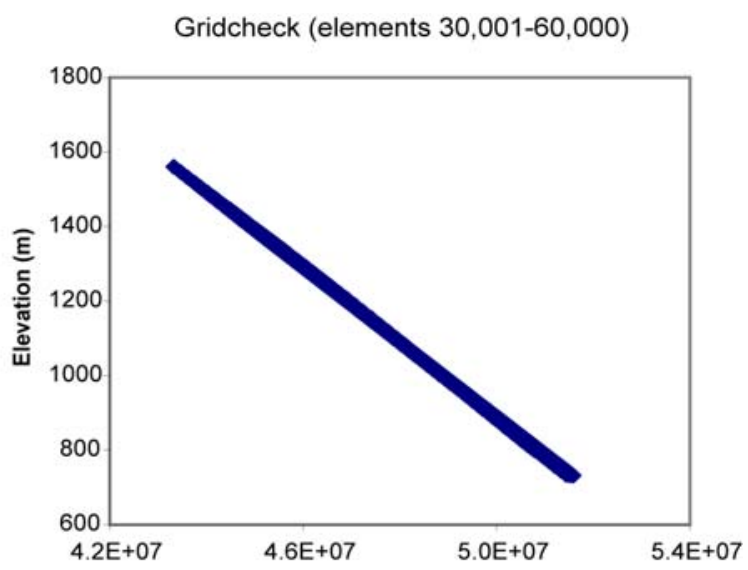

(b)
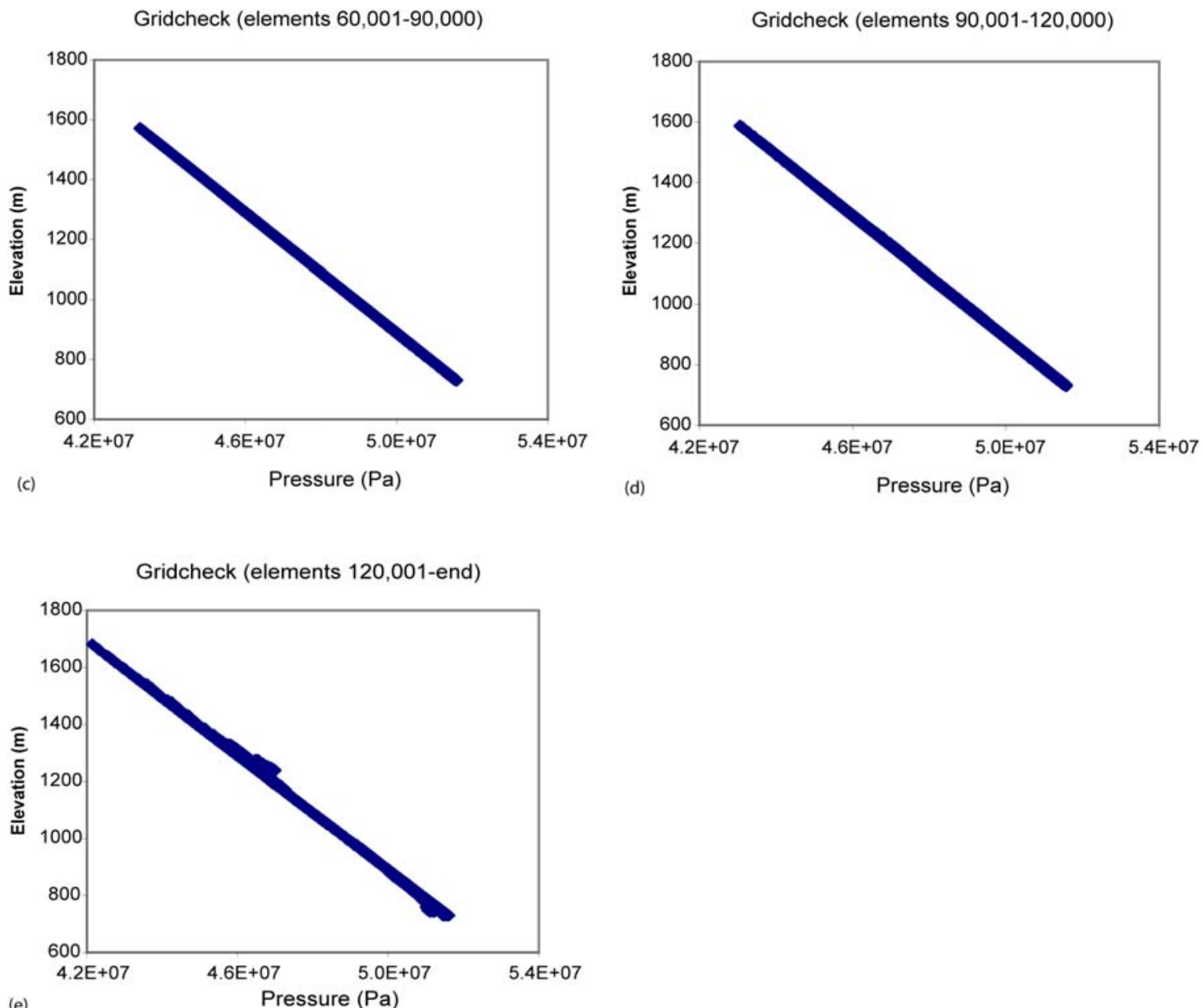

(e)

$$
\text { Pressure }(\mathrm{Pa})
$$

Output: DTN LB03023DKMGRID.001.

Figure C4-1. Pressure-Evaluation Relations of 3-D Mesh (124,795 elements) after TOUGH2 Test Simulation 


\section{INTENTIONALLY LEFT BLANK}

